\title{
Tall building foundations: design methods and applications
}

\author{
Harry G. Poulos ${ }^{1}$
}

Received: 11 May 2016/Accepted: 12 May 2016/Published online: 13 June 2016

(C) Springer International Publishing Switzerland 2016. This article is published with open access at Springerlink.com

\begin{abstract}
This paper will review some of the challenges faced by designers of foundations for very tall buildings, primarily from a geotechnical viewpoint. Some characteristic features of such buildings will be reviewed and then the options for foundation systems will be discussed. A threestage process of foundation design and verification will be described, and the importance of proper ground characterization and assessment of geotechnical parameters will be emphasised. The application of the foundation design principles will be illustrated via four projects, each of which has presented a different challenge to the designers:

1. The La Azteca building in Mexico City, Mexico.

2. The Burj Khalifa in Dubai.

3. The Incheon 151 Tower in Incheon, South Korea.

4. A high-rise tower in Jeddah, Saudi Arabia.
\end{abstract}

Keywords Case history · Design · Foundation · Pile group $\cdot$ Settlement $\cdot$ Tall building

\section{Introduction}

The past two decades have seen a remarkable increase in the rate of construction of "super-tall" buildings in excess of $300 \mathrm{~m}$ in height. Figure 1 shows the significant growth in the number of such buildings either constructed (to 2010) or projected (2015 and beyond). A large number of these buildings are in the Middle East or in China. Dubai has now the tallest building in the world, the Burj Khalifa,

\footnotetext{
$\bigotimes$ Harry G. Poulos

Harry.Poulos@coffey.com

1 Coffey Geotechnics, Sydney, Australia
}

which is $828 \mathrm{~m}$ in height, while in Jeddah, Saudi Arabia, the Kingdom Tower is currently under construction and will eventually exceed $1000 \mathrm{~m}$ in height.

Super-tall buildings in excess of $300 \mathrm{~m}$ in height are presenting new challenges to engineers, particularly in relation to structural and geotechnical design. Many of the traditional design methods cannot be applied with any confidence since they require extrapolation well beyond the realms of prior experience, and accordingly, structural and geotechnical designers are being forced to utilise more sophisticated methods of analysis and design. In particular, geotechnical engineers involved in the design of foundations for super-tall buildings are leaving behind empirical methods and are employing state-of-the art methods increasingly.

This paper will review some of the challenges that face designers of foundations for very tall buildings, primarily from a geotechnical viewpoint. Some characteristic features of such buildings will be reviewed and then the options for foundation systems will be discussed. The process of foundation design and verification will be described, and then the application of these principles will be illustrated via four projects, each of which has presented a different challenge to the foundation designers:

5. The La Azteca building in Mexico City, Mexico.

6. The Burj Khalifa in Dubai.

7. The Incheon 151 Tower in Incheon, South Korea.

8. A high-rise tower in Jeddah, Saudi Arabia.

\section{Characteristics of tall buildings}

There are a number of characteristics of tall buildings that can have a significant influence on foundation design, including the following: 


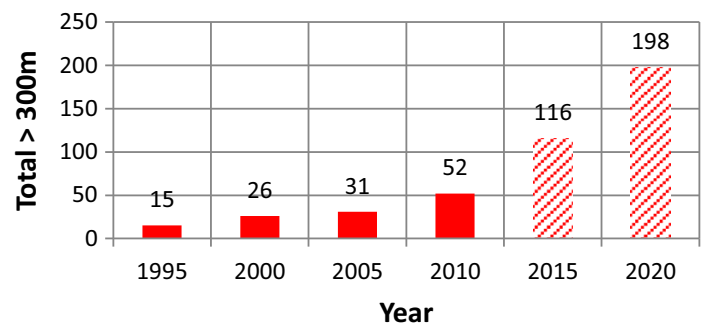

Fig. 1 Total number of buildings in excess of $300 \mathrm{~m}$ tall (after [13])

- The building weight, and thus the vertical load to be supported by the foundation, can be substantial. Moreover, the building weight increases non-linearly with height, and so both ultimate bearing capacity and settlement need to be considered carefully.

- High-rise buildings are often surrounded by low-rise podium structures which are subjected to much smaller loadings. Thus, differential settlements between the high- and low-rise portions need to be controlled.

- The lateral forces imposed by wind loading, and the consequent moments on the foundation system, can be very high. These moments can impose increased vertical loads on the foundation, especially on the outer piles within the foundation system. The structural design of the piles needs to take account of these increased loads that act in conjunction with the lateral forces and moments.

- The wind-induced lateral loads and moments are cyclic in nature. Thus, consideration needs to be given to the influence of cyclic vertical and lateral loading on the foundation system, as cyclic loading has the potential to degrade foundation capacity and cause increased settlements.

- Seismic action will induce additional lateral forces in the structure and also induce lateral motions in the ground supporting the structure. Thus, additional lateral forces and moments can be induced in the foundation system via two mechanisms:

- Inertial forces and moments developed by the lateral excitation of the structure;

- Kinematic forces and moments induced in the foundation piles by the action of ground movements acting against the piles.

- The wind-induced and seismically induced loads are dynamic in nature, and as such, their potential to give rise to resonance within the structure needs to be assessed. The risk of dynamic resonance depends on a number of factors, including the predominant period of the dynamic loading, the natural period of the structure and the stiffness and damping of the foundation system.
- The dynamic response of tall buildings poses some interesting structural and foundation design challenges. In particular, the fundamental period of vibration of a very tall structure can be very high (10 s or more), and conventional dynamic loading sources such as wind and earthquakes have a much lower predominant period and will generally not excite the structure via the fundamental mode of vibration. However, some of the higher modes of vibration will have significantly lower natural periods and may well be excited by wind or seismic action. These higher periods will depend primarily on the structural characteristics but may also be influenced by the foundation response characteristics.

\section{Foundation options}

\section{Factors affecting foundation selection}

The factors that may influence the type of foundation selected to support a tall building include the following:

- Location and type of structure.

- Magnitude and distribution of loadings.

- Ground conditions.

- Access for construction equipment.

- Durability requirements.

- Effects of installation on adjacent foundations, structures, people.

- Relative costs.

- Local construction practices.

The common foundation options are discussed below.

\section{Raft or mat foundations}

If high-rise developments contain a multi-level basement, the base of the development may be founded close to, or even embedded into, competent rock. A raft (mat) foundation to support the entire structure may be feasible for buildings of moderate height. However, for very tall buildings, such a shallow foundation may not be able to develop adequate resistance to horizontal and moment loadings.

Raft/mat foundations are relatively large in size; hence the foundation vertical bearing capacity is generally not the controlling factor in the design. The effects of lateral and moment loading should be incorporated into the assessment of ultimate bearing pressure. Soil stiffness is important in the raft/mat design to understand load distribution in the mat and for evaluating bending moments and shears in the raft. It is often good practice to look at an upper and lower bound set of soil stiffness values to evaluate raft performance. 
The soil and rock parameters adopted for design should be carefully chosen considering the variation in the ground conditions (both vertical and horizontal) across the relatively wide foundation area. The possible effect of future construction activity should also be considered in the estimation of bearing capacity.

For rafts founded on rock, the bearing capacity is highly dependent on factors such as the intensity and orientation of joints, degree of weathering and other local or general defects. For a weak rock mass having very closely spaced discontinuities or heavily weathered rock materials, it is common practice to consider the conventional bearing capacity equations for soil mechanics for the foundation design. For more accurate evaluation of the bearing capacity, the geotechnical strength parameters can be obtained from large-scale field tests in conjunction with an in situ test program, which will also provide the deformation characteristics of the ground.

\section{Compensated raft foundations}

Tall buildings very frequently have one or more basements to cater for car parking and/or commercial and retail space. In such cases, the construction of the raft involves excavation of the soil prior to construction of the foundation and the superstructure. Because of the stress reduction in the underlying ground caused by excavation, the net increase in ground stress due to the structure will be decreased, and hence it may be expected that the settlement and differential settlement of the foundation will also be decreased. The resulting foundation is termed a compensated or buoyancy raft, and can be very beneficial when constructing buildings on soft clay or loose sand, as the settlements that occur can be significantly less than those if the foundation was located at or near the ground surface.

\section{Piled foundations}

Often the ground conditions at a site are not suitable for a shallow raft/mat foundation system, especially for high-rise buildings where the vertical and lateral loadings imposed on the foundation are significant. In these circumstances, it is necessary to support the building loads on piles, either single piles or pile groups, generally located beneath columns and load bearing walls.

A piled foundation for high-rise structures often comprises a large numbers of piles and, therefore, the challenge in the design is capturing the effects of the group interaction. It is well recognised that the settlement of a pile group can differ significantly from that of a single pile at the same average load level due to group effects. Also, the ultimate load that can be supported by a group of piles may not be equal to the sum of the ultimate load which can be carried by each pile within the group, and so consideration must be given to the pile group efficiency.

\section{Piled raft foundations}

Many high-rise buildings are constructed with thick basement slabs. When piles are used in the foundation it is generally assumed that the basement slab does not carry any of the foundation loads. In some cases, it is possible to utilise the basement slab, in conjunction with the piles, to obtain a foundation that satisfies both bearing capacity and settlement criteria.

A piled raft foundation is a composite system in which both the piles and the raft share the applied structural loadings. Within a conventional piled foundation, it may be possible for the number of piles to be reduced significantly by considering the contribution of the raft to the overall foundation capacity. In such cases, the piles provide the majority of the foundation stiffness while the raft provides a reserve of load capacity. In situations where a raft foundation alone might be used, but does not satisfy the design requirements (in particular the total and differential settlement requirements), it may be possible to enhance the performance of the raft by the addition of piles. In such cases, the use of a limited number of piles, strategically located, may improve both the ultimate load capacity and the settlement and differential settlement performance of the raft and allows the design requirements to be met.

The main advantages of adopting a piled raft foundation are the following:

- As piles need not be designed to carry all the load, there is the potential for substantial savings in the cost of the foundations.

- Piles may be located strategically beneath the raft so that differential settlements can be controlled.

- Piles of different length and/or diameter can be used at different locations to optimise the foundation design.

- Varying raft thicknesses can be used at different locations to optimise the foundation design.

- Piles can be designed to carry a load approaching (or equal to) their ultimate geotechnical load, provided that the raft can develop an adequate proportion of the required ultimate load capacity.

The most effective application of piled rafts occurs when the raft can provide adequate load capacity, but the settlement and/or differential settlements of the raft alone exceed the allowable values. Poulos [56] has examined a 
number of idealised soil profiles and found that the following situations may be favourable:

- Soil profiles consisting of relatively stiff clays.

- Soil profiles consisting of relatively dense sands.

In both circumstances, the raft can provide a significant proportion of the required load capacity and also contribute to the foundation stiffness, especially after the pile capacity has been fully mobilised.

It has also been found that the performance of a piled raft foundation can be optimised by selecting suitable locations for the piles below the raft. In general, the piles should be concentrated in the most heavily loaded areas, while the number of piles can be reduced, or even eliminated, in less heavily loaded areas [31].

There are soil profiles in which piled rafts may not provide much, if any, advantage over a conventional piled foundation as follows:

- Profiles with very soft clays at or near the surface of the raft, where the raft can contribute only a relatively small proportion of the required ultimate load capacity.

- Profiles which may be subjected to long-term consolidation settlement; in this case, the soil may lose contact with the raft and transfer all the load to the piles.

- Profiles which may be subjected to expansive (upward) movements; in this case, the soil movements will result in increased contact pressures on the raft and the consequent development of tensile forces in the piles.

\section{Compensated piled raft foundations}

There is a reluctance on the part of many foundation designers to consider the use of piled raft foundations in soft clays, for at least two reasons:

- The soft clay often provides only a modest bearing capacity and stiffness for the raft, with the piles having to carry the vast majority of load.

- If the soft clay is likely to undergo settlement, for example due to reclamation filling or dewatering, the soil may settle away from the base of the raft, again leaving the piles to carry the load.

Despite these reservations, piled rafts have been used successfully in the past, most notably in Mexico City, where Zeevaert [78, 79] pioneered the use of rafts and compensated rafts with friction piles.

As the total piled-raft stiffness is directly related to the pile stiffness, the overall behaviour of a "compensated piled raft" will be affected by the excavation sequence. If the raft weight is lower than the effective excavation weight, the soil will still behave as an over-consolidated soil during the first stage of raising the building structure.

For compensated pile rafts, the excavation and pile installation process must be selected to suit each case. In some buildings, with shallow excavations, the piles can be executed before the excavation, from the ground level. In others, where greater depth must be achieved, part or the whole excavation is carried out first and the piles are installed once excavation is complete. The presence of groundwater can also influence the construction process.

When the piles are constructed in advance of the excavation, the piles will act as anchors, reducing the tendency for bottom soil heave. The upward soil movement will generate tensile stresses in the piles. Sommer [75, 76] reported "locked in stresses" for the piles of the Messeturm Building, in Frankfurt, of about 1.5 MN after excavation.

\section{The design process}

\section{Stages of design}

There are commonly three broad stages in foundation design:

1. A preliminary design, which provides an initial basis for the development of foundation concepts and costing.

2. A detailed design stage, in which the selected foundation concept is analysed and progressive refinements are made to the layout and details of the foundation system. This stage is desirably undertaken collaboratively with the structural designer, as the structure and the foundation act as an interactive system.

3. A final design phase, in which both the analysis and the parameters employed in the analysis are finalised.

It should be noted that the geotechnical parameters used for each stage may change as more knowledge of the ground conditions, and the results of in situ and laboratory testing, become available. The parameters for the final design stage should also incorporate the results of foundation load tests.

\section{Design issues and criteria}

The following issues will generally need to be addressed in the design of foundations for high-rise buildings:

1. Ultimate capacity of the foundation under vertical, lateral and moment loading combinations.

2. The influence of the cyclic nature of wind, earthquakes and wave loadings (if appropriate) on foundation capacity and movements. 
3. Overall settlements.

4. Differential settlements, both within the high-rise footprint, and between high-rise and low-rise areas.

5. Possible effects of externally imposed ground movements on the foundation system, for example, movements arising from excavations for pile caps or adjacent facilities.

6. Dynamic response of the structure-foundation system to wind-induced (and, if appropriate, wave) forces.

7. Earthquake effects, including the response of the structure-foundation system to earthquake excitation, and the possibility of liquefaction in the soil surrounding and/or supporting the foundation.

8. Structural design of the foundation system, including the load-sharing among the various components of the system (for example, the piles and the supporting raft) and the distribution of loads within the piles. For this, and most other components of design, it is essential that there be close cooperation and interaction between the geotechnical designers and the structural designers.

The above design issues are discussed below.

\section{Ultimate capacity}

There is an increasing trend for limit state design principles to be adopted in foundation design, for example, in the Eurocode 7 requirements and those of the Australian Piling Code $(1995,2007)$. In terms of limit state design using a load and resistance factor design approach (LRFD), the design criteria for the ultimate limit state are as follows:

$R_{s}^{*} \geq S^{*}$

$R_{g}^{*} \geq S^{*}$

where $R_{s}^{*}=$ design structural strength $=\phi_{\mathrm{s}} . R_{\mathrm{us}}, R_{g}^{*}=$ design geotechnical strength $=\phi_{\mathrm{g}} . R_{\mathrm{ug}}, R_{\mathrm{us}}=$ ultimate structural strength, $R_{\text {ug }}=$ ultimate strength (geotechnical capacity), $\phi_{\mathrm{s}}=$ structural reduction factor, $\phi_{\mathrm{g}}=$ reduction factor for geotechnical strength, and $S^{*}=$ design action effect (factored load combinations).

The above criteria are applied to the entire foundation system, while the structural strength criterion (Eq. 1) is also applied to each individual pile. It is not considered to be good practice to apply the geotechnical criterion (Eq. 2) to each individual pile within the group, as this can lead to considerable over-design. $R_{s}^{*}$ and $R_{g}^{*}$ can be obtained from the estimated ultimate structural and geotechnical capacities, multiplied by appropriate reduction factors. The structural and geotechnical reduction factors are often specified in national codes or standards. The selection of suitable values of $\phi_{\mathrm{g}}$ requires engineering judgment and should take into account a number of factors that may influence the foundation performance. As an example, the Australian Piling Code AS2159-2007 specifies an approach involving a subjective risk assessment, with lower values of $\phi_{\mathrm{g}}$ being associated with greater levels of uncertainty and higher values being relevant when ground conditions are reasonably well-known and a significant amount of load testing is to be carried out.

If any of the design requirements are not satisfied, then the design will need to be modified accordingly to increase the strength of the overall system or of those components of the system that do not satisfy the criteria.

\section{Load combinations}

The required load combinations for which the structure and foundation system have to be designed will usually be dictated by an appropriate structural loading code. In some cases, a large number of combinations may need to be considered. These may include several ultimate limit state combinations and serviceability combinations incorporating long-term and short-term loadings.

\section{Cyclic loading considerations}

In addition to the normal design criteria, as expressed by Eqs. 1 and 2, it is suggested that an additional criterion be imposed for the whole foundation of a tall building to cope with the effects of repetitive loading from wind and/or wave action, as follows:

$\eta R_{\mathrm{gs}}^{*} \leq S_{c}^{*}$,

where $R_{\mathrm{gs}}^{*}=$ design geotechnical shaft capacity, $S_{c}^{*}=$ maximum amplitude of wind loading and $\eta=\mathrm{a}$ reduction factor.

This criterion attempts to avoid the full mobilisation of shaft friction along the piles, thus reducing the risk that cyclic loading will lead to a degradation of shaft capacity. In most cases, it is suggested that $\eta$ can be taken as 0.5 , while $S_{c}^{*}$ can be obtained from computer analyses which give the cyclic component of load on each pile, for various wind loading cases.

\section{Serviceability—settlement and differential settlement}

The design criteria for the serviceability limit state are as follows:

$\rho_{\max } \leq \rho_{\text {all }}$

$\theta_{\max } \leq \theta_{\text {all }}$,

where $\rho_{\max }=$ maximum computed settlement of foundation, $\rho_{\text {all }}=$ allowable foundation settlement, $\theta_{\max }=$ 
maximum computed local angular distortion and $\theta_{\text {all }}=$ allowable angular distortion.

For the serviceability analysis, the best-estimate (unfactored) values of foundation resistances and stiffnesses are employed and the serviceability limit state (SLS) loads are applied. The design will be satisfactory if the computed deflections and rotations are within the specified allowable limits (Eqs. 4, 5).

Values of $\rho_{\text {all }}$ and $\theta_{\text {all }}$ depend on the nature of the structure and the supporting soil. Table 1 sets out some suggested criteria from work reported by Zhang and $\mathrm{Ng}$ [81]. This table also includes values of intolerable settlements and angular distortions. The figures quoted in Table 2 are for deep foundations, but the Zhang and $\mathrm{Ng}$ also consider allowable settlements and angular distortions for shallow foundations, different types of structure, different soil types and different building usage. Criteria specifically for very tall buildings do not appear to have been set, but it should be noted that it may be unrealistic to impose very stringent criteria on very tall buildings on clay deposits, as they may not be achievable. In addition, experience with tall buildings in Frankfurt suggests that total settlements well in excess of $100 \mathrm{~mm}$ can be tolerated without any apparent impairment of function. It should also be noted that the allowable angular distortion and the overall allowable building tilt reduce with increasing building height, both from a functional and a visual viewpoint.

\section{Design for ground movements}

Foundation design has traditionally focused on loads applied by the structure, but significant loads can also be applied to the foundation system because of ground movements. There are many sources of such movements, including the following that may be relevant to tall buildings:

1. Settlement of the ground due to site filling, reclamation or dewatering. Such effects can persist for many years and may arise from activities that occurred decades ago and perhaps on sites adjacent to the present site of interest. Such vertical ground movements give rise to negative skin friction on the piles within the settling layers.

2. Heave of the ground due to excavation of the site for basement construction. Ground heave can induce tensile forces in piles located within the heaving ground. Excavation can also give rise to lateral ground movements, which can induce additional bending moments and shears in existing piles.

3. Lateral and vertical movements arising from the installation of piles near already-installed piles. These
Table 1 Suggested serviceability criteria for structures [81]
Table 2 Human perception levels of dynamic motion [44]

\begin{tabular}{lll}
\hline Quantity & Value & Comments \\
\hline $\begin{array}{l}\text { Limiting tolerable settlement } \\
(\mathrm{mm})\end{array}$ & 106 & $\begin{array}{l}\text { Based on } 52 \text { cases of deep } \\
\text { foundations }\end{array}$ \\
$\begin{array}{l}\text { Observed intolerable settlement } \\
(\mathrm{mm})\end{array}$ & 349 & $\begin{array}{l}\text { Based on } 52 \text { cases of deep } \\
\text { foundations }\end{array}$ \\
$\begin{array}{l}\text { Limiting tolerable angular } \\
\text { distortion (rad) }\end{array}$ & $1 / 500$ & $\begin{array}{l}\text { Based on } 57 \text { cases of deep } \\
\text { foundations }\end{array}$ \\
$\begin{array}{l}\text { Limiting tolerable angular } \\
\text { distortion (rad) }\end{array}$ & $1 / 250(H<24 \mathrm{~m})$ to $1 / 1000$ & $\begin{array}{l}\text { From 2002 Chinese code } \\
H=\text { building height }\end{array}$ \\
$\begin{array}{l}\text { Observed intolerable angular } \\
\text { distortion (rad) }\end{array}$ & $1 / 125$ & $\begin{array}{l}\text { Based on } 57 \text { cases of deep } \\
\text { foundations }\end{array}$ \\
\hline
\end{tabular}

\begin{tabular}{|c|c|c|}
\hline $\begin{array}{l}\text { Level of } \\
\text { motion }\end{array}$ & $\begin{array}{l}\text { Acceleration } \\
\left(\mathrm{m}^{2} / \mathrm{s}\right)\end{array}$ & Effect \\
\hline 1 & $<0.05$ & Humans cannot perceive motion \\
\hline 2 & $0.05-0.1$ & Sensitive people can perceive motion. Objects may move slightly \\
\hline 3 & $0.1-0.25$ & $\begin{array}{l}\text { Most people perceive motion. Level of motion may affect desk work. Long } \\
\text { exposure may produce motion sickness }\end{array}$ \\
\hline 4 & $0.25-0.4$ & Desk work difficult or impossible. Ambulation still possible \\
\hline 5 & $0.4-0.5$ & $\begin{array}{l}\text { People strongly perceive motion, and have difficulty in walking. Standing } \\
\text { people may lose balance }\end{array}$ \\
\hline 6 & $0.5-0.6$ & Most people cannot tolerate motion and are unable to walk naturally \\
\hline 7 & $0.6-0.7$ & People cannot walk or tolerate motion \\
\hline 8 & $>0.85$ & Objects begin to fall and people may be injured \\
\hline
\end{tabular}


movements may induce additional axial and lateral forces and bending moment in the existing piles.

4. Dynamic ground motions arising from seismic activity. Such kinematic motions can induce additional moments and shears in the piles, in addition to the inertial forces applied by the structure to the foundation system.

Such ground movements do not reduce the geotechnical ultimate capacity of the piles, but have a twofold influence:

- The foundations are subjected to additional movements which must be considered in relation to the serviceability requirements.

- Additional axial and shear forces and bending moments are induced in the piles.

Because the action of ground movements on piles is a soil-structure interaction problem, the most straight-forward approach to design the piles for the additional forces and moments is to compute the best-estimate values and then factor up these computed values to obtain the design values.

\section{Dynamic loading}

Issues related to dynamic wind loading are generally dealt with by the structural engineer, with geotechnical input being limited to an assessment of the stiffness and damping characteristics of the foundation system. However, the following general principles of design can be applied to dynamic loadings:

- The natural frequency of the foundation system should be greater than that of the structure it supports, to avoid potential resonance phenomena. The natural frequency depends primarily on the stiffness of the foundation system and its mass, although damping characteristics may also have some influence.

- The amplitude of dynamic motions of the structurefoundation system should be within tolerable limits. The amplitude will depend on the stiffness and damping characteristics of both the foundation and the structure.

The acceptable levels of dynamic motion can be expressed in terms of dynamic amplitude of motion, or velocity or acceleration. Table 2 reproduces guidelines for human perception levels of dynamic motion, expressed in terms of acceleration [44]. These are for vibration in the low-frequency range of $0-1 \mathrm{~Hz}$ encountered in tall buildings, and incorporate such factors as the occupants' expectancy and experience, their activity, body posture and orientation, visual and acoustic cues. They apply to both the translational and rotational motions to which the occupant is subjected. The acceleration levels are a function of the frequency of vibration and decrease as the frequency increases. For example, allowable vibration levels at a frequency of $1 \mathrm{~Hz}$ are typically only $40-50 \%$ of those acceptable at a frequency of $0.1 \mathrm{~Hz}$. It is understood that, for a 10-year return period event, with a duration of $10 \mathrm{~min}$. American practice typically allows accelerations of between 0.22 and $0.25 \mathrm{~m}^{2} / \mathrm{s}$ for office buildings, reducing to $0.10-0.15 \mathrm{~m}^{2} / \mathrm{s}$ for residential buildings.

\section{Earthquake loading}

Soil deposits at a site subjected to an earthquake may experience the following effects:

- Increases in pore pressure;

- Time-dependent vertical ground movements during and after the earthquake;

- Time-dependent lateral ground movements during the earthquake.

In foundation design, consideration must, therefore be given to possible reductions in soil strength arising from the build-up of excess pore pressures during and after the earthquake. In extreme cases, the generation of pore pressures may lead to liquefaction in relatively loose sandy and silty soils.

As a consequence of the earthquake-induced ground movements, piles and other deep foundations will be subjected to two sources of additional lateral loading:

(a) Inertial loadings-these are forces that are induced in the piles because of the accelerations generated within the structure by the earthquake. Consideration is generally confined to lateral inertial forces and moments, which are assumed to be applied at the pile heads.

(b) Kinematic loadings-these are forces and bending moments that are induced in the piles because of the ground movements that result from the earthquake. Such movements will interact with the piles and, because of the difference in stiffness of the piles and the moving soil, there will be lateral stresses developed between the pile and the soil, resulting in the development of shear forces and bending moments in the piles. These actions will be timedependent and need to be considered in the structural design of the piles.

Thus, in addition to the usual design considerations for static loading, the above factors of strength reduction, inertial loadings and kinematic loadings, need to be incorporated into the design process.

When considering both the strength and stiffness of soils, consideration should also be given to the effects of 
the rapid rate of loading that occurs during a seismic event. Such loading rate effects tend to increase both the strength and stiffness of soils, especially fine grained soils.

Appropriate assessment of the geotechnical parameters is a critical component of geotechnical design for seismic actions, as it is for other types of imposed loadings. This issue is outside the scope of the present paper, and reference should be made to sources such as Kramer [36] who discusses such issues as the effects of strain, cyclic loading and loading rate effects on soil stiffness and damping.

\section{Structural design—-soil-structure interaction issues}

\section{Factoring of resistances}

When considering soil-structure interaction to obtain foundation actions for structural design (for example, the bending moments in the raft of a piled raft foundation system), the most critical response may not occur when the pile and raft capacities are factored downwards (for example, at a pile location where there is not a column, load acting, the negative moment may be larger if the pile capacity is factored up).

For this reason, in the structural design of the raft and the piles, the results of the ULS overall stability analysis are not considered to be relevant, because the loads that can be sustained by the piles are artificially reduced by the geotechnical reduction factor. Consequently, it is suggested that the most rational approach is one in which a separate ULS analysis is carried out using the various ULS load combinations but in which the unfactored resistances of the foundation components are employed. The consequent computed foundation actions (i.e., pile forces and, if appropriate, raft moments and shears) are then multiplied by a structural action factor (for example 1.5) to obtain the values for structural design.

\section{Stiffening effect of the superstructure}

It is common in geotechnical design to analyse a raft or piled raft without considering the stiffening effect of any structure that is supported by the raft. Methods of incorporating the stiffness of a structure into a raft analysis have been examined by several authors including Lee and Brown [38], Poulos [50] and Brown and Yu [8]. Zhang and Small [82] analysed three-dimensional framed buildings on raft foundations and demonstrated that the larger the relative stiffness of the building frame, the smaller the differential deflections in the raft. Such approaches can be extended to piled raft foundations.

Brown and $\mathrm{Yu}$ [8] also showed that as a building is constructed, the stiffness of the overall structure increases and this affects the differential displacement in the raft.
Gusmao Filho and Guimaraes [25] have also looked at construction sequence and have noted that the loads in columns reach a maximum (or minimum) value as more storeys are added to the building, leading to the idea of the building reaching a "limit stiffness".

It may, therefore, be concluded that the stiffness of a structure will influence the calculated settlements and differential settlements of a raft or piled raft foundation, but this depends on the stiffness of the structure relative to the raft. For buildings with rigid shear walls, the stiffening effect on the raft will be significant. However, for flexible light-frame structures, the effect of the structure on a thick raft will be small.

When undertaking a piled raft analysis, it may be convenient to represent the stiffness of the structure using thicker raft elements at locations where are walls and larger columns. While not providing any information on the structural behaviour, such an approach can provide a more realistic assessment of differential settlements within the footprint of a structure [71].

A convenient approach to foundation-structure interaction is for the piles to be represented by springs, the stiffness of which are computed by the geotechnical engineer and which include the important effects of interaction among the piles and the raft. Such interaction can significantly reduce the axial and lateral stiffness of piles within a group, as compared with the values for an isolated single pile. In this way, a more reliable analysis can be undertaken to compute not only the structural forces, but also the pile loads, the raft moments and the distribution of settlement within the foundation system.

\section{Estimation of pile load distribution}

In checking the structural loads within the piles in a piled raft system, it is essential to give proper consideration to the flexibility of the raft. Making the common assumption that the raft is rigid can lead to very misleading outcomes, as it tends to over-estimate the loads in the outer piles within the system. In addition, consideration of the superstructure stiffness in a piled raft analysis can also have a significant influence on the computed distribution of axial pile loads.

\section{Durability}

The durability design of foundations is frequently given very little attention, in comparison with strength and serviceability design issues. However, durability can be an important issue, especially if the foundation system is exposed to unsaturated ground conditions. Durability is not a specific property of a material but relates to the environment to which the material is exposed. For example, a 
concrete pile which is durable for non-aggressive soils may have inadequate durability when exposed to a coastal or marine environment.

Baker and Pawlikowski [4] describe such a situation with respect to the concrete in the tower foundation system of the Burj Khalifa, where the groundwater was extremely corrosive and contained about three times the sulphates and chlorides of seawater. A rigorous program of anti-corrosion measures of various types was followed to ensure its longterm integrity, including special waterproofing systems, increased concrete cover, addition of corrosion inhibitors to the concrete mix, and a cathodic protection system utilising titanium mesh.

\section{Preliminary design tools}

For preliminary design, use can be made of spreadsheets, MATHCAD sheets or simple hand or computer methods which are based on reliable but simplified methods. It can often be convenient to simplify the proposed foundation system into an equivalent pier and then examine the overall stability and settlement of this pier. For the ultimate limit state, the bearing capacity under vertical loading can be estimated from the classical approach in which the lesser of the following two values is adopted:

1. The sum of the ultimate capacities of the piles plus the net area of the raft (if in contact with the soil);

2. the capacity of the equivalent pier containing the piles and the soil between them, plus the capacity of the portions of the raft outside the equivalent pier.

For assessment of the average foundation settlement under working or serviceability loads, the elastic solutions for the settlement and proportion of base load of a vertically loaded pier [57] can be used, provided that the geotechnical profile can be simplified to a soil layer overlying a stiffer layer. Figure 2a, b reproduces these solutions, from which simplified load-settlement curves for an equivalent pier containing different numbers of piles can be estimated, using the procedure described by Poulos and Davis [65]. In these figures, the symbol definition is as follows:

$P=$ applied load, $E_{\mathrm{s}}=$ Young's modulus of soil, $E_{\mathrm{pe}}=$ Young's modulus of equivalent pier (pile + soil), $d_{\mathrm{e}}=$ diameter of equivalent pier, $I_{\mathrm{s}}=$ settlement influence factor, $P_{\mathrm{b}}=$ load on base of equivalent pier.

An alternative approach can be adopted, using the "PDR" approach described by Poulos [56]. In this approach, the simplified equations developed by Randolph [68] can be used to obtain an approximate estimate of the relationship between average settlement and the number of piles, and between the ultimate load capacity and the number of piles. From these relationships, a first estimate
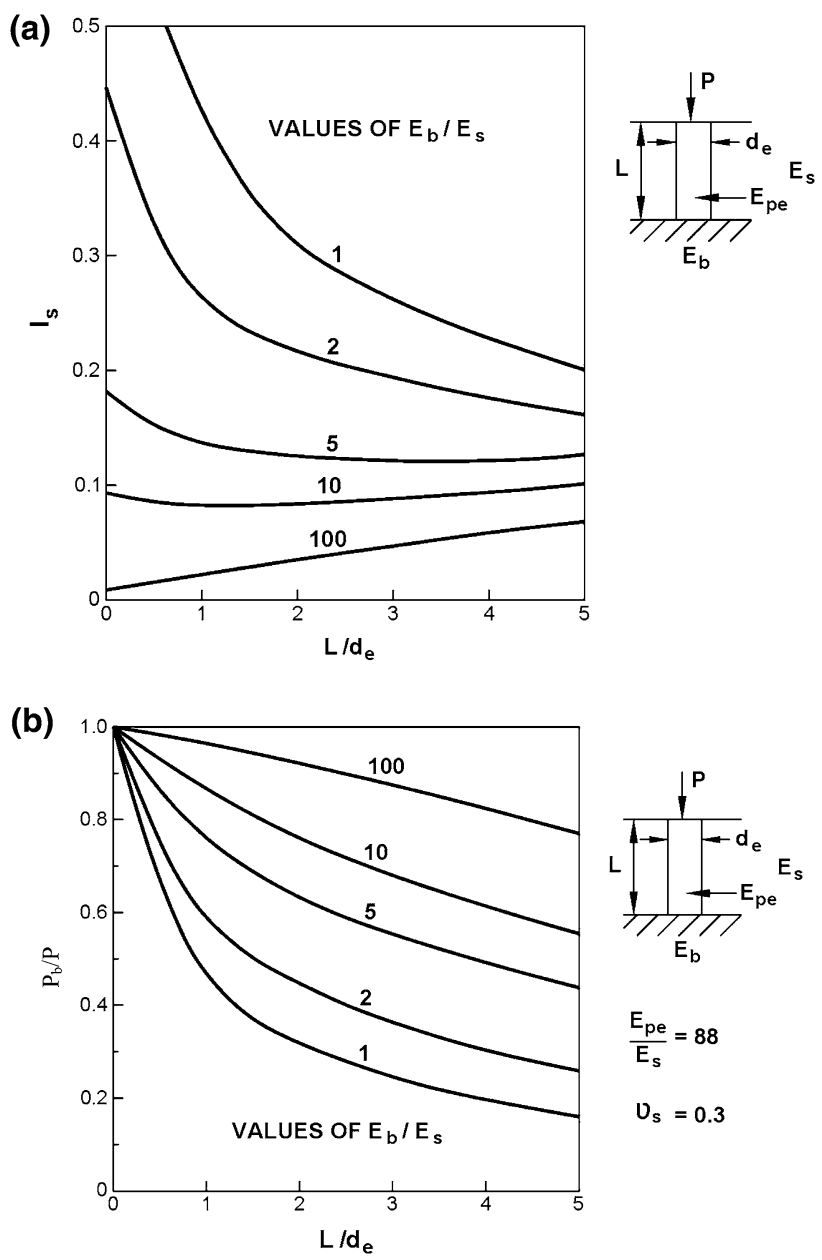

Fig. 2 a Settlement of equivalent pier in soil layer [57]. $S=P \cdot I_{\mathrm{S}} /$ $d_{\mathrm{e}} \cdot E_{\mathrm{s}}$. b Proportion of base load for equivalent pier [57]

can be made of the number of piles, of a particular length and diameter, to satisfy the design requirements.

The definition of the pile problem considered by Randolph is shown in Fig. 3. Using his approach, the stiffness of the piled raft foundation can be estimated as follows:

$K_{\mathrm{pr}}=\left(K_{\mathrm{p}}+K_{\mathrm{r}}\left(1-\alpha_{\mathrm{cp}}\right)\right) /\left(1-\alpha_{\mathrm{cp}}^{2} K_{\mathrm{r}} / K_{\mathrm{p}}\right)$,

where $K_{\mathrm{pr}}=$ stiffness of piled raft, $K_{\mathrm{p}}=$ stiffness of the pile group, $K_{\mathrm{r}}=$ stiffness of the raft alone, $\alpha_{\mathrm{cp}}=$ raft-pile interaction factor.

The raft stiffness $K_{\mathrm{r}}$ can be estimated via elastic theory, for example using the solutions of Fraser and Wardle [21] or Mayne and Poulos [41]. from elastic theory, using approaches such as those described by Poulos and Davis [65], Fleming et al. [19] or Poulos [53]. In the latter cases, the single pile stiffness is computed from elastic theory and then multiplied by a group stiffness efficiency factor which is estimated approximately from elastic solutions. 

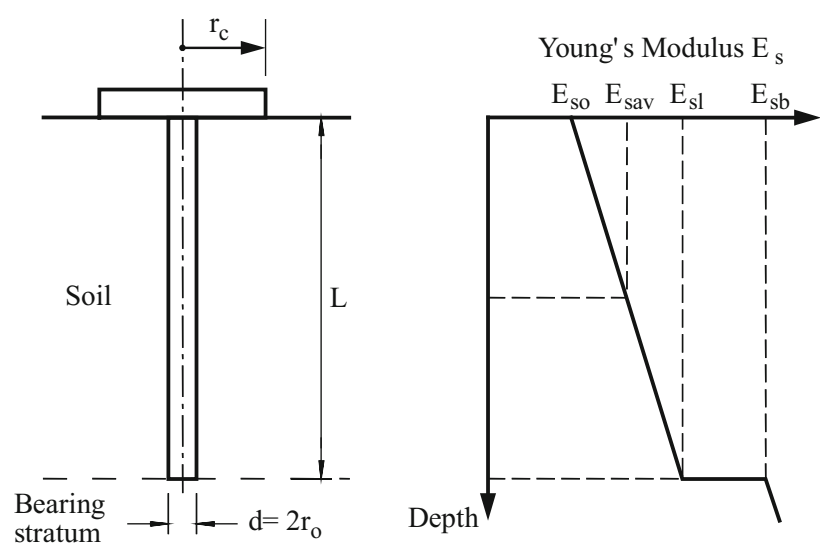

Fig. 3 Simplified representation of pile-cap unit

The proportion of the total applied load carried by the raft is

$P_{\mathrm{r}} / P_{\mathrm{t}}=K_{\mathrm{r}}\left(1-\alpha_{\mathrm{cp}}\right) /\left(K_{\mathrm{p}}+K_{\mathrm{r}}\left(1-\alpha_{\mathrm{cp}}\right)\right)=X$,

where $P_{\mathrm{r}}=$ load carried by the raft, $P_{\mathrm{t}}=$ total applied load.

The raft-pile interaction factor $a_{\mathrm{cp}}$ can be estimated as follows:

$\alpha_{\mathrm{cp}}=1-\ln \left(r_{\mathrm{c}} / r_{0}\right) / \varsigma$,

where $r_{\mathrm{c}}=$ average radius of pile cap (corresponding to an area equal to the raft area divided by number of piles) and $r_{0}=$ radius of pile.

$\varsigma=\ln \left(r_{\mathrm{m}} / r_{0}\right)$

$r_{\mathrm{m}}=\{0.25+\varsigma[2.5 \rho(1-v)-0.25) * L$

$\varsigma=E_{\mathrm{sl}} / E_{\mathrm{sb}}$

$\rho=E_{\mathrm{sav}} / E_{\mathrm{sl}}$,

where $v=$ Poisson's ratio of soil, $L=$ pile length, $E_{\mathrm{sl}}=$ soil Young's modulus at level of pile tip, $E_{\mathrm{sb}}=$ soil Young's modulus of bearing stratum below pile tip and $E_{\mathrm{sav}}=$ average soil Young's modulus along pile shaft.

The above equations can be used to develop a tri-linear load-settlement curve as shown in Fig. 4. First, the stiffness of the piled raft is computed from Eq. (6) for the number of piles being considered. This stiffness will remain operative until the pile capacity is fully mobilised. Making the simplifying assumption that the pile load mobilisation occurs simultaneously, the total applied load, $P_{1}$, at which the pile capacity is reached is given by

$P_{1}=P_{\text {up }} /(1-X)$,

where $P_{\text {up }}=$ ultimate load capacity of the piles in the group and $X=$ proportion of load carried by the piles (Eq. 7).

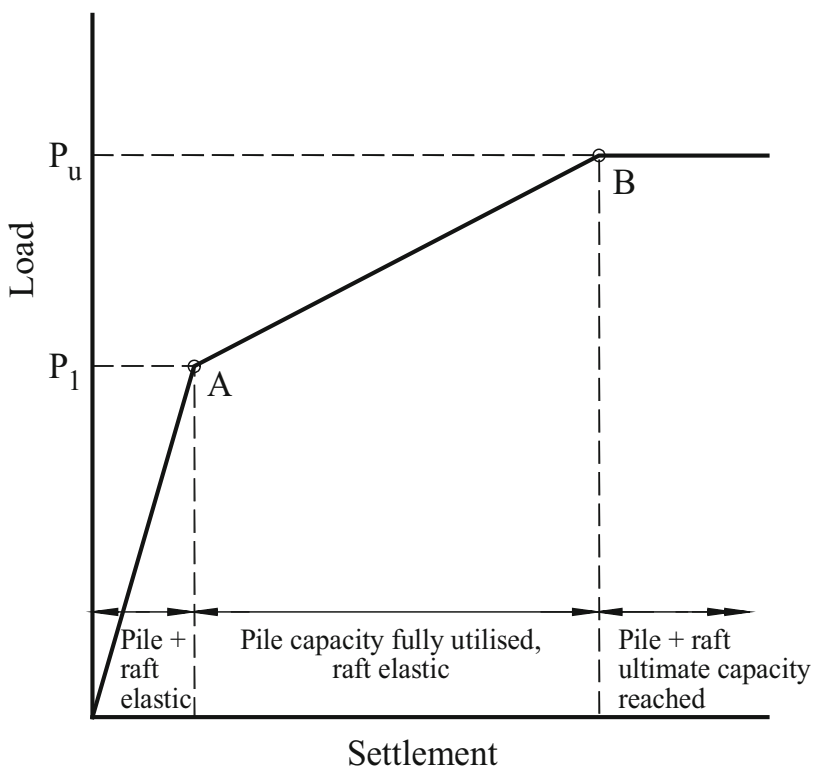

Fig. 4 Simplified trilinear load-settlement curve for piled raft

Beyond that point (Point A in Fig. 4), the stiffness of the foundation system is that of the raft alone $\left(K_{\mathrm{r}}\right)$, and this holds until the ultimate load capacity of the piled raft foundation system is reached (Point B in Fig. 4). At that stage, the load-settlement relationship becomes horizontal.

The load-settlement curves for a raft with various numbers of piles can be computed with the aid of a computer spreadsheet or a mathematical program such as MATHCAD. In this way, it is simple to compute the relationship between the number of piles and the average settlement of the foundation. Such calculations provide a rapid means of assessing whether the design philosophies for creep piling or full pile capacity utilisation are likely to be feasible.

\section{Detailed design tools and computer programs}

\section{Analysis requirements}

The preliminary stage of design can generally be undertaken with relatively simple and straight-forward techniques to assess both ultimate capacity and overall settlement performance. However, for the detailed and final design stages, more refined techniques are generally required. For these stages, the programs(s) used should ideally have the capabilities listed below:

1. For overall stability, the program should be able to consider the following:

- Non-homogeneous and layered soil profiles;

- Non-linearity of pile and, if appropriate, raft behaviour; 
- Geotechnical and structural failure of the piles (and the raft);

- Vertical, lateral and moment loading (in both lateral directions), including torsion; and

- piles having different characteristics within the same group.

2. For serviceability analysis, the above characteristics are also desirable, and in addition, the program should have the ability to consider the following:

- Pile-pile interaction, and if appropriate, raft-pile and pile-raft interaction;

- flexibility of the raft or pile cap;

- some means by which the stiffness of the supported structure can be taken into account.

\section{Commercially available packages}

There do not appear to be any commercially available software packages that have all of the above desirable characteristics, other than three-dimensional finite-element packages such as PLAXIS 3D or ABAQUS, or the finite difference program FLAC3D. The programs REPUTE, PIGLET and DEFPIG have some of the requirements, but fall short of a number of critical aspects, particularly in their inability to include raft-soil contact and raft flexibility.

\section{Other packages}

The author has developed the pile group analysis packages that, between them, provide several of the features listed above. The programs are as follows:

- Pile Group Settlement (PIGS): PIGS is a proprietary FORTRAN program that analyses the settlement and load distribution within a group of piles subjected to axial and moment loading and can also consider (in an approximate manner) the effects of externally imposed vertical ground movements such as those due to swelling or consolidation of the soil profile. Different pile types can be specified within the pile group, as can varying soil profiles. The underlying principles of this program are described by Poulos [59].

- Combined loading analysis of piles (CLAP): this proprietary program is a development of the commercially available program DEFPIG and can consider all six components of loading, rather than only vertical loading and horizontal and moment loading in one direction. Nonlinear pile behaviour is allowed for so that the program can be used to assess the overall stability of a pile group or a piled raft. It can also be used to compute single pile stiffness values and pile to pile interaction factors.

- General analysis of rafts with piles (GARP) is a proprietary program based on a finite-element analysis of the raft and a boundary element analysis of the piles. Small and Poulos [73] describe the basis of the GARP analysis. The contact stress that acts between the raft and the soil is assumed to be made up of a series of uniform blocks of pressure that act over each element in the raft. Each of the piles is assumed to apply a reaction to the raft at a point (corresponding to a node in the raft). The raft can have different thicknesses assigned to the elements that make up the mesh to represent areas of varying raft thickness. The deflections, shear forces and moments in the raft and the vertical loads on the piles due to the loading can be assessed. Because it can take raft (or pile cap) flexibility into account, it is suitable for assessing serviceability requirements. It is also useful for obtaining the axial stiffness of the piles within the group, which can then be passed on to the structural designer for incorporation into the overall structural analysis. In this way, it is possible to obtain more reliable bending moments and shears within the raft than is obtained directly from GARP, since account is taken of the stiffness of the supported structure.

\section{Summary of design analysis process}

A summary of the analyses that are recommended to be carried out for building foundation design are given in Table 3. These analyses involve various combinations of factored/unfactored geotechnical strengths and Ultimate Limit State (ULS) or Serviceability Limit State (SLS) loadings.

The assessment of the geotechnical reduction factor $\phi_{\mathrm{g}}$ is an important part of the design process. Procedures are described in various codes and standards, for example Eurocode 7, and Standrads Australia Piling Code (AS21592009). Various attempts have also been made to rationalise the selection of $\phi_{\mathrm{g}}$ based on probabilistic methods and the achievement of a target reliability index.

In practice, a series of factors need to be considered in making an assessment of $\phi_{\mathrm{g}}$, including the following in AS2159-2009:

- The geological complexity of the site;

- the extent of ground investigation;

- the amount and quality of geotechnical data;

- experience with similar foundations in similar geological conditions;

- the method of assessment of geotechnical parameters for design; 
Table 3 Summary of design analyses

\begin{tabular}{|c|c|c|c|c|}
\hline Case & Purpose & $\begin{array}{l}\text { Factor applied to } \\
\text { geotechnical strength } \\
\text { parameters }\end{array}$ & $\begin{array}{l}\text { Load } \\
\text { case }\end{array}$ & Comment \\
\hline 1 & Geotechnical design capacity & $\phi_{\mathrm{g}}$ & ULS & $\begin{array}{l}\text { Geotechnical reduction factor, } \phi_{\mathrm{g}} \text {, applied } \\
\text { to strength parameters to assess overall stability } \\
\text { of the pile group }\end{array}$ \\
\hline 2 & Structural design capacity & 1.0 & ULS & $\begin{array}{l}\text { Unfactored geotechnical strength parameters are adopted to } \\
\text { assess maximum pile axial load and pile bending } \\
\text { moment using short term pile modulus }\end{array}$ \\
\hline 3 & Serviceability & 1.0 & SLS & $\begin{array}{l}\text { Unfactored geotechnical strength parameters } \\
\text { are adopted to assess pile head deflections and rotations }\end{array}$ \\
\hline
\end{tabular}

- the design method adopted;

- the method of utilising the results of in situ test data and pile installation data;

- the level of construction control and

- the level of performance monitoring of the supported structure during and after construction.

$\phi_{\mathrm{g}}$ can typically range between 0.4 for conservative designs involving little or no pile testing and uncertain ground conditions, up to 0.8 for cases in which a significant amount of testing is carried out and the ground conditions and design parameters have been carefully assessed.

\section{Ground investigation and characterization}

\section{Ground information for geotechnical model development}

In the assessment of a geotechnical model and the associated parameters for foundation design, it is first necessary to review the geology of the site and identify any geological features that may influence the design and performance of the foundations. A desk study is usually the first step, followed by site visits to observe the topography and any rock or soil exposures. Local experience, coupled with a detailed site investigation program, is then required. The site investigation is likely to include a comprehensive borehole drilling and in situ testing program, together with a suite of laboratory tests to characterise strength and stiffness properties of the subsurface conditions. Based on the findings of the site investigation, the geotechnical model and associated design parameters are developed for the site and then used in the foundation design process.

Geophysical methods are being used increasingly to supplement data from conventional borehole drilling. Such methods, which include downhole and cross-hole techniques, have a number of major benefits, including the following:
- They provide a means of identifying the stratigraphy between boreholes;

- they can identify localised anomalies in the ground profile, for example cavities, sinkholes or localised pockets of softer or harder material;

- they can identify bedrock levels;

- they provide quantitative measurements for the shear wave and compression wave velocities. This information can be used to estimate the in situ values of soil stiffness at small strains and hence to provide a basis for quantifying the deformation properties of the soil strata.

The in situ and laboratory tests are desirably supplemented with a program of instrumented vertical and lateral load testing of prototype piles [e.g., bi-directional load cell (Osterberg Cell) tests] to allow calibration of the foundation design parameters and hence to better predict the foundation performance under loading. Completing the load tests on prototype piles prior to final design can provide conformation of performance (i.e., pile construction, pile performance, ground behaviour and properties) or else may provide data for modifying the design prior to construction.

\section{Assessment of geotechnical design parameters}

\section{Key parameters}

Many contemporary foundation systems incorporate both piles and a raft, and in such cases, the following parameters require assessment:

- the ultimate skin friction for piles in the various strata along the pile.

- The ultimate end bearing resistance for the founding stratum.

- The ultimate lateral pile-soil pressure for the various strata along the piles.

- The ultimate bearing capacity of the raft. 
- The stiffness of the soil strata supporting the piles, in the vertical direction.

- The stiffness of the soil strata supporting the piles, in the horizontal direction.

- The stiffness of the soil strata supporting the raft.

It should be noted that the soil stiffness values are not unique values but will vary, depending on whether longterm values are required (for long-term settlement estimates) or short-term values are required (for dynamic response to wind and seismic forces). For dynamic response of the structure-foundation system, an estimate of the internal damping of the soil is also required, as it may provide the main source of damping. Moreover, the soil stiffness values will generally vary with applied stress or strain level and will tend to decrease as either the stress or strain level increases.

\section{Empirical correlations}

Initial assessments for preliminary design are often based on the results of simple in situ tests such as the Standard Penetration Test (SPT) and the Static Cone Penetration Test (CPT).

\section{Correlations with SPT}

Typical of the correlations are the following which the author has employed are those based on the work of Decourt $[15,16]$ using the SPT:

- Raft ultimate bearing capacity:

$p_{\mathrm{ur}}=K_{1} \cdot N_{\mathrm{r}} \mathrm{kPa}$.

- pile ultimate shaft resistance:

$f_{\mathrm{s}}=a \cdot\left[2.8 N_{\mathrm{s}}+10\right] \mathrm{kPa}$

- pile ultimate base resistance:

$f_{\mathrm{b}}=K_{2} \cdot N_{\mathrm{b}} \mathrm{kPa}$

- soil Young's modulus below raft:

$E_{\mathrm{sr}}=2 N \mathrm{MPa}$

- Young's modulus along and below pile (vertical loading):

$$
E_{\mathrm{s}}=3 N \mathrm{MPa}
$$

where $N_{\mathrm{r}}=$ average SPT $\left(\mathrm{N}_{60}\right)$ value within depth of onehalf of the raft width, $N_{\mathrm{s}}=$ SPT value along pile shaft, $N_{\mathrm{b}}=$ average SPT value close to pile tip, $K_{1}, K_{2}=$ factors shown in Table 4, $a=1$ for displacement piles in all soils and non-displacement piles in clays, $a=0.5-0.6$ for nondisplacement piles in granular soils.
Table 4 Correlation factors $K_{1}$ and $K_{2}$ (after [16])

\begin{tabular}{llll}
\hline Soil type & $\begin{array}{l}K_{1} \\
(\text { raft })\end{array}$ & $\begin{array}{l}K_{2} \text { displacement } \\
\text { piles }\end{array}$ & $\begin{array}{l}K_{2} \text { non-displacement } \\
\text { piles }\end{array}$ \\
\hline Sand & 90 & 325 & 165 \\
Sandy silt & 80 & 205 & 115 \\
Clayey silt & 80 & 165 & 100 \\
Clay & 65 & 100 & 80 \\
\hline
\end{tabular}

- Small strain shear Modulus, $G_{0}$ :

Many correlations have been proposed to relate the smallstrain shear modulus $G_{0}$ to the SPT-N value. These generally take the following form:

$G_{0} \approx X\left[N_{1(60)}\right]^{y} \mathrm{MPa}$,

where $\left[N_{1(60)}\right]=$ SPT value, corrected for overburden pressure and hammer energy, $X$ and $y$ are parameters that may depend on soil type.

Typical values of $X$ and $y$ are shown in Table 5 .

\section{Correlations with CPT}

- Ultimate square or circular raft (or footing) bearing capacity [43]:

$p_{\mathrm{ur}}=a_{1}\left[1+a_{2} \cdot D / B\right] q_{\mathrm{c}}+q_{0}$

where $a_{1}, a_{2}$ are parameters depending on soil type and condition (Table 6 ), $q_{0}=$ overburden pressure at level of base, $q_{\mathrm{c}}=$ measured cone tip resistance, $D=$ depth of embedment below surface and $B=$ width of footing or raft.

- Pile ultimate shaft resistance [10, 18]:

$$
f_{\mathrm{s}}=q_{\mathrm{c}} / k_{\mathrm{s}} \leq f_{\mathrm{sl}}
$$

- Pile ultimate base capacity [20]:

Table 5 Typical parameters for small-strain shear modulus correlations (after [27])

\begin{tabular}{lll}
\hline Soil type & $X$ & $Y$ \\
\hline Sandy soils & 90.8 & 0.32 \\
Clayey soils & 97.9 & 0.27 \\
All soils & 90.0 & 0.31 \\
\hline
\end{tabular}

Table 6 Parameters $a_{1}$ and $a_{2}$ for ultimate bearing capacity of square shallow footings and rafts (after [43])

\begin{tabular}{llll}
\hline Soil type & Condition & $a_{1}$ & $a_{2}$ \\
\hline Clay, silt & All & 0.32 & 0.35 \\
Sand, gravel & Loose & 0.14 & 0.35 \\
& Medium & 0.11 & 0.50 \\
& Dense & 0.08 & 0.85 \\
Chalk & - & 0.17 & 0.27 \\
\hline
\end{tabular}


Table 7 Ultimate shaft friction correlation factors for CPT tests [43]

\begin{tabular}{|c|c|c|c|c|c|c|c|c|c|c|}
\hline \multirow[t]{2}{*}{ Pile type } & \multicolumn{5}{|c|}{ Clay and silt } & \multicolumn{3}{|c|}{ Sand and gravel } & \multicolumn{2}{|c|}{ Chalk } \\
\hline & Soft & Stiff & & Hard & & Loose & Med. & Dense & Soft & Weathered \\
\hline \multicolumn{11}{|l|}{ Drilled } \\
\hline$k_{\mathrm{s}}$ & - & - & $75^{\mathrm{a}}$ & - & 80 & 200 & 200 & 200 & 125 & 80 \\
\hline$f_{\mathrm{sl}}(\mathrm{kPa})$ & 15 & 40 & 80 & 40 & & - & - & 120 & 40 & 120 \\
\hline \multicolumn{11}{|c|}{ Drilled removed casing } \\
\hline$k_{\mathrm{s}}$ & - & 100 & $100^{\mathrm{b}}$ & - & $100^{\mathrm{b}}$ & 250 & 250 & 300 & 125 & 100 \\
\hline$f_{\mathrm{sl}}(\mathrm{kPa})$ & 15 & 40 & 60 & 40 & 80 & - & 40 & 120 & 40 & 80 \\
\hline \multicolumn{11}{|c|}{ Steel-driven close-ended } \\
\hline$k_{\mathrm{s}}$ & - & 120 & & 150 & & 300 & 300 & 300 & c & \\
\hline$f_{\mathrm{sl}}(\mathrm{kPa})$ & 15 & 40 & & 80 & & - & - & 120 & & \\
\hline \multicolumn{11}{|c|}{ Driven concrete } \\
\hline$k_{\mathrm{s}}$ & - & 75 & & - & & 150 & 150 & 150 & $\mathrm{c}$ & \\
\hline$f_{\mathrm{sl}}(\mathrm{kPa})$ & 15 & 80 & & 80 & & - & - & 120 & & \\
\hline
\end{tabular}

${ }^{a}$ Trimmed and grooved at the end of drilling

b Dry excavation, no rotation of casing

${ }^{\mathrm{c}}$ In chalk, $f_{\mathrm{s}}$ can be very low for some types of piles; a specific study is needed

$$
f_{\mathrm{b}}=k_{\mathrm{b}} \cdot q_{\mathrm{c}}
$$

where; $k_{\mathrm{s}}=$ shaft factor; $f_{\mathrm{sl}}=$ limiting ultimate shaft friction; $k_{\mathrm{b}}=$ base factor.

Table 7 gives recommended values of $k_{\mathrm{s}}$ and $f_{\mathrm{sl}}$, which depend on soil type and pile type. Values of $k_{\mathrm{b}}$ are given in Table 8. Here, the value of $q_{\mathrm{c}}$ used in Eq. 18 should be the average value within a distance of 1.5 base diameters above and below the base. Excessively large and low values are excluded from the average [10].

- Small strain shear modulus $G_{0}[40,42]$ :

$G_{0}=406\left(q_{\mathrm{c}}\right)^{0.695} / e_{0}^{1.130} \mathrm{kPa}$

where $q_{\mathrm{c}}=$ cone resistance, in $\mathrm{kPa}$ and $e_{0}=$ initial void ratio.

\section{Correlations with unconfined compressive strength}

For piles in rock, it is common to correlate design parameters with the unconfined compressive strength, $q_{\mathrm{u}}$, at least for preliminary purposes. Some of the available correlations are summarised in Table 9.

In employing such correlations, it should be recognised that, in the field, they may be influenced by geological features and structure that cannot be captured by a small and generally intact rock sample. Nevertheless, in the absence of other information, such correlations provide at least an indication of the order of magnitude.

More detailed correlations for rock mass modulus are provided by Hoek and Diederichs [30], who relate the rock
Table 8 Base capacity factors for CPT (after [43])

\begin{tabular}{llll}
\hline Soil type & $q_{\mathrm{c}}(\mathrm{MPa})$ & $k_{\mathrm{b}}$ & $k_{\mathrm{b}}$ \\
\hline Clay silt & & 0.40 & 0.55 \\
A & $<3$ & & \\
B & & & \\
$\quad$ Stiff & $3-6$ & & \\
C & $>6$ & & \\
Hard & & 0.15 & \\
Sand gravel & $<5$ & & \\
A & & & \\
Loose & $8-15$ & & \\
B & & & \\
Medium & $>20$ & & \\
C & & 0.30 \\
Dense & & & \\
Chalk & & & \\
A & $>5$ & 0.30 & \\
Soft & & & \\
B & & & \\
Weathered & & & \\
\hline
\end{tabular}

$N D$ non displacement pile, $D$ displacement pile

mass modulus to the Geological Strength Index, GSI, and a disturbance factor that reflects the geological structure.

\section{Parameters for lateral pile response}

The above correlations are for vertical loading on piles and raft. For lateral response analyses of piles, the above 
Table 9 Correlations of design parameters for piles in rock

\begin{tabular}{|c|c|c|}
\hline Parameter & Correlation & Remarks \\
\hline Ultimate bearing capacity (raft) & $p_{\mathrm{ur}}=a_{0} q_{\mathrm{u}}$ & $\begin{array}{l}a_{0} \text { Can vary from about } 0.1 \text { for extremely poor quality rock to } \\
24 \text { for intact high-strength rock [45]. A value of } 2 \text { is likely to } \\
\text { be reasonable and conservative in many cases }\end{array}$ \\
\hline Ultimate shaft friction, $f_{\mathrm{s}}$ & $f_{\mathrm{s}}=a\left(q_{\mathrm{u}}\right)^{b}$ & $\begin{array}{l}a \text { Generally varies between } 0.20 \text { and } 0.45 ; b \text { in most } \\
\text { correlations is } 0.5\end{array}$ \\
\hline Ultimate end bearing, $f_{\mathrm{b}}$ & $f_{\mathrm{b}}=a_{1}\left(q_{\mathrm{u}}\right)^{b 1}$ & $\begin{array}{l}a_{1} \text { Generally varies between } 3 \text { and } 5, b_{1} \text { in most correlations is } \\
1.0 \text {, although Zhang and Einstein }[80] \text { adopt } b_{1}=0.5\end{array}$ \\
\hline Young's modulus for vertical loading, $E_{\mathrm{sv}}$ & $E_{\mathrm{sv}}=a_{2}\left(q_{\mathrm{u}}\right)^{b 2}$ & $\begin{array}{l}a_{2} \text { Varies between about } 100 \text { and } 500 \text { for a wide range of rocks, } \\
b_{2} \text { is generally taken as } 1.0\end{array}$ \\
\hline
\end{tabular}

correlations need to be modified, and as a first approximation, the following adjustments are suggested:

1. Young's modulus values for vertical loading should be reduced by multiplying by a factor of 0.7 , to allow for the greater soil strain levels arising from lateral loading.

2. The ultimate lateral pile-soil pressure, $p_{y}$, can be approximately related to the ultimate end bearing $f_{\mathrm{b}}$, as follows:

$p_{y}=h \cdot f_{\mathrm{b}}$

where $\eta=0.22(1+z / d) \leq 1.0, z=$ depth below ground surface and $d=$ pile diameter or width.

\section{Laboratory testing}

\section{Triaxial and stress path testing}

Conventional triaxial testing is of limited value for assessing design parameters for pile foundations, as the method of stress application does not reflect the way in which load transfer occurs from the piles to the surrounding soil. However, cyclic triaxial testing may be useful in providing an indication of the degradation effects on the stiffness/strength properties of the foundation ground material due to cyclic loading. For the Burj Khalifa project, cyclic triaxial test results indicated that a degree of degradation was possible in the mass ground strength/ stiffness properties, but that under the anticipated applied loading, the foundations would be loaded to small strain levels such that potential degradation of strength and stiffness would be limited.

More sophisticated stress path testing can provide stiffness parameters over a range of stress appropriate to the foundation system, and can be used to compare with values from other means of assessment.

\section{Resonant column testing}

The resonant column test is commonly used for laboratory measurement of the low-strain properties of soils. It subjects solid or hollow cylindrical specimens to torsional or axial loading by an electromagnetic loading system. Usually harmonic loads for which frequency and amplitude can be controlled. It can be used to measure the small strain shear modulus and damping ratio of a soil or rock sample, and the variation in modulus and damping ratio with increasing shear strain level. Such data are valuable for carrying out dynamic response analyses of the foundation system.

\section{Constant normal stiffness (CNS) testing}

It has generally been accepted by practitioners that there is no suitable laboratory test which can be used reliably to measure the ultimate shaft friction $f_{\mathrm{s}}$. However, there has been a significant advance in recent years in direct shear testing of interfaces, with the development of the "constant normal stiffness" (CNS) test $[37,48]$. The basic concept of this test is illustrated in Fig. 5, and involves the presence of a spring of appropriate stiffness against which the normal stress on the interface acts. This test provides a closer simulation of the conditions at a pile-soil interface than the conventional constant normal stress direct shear test. The normal stiffness $K_{\mathrm{n}}$ represents the restraint of the soil surrounding the pile, and is given by:

$K_{\mathrm{n}}=4 G_{\mathrm{s}} / d$

where $G_{\mathrm{s}}=$ shear modulus of surrounding soil; $d=$ pile diameter.

The effects of interface volume changes and dilatancy can be tracked in a CNS test, and the results are particularly enlightening when cyclic loading is applied, as they demonstrate that the cyclic degradation is due to the 


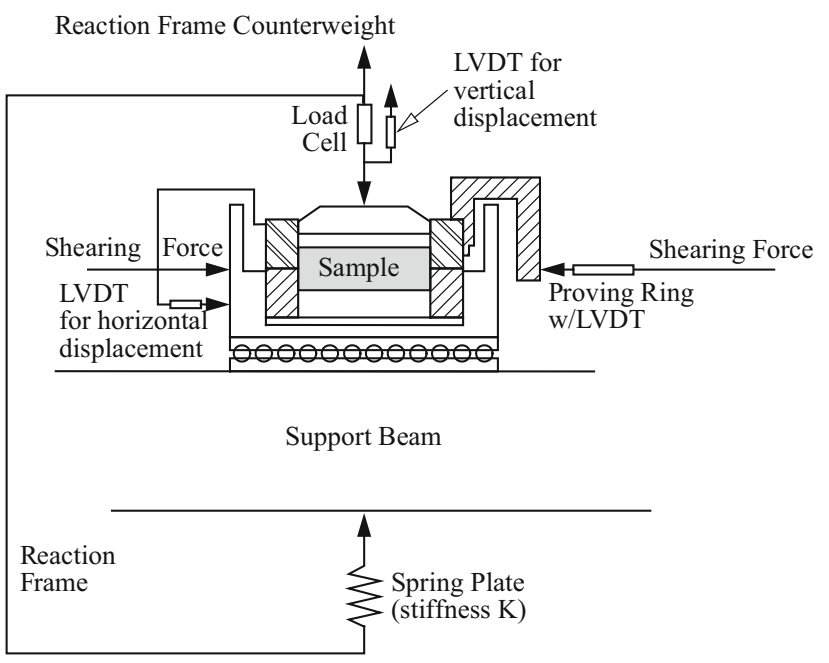

Fig. 5 Constant normal stiffness test setup

reduction in normal stress arising from the volume changes caused by the cyclic displacements applied to the interface.

\section{In-situ testing}

\section{Penetration testing}

Conventional SPT and CPT testing is usually undertaken as a means of classifying and approximately quantifying the soil strata, and of facilitating estimation of geotechnical design parameters via correlations such as those mentioned previously.

\section{Pressuremeter testing}

Pressuremeter testing can be used to estimate both strength and stiffness properties of the ground. The interpretation of test data is discussed by Briaud [7] and Mair and Wood [39]. The stiffness values relevant to foundation design are generally the values derived from an unload/reload loop.

\section{Geophysical testing}

Geophysical testing is becoming more widely used in geotechnical investigations. At least three major advantages accrue by use of such methods:

1. Ground conditions between boreholes can be inferred.

2. Depths to bedrock or a firm bearing stratum can be estimated.

3. Shear wave velocities in the various layers within the ground profile can be measured, and tomographic images developed to portray both vertical and lateral inhomogeneity.
4. From the measured shear wave velocity, $v_{\mathrm{s}}$, the smallstrain shear modulus, $G_{0}$, can be obtained as follows:

$G_{0}=\rho v_{\mathrm{s}}^{2}$

where $\rho=$ mass density of soil.

Allowance must be made for the effects of shear strain on the soil stiffness, which will lead to a reduction in the secant modulus value that may be useful for routine design, as discussed below.

\section{Derivation of secant values of soil modulus for foundation analysis}

For application to routine design, allowance must be made for the reduction in the shear modulus because of the relatively large strain levels that are relevant to foundations under normal serviceability conditions. As an example, Poulos et al. [63] have suggested the reduction factors shown in Fig. 6 for the case where $G_{0} / s_{\mathrm{u}}=500\left(s_{\mathrm{u}}=\right.$ undrained shear strength). This figure indicates that:

- The secant modulus for axial loading may be about $20-40 \%$ of the small-strain value for a practical range of factors of safety;

- The secant modulus for lateral loading is smaller than that for axial loading, typically by about $30 \%$ for comparable factors of safety.

Haberfield [26] has demonstrated that, when allowance is made for strain level effects, modulus values derived from geophysical tests can correlate well with those from pressuremeter tests. Figure 7 reproduces such an example

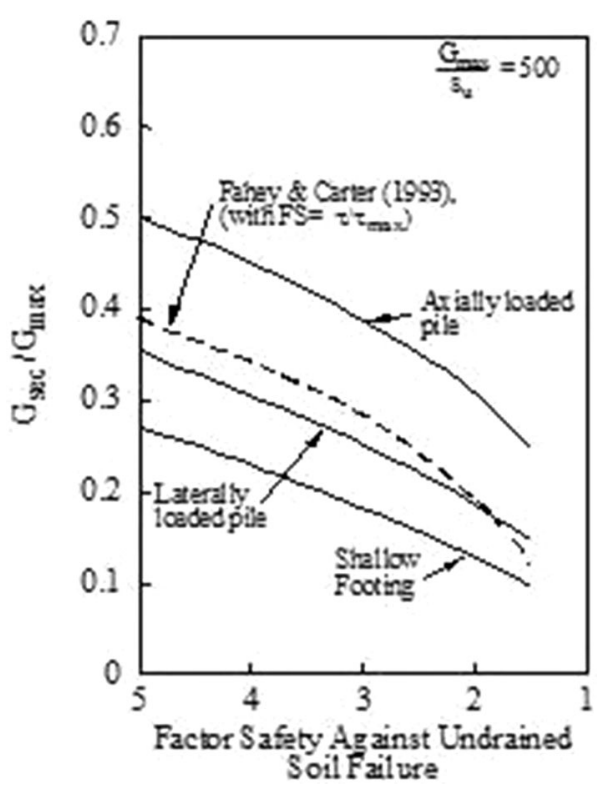

Fig. 6 Example of ratio of secant shear modulus to small-strain value [63] 

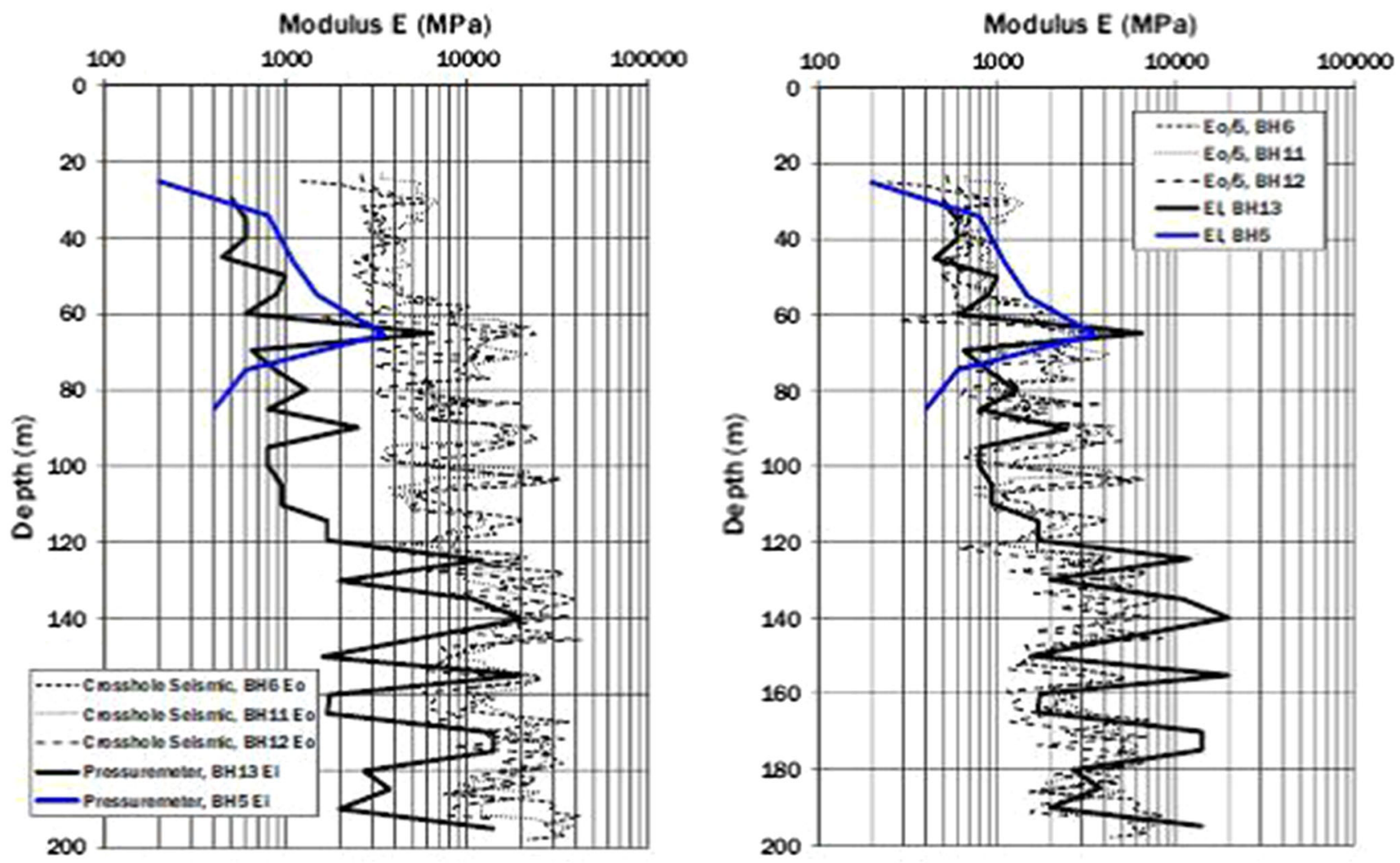

Fig. 7 Comparison of modulus values from pressuremeter and cross-hole seismic tests [26]

in which a reduction factor of 0.2 has been applied to the small-strain modulus values derived from cross-hole seismic test results. The modulus values so derived were found to be consistent with values obtained from subsequent pile load tests.

\section{Pile load testing}

\section{Introduction}

From the foundation designer's viewpoint, pile load testing should ideally be able to satisfy the following requirements:

- Provide information on the design issues;

- Be able to be undertaken on pre-production piles;

- Be able to be undertaken on any of the production piles without special preparation;

- Be relatively inexpensive;

- Provide reliable and unequivocal information which can be applied directly to the design process.

Some of the common methods of pile testing are summarised below, and then suggestions for the interpretation of the tests are offered.

\section{Static vertical load test}

This type of test is the most fundamental and involves the application of vertical load directly to the pile head, usually via a series of increments. Test procedures have been developed and specified by various codes, for example, ASTM D1143. The static load test is generally regarded as the definitive test and the one against which other types of test are compared. The test may take a variety of forms, depending on the means by which the reaction for the applied loading on the pile is supplied. This is the type of test which the designer would like to carry out, as it best simulates the way in which a structural load is applied to the pile. Unfortunately, the ideal test cannot usually be achieved in practice, as the reaction system interacts with the test pile, thus creating some potential problems with the interpretation of the test data.

The usual basic information from such a test is the loadsettlement relationship, from which the load capacity and pile head stiffness can be interpreted. However, such interpretation should be carried out with caution, as the measured pile settlement may be influenced by interaction between the test pile and the reaction system. Of concern is the fact that such interaction tends to lead to over-estimates 
of both capacity and stiffness, and, therefore, can lead to unconservative results, unless appropriate allowances are made for the effects of the interaction between the test pile, the reaction system and the settlement measuring system [65].

\section{Static lateral load test}

There are several forms of the lateral load test, but the most common and convenient is that which involves the jacking of one pile against one or more other piles; for example, ASTM Standard D3966 outlines a procedure for lateral load testing and for test interpretation.

As with the static vertical load test, there are "side effects" if two piles are jacked against other piles. In particular, because the direction of loading of each pile is different, the interaction between the piles will tend to cause a reduced head deflection of each pile, and as a consequence, the measured lateral stiffness of the pile will be greater than the true value.

\section{Dynamic load test}

- The principles of the dynamic load test are now very well-established [24, 69]. The test is now accepted as a routine procedure, especially for quality control and design confirmation purposes. Despite its widespread use, the dynamic pile load test has a number of potential limitations, including the fact that the loadsettlement behaviour estimated from the test is not unique, but is a best-fit estimate. Two measurements (strain and acceleration versus time) are taken, and from these, the complete distribution of resistance along the pile, as well as the load-settlement behaviour, are interpreted. Also, the load is applied far more rapidly than in most actual situations in practice, and hence time-dependent settlements are not developed during the test. Fortunately, under normal design load levels, the amount of time-dependency (from both consolidation and creep) is relatively small as most of the settlement arises from shear deformation at or near the pile-soil interface. Hence, the dynamic test may give a reasonable (if over-estimated) assessment of the pile head stiffness at the design load. However, it may be expected to be increasingly inaccurate as the load level approaches the ultimate value.

For heavily loaded foundations such as those supporting tall buildings, dynamic load testing is generally not feasible as insufficient energy can be imparted to the pile to fully mobilise its capacity. In some cases, however, the test may provide a convenient means of obtaining the head stiffness of a single pile.

\section{Bi-directional (Osterberg cell) test}

This test was originally developed by Osterberg [49] (a similar test was employed in Japan by [22]), and the test has been used increasingly over the past decade or more. A special cell is cast in or near the pile base, and pressure is applied. The base is jacked downwards while the shaft provides reaction and is jacked upwards. The test can continue until the element with the smaller capacity reaches its ultimate resistance. Using the Osterberg cell, load tests of up to $150 \mathrm{MN}$ have been carried out. Despite its ability to provide "self-reaction", the Osterberg cell test (like all tests) has its limitations and shortcomings, including the following:

- It is applicable primarily to bored piles;

- the cell must be pre-installed prior to the test; and

- there is interaction between the base and the shaft, and each will tend to move less than the "real" movement so that the apparent shaft and base stiffnesses will tend to be larger than the real values.

\section{Statnamic test}

Statnamic testing was jointly developed in Canada and the Netherlands [5, 46] and has also found considerable use and development in Japan. Comparative tests on piles subjected to conventional static testing and Statnamic testing have shown good agreement in load-settlement performance [6].

Statnamic testing appears to offer some advantages over other test types, including that

- the test is quick and easily mobilised.

- High loading capacity is available.

- The loading is accurately centred and can be applied to both single piles and pile groups.

- The test does not require any pre-installation of the loading equipment.

- The test is quasi-static and does not involve the development of potentially damaging compressive and tensile stresses in the test pile.

Inevitably, there are also some potential shortcomings, including the following:

- Certain assumptions need to be made in the interpretation of the test, especially in relation to the unloading of the pile.

- It cannot provide information on time-dependent settlements or movements. While this may not be of great importance for single piles, it can be a major limitation when testing pile groups, especially if compressible layers underlie the pile tips. 


\section{Test interpretation}

\section{Ultimate axial capacity}

For conventional static load testing, it is common for the test to be stopped prior to complete plunging failure being achieved. A vast number of suggestions have been made on how the ultimate axial load capacity can be estimated from such tests, for example Chen and Fang [11] and Reese and O'Neill [70] some of which have been reviewed and assessed by Hwang et al. [33]. They can be classified into the following categories:

1. "Conspicuous turning point of the load-settlement curve". This is often a subjective assessment.

2. Settlement $\mathrm{S}$ of the pile head, including

(a) $S=10 \%$ of diameter typically (attributed to [77]).

(b) Tangent flexibility of pile head, for example, Fuller and Hoy [23].

3. Residual settlement $\left(S_{\mathrm{p}}\right)$ of pile head. Examples include Davisson [14], who suggests that the ultimate capacity is the load at which the pile head settlement $=0.15+0.1 d$ (inches), where $d=$ pile diameter, in inches, and DIN4026 (Germany) in which the residual settlement upon unloading from the ultimate load is $2.5 \%$ of the diameter.

4. Creep rate of head settlement, where the ultimate capacity is taken as the load at which a sudden increase in the slope of the settlement-time curve occurs.

5. Coordinate transformation of the load-settlement curve, with the procedure of Chin [12] being typical. This involves plotting the ratio of settlement to load as a function of settlement and defining the ultimate capacity from the slope of the straight line portion of this plot.

6. Employing a specified shape of load-settlement curve, such as that employed by Hirany and Kulhawy [29].

Hwang et al. [33] concluded that the approach attributed to Terzaghi [77] was preferable to many of the other approaches.

The emergence of the bi-directional cell test has facilitated the interpretation of the ultimate load capacity, since a well-designed test will permit full (or almost full) mobilisation of both the shaft and base resistances.

\section{Ground modulus values}

Interpretation of the pile load test to assess the pile and ground stiffness characteristics requires that account be taken of the site stratigraphy. If there is no instrumentation along the pile, and hence no detailed load transfer information along the pile shaft, an assumption has to be made regarding the distribution of soil stiffness and strength with depth. This needs to be done in relation to the geotechnical profile to obtain reliable results. For the model of ground behaviour assumed in the pile analysis, the relevant ground parameters need to be interpreted from the measured load-settlement behaviour. For example, if a load transfer $(t-z)$ approach is adopted, the initial slope and subsequent shape of the load transfer curves must be assumed and then the parameters for the curves derived via a process of trial and error.

If an elastic-plastic soil model is assumed, then a distribution of Young's modulus and ultimate shaft friction with depth must be assumed and again, a trial and error process will generally be required to obtain a fit between the load-settlement behaviour from the theoretical model and the measured load-settlement behaviour.

If instrumentation has been installed in the pile, and if proper account is taken of residual stresses in the interpretation of the results, then the value of Young's modulus of the ground, $E_{\mathrm{s}}$, between each adjacent set of instrumentation can be interpreted by use of the following relationship developed by Randolph and Wroth [67]:

$E_{\mathrm{s}}=\left(\tau / w_{\mathrm{s}}\right) d(1+v) \ln \left(2 r_{\mathrm{m}} / d\right)$,

where $\tau=$ local shear stress, $w_{\mathrm{s}}=$ local settlement, $d=$ pile diameter, $v=$ ground Poisson's ratio, $r_{\mathrm{m}}=$ radius at which displacements become very small, $\tau / w_{\mathrm{s}}=$ the slope of the derived load transfer $(t-z)$ curve.

Randolph and Wroth (1978) give an expression for $r_{\mathrm{m}}$ and indicate that it is in the order of the length of the pile.

\section{Typical high-rise foundation settlements}

It may be useful to review the settlement performance of some high-rise buildings to gain some appreciation of the settlements that might be expected from two foundation types founded on various deposits. Table 10 summarises details of the foundation settlements of some tall structures founded on raft or piled raft foundations, based on documented case histories in Hemsley [28], Katzenbach et al. [35], and from the author's own experiences. The average foundation width in these cases ranges from about 40-100 m. The results are presented in terms of the settlement per unit applied pressure, and it can be seen that this value decreases as the stiffness of the founding material increases. Typically, these foundations have settled between 25 and $300 \mathrm{~mm} / \mathrm{MPa}$.

Some of the buildings supported by piled rafts in stiff Frankfurt clay have settled more than $100 \mathrm{~mm}$, and despite this apparently excessive settlement, the performance of the structures appears to be quite satisfactory. It may, 
Table 10 Examples of settlement of tall structure foundations

\begin{tabular}{lllll}
\hline $\begin{array}{l}\text { Foundation } \\
\text { type }\end{array}$ & $\begin{array}{l}\text { Founding } \\
\text { condition }\end{array}$ & Location & No. of cases & $\begin{array}{l}\text { Settlement per unit } \\
\text { pressure (mm/MPa) }\end{array}$ \\
\hline Raft & Stiff clay & Houston & 2 & $227-308$ \\
\multirow{3}{*}{ Piled raft } & Limestone & Amman; Riyadh & 2 & $25-44$ \\
& Stiff clay & Frankfurt & 5 & $218-258$ \\
& Dense sand & Berlin; Niigata & 2 & $83-130$ \\
& Weak rock & Dubai & 5 & $32-66$ \\
& Limestone & Frankfurt & 1 & 38 \\
\hline
\end{tabular}

therefore, be concluded that the tolerable settlement for tall structures can be well in excess of the conventional design values of $50-65 \mathrm{~mm}$. A more critical issue for such structures may be overall tilt and differential settlement between the high-rise and low-rise portions of a project.

\section{Case 1-La Azteca building Mexico}

The case of the La Azteca building was described by Zeevaert [78]. Figure 8 shows the original building. This building exerted a total average loading of about $118 \mathrm{kPa}$ and was located on a deep, highly compressible clay deposit which was also subjected to ground surface subsidence arising from groundwater extraction. The building was founded on a compensated piled raft foundation, consisting of an excavation $6 \mathrm{~m}$ deep with a raft supported by 83 concrete piles, $400 \mathrm{~mm}$ in diameter, driven to a depth of $24 \mathrm{~m}$ (i.e., the piles were about $18 \mathrm{~m}$ long below the raft).

The challenges in this case were to design the foundation for a relatively tall building founded on a very deep deposit of soft clay, in a pre-computer era.

Figure 9 shows, reproduced from Zeevaert's paper, details of the foundation, the soil profile, the settlement computed by Zeevaert and the measured settlements. The settlement without piles computed by Zeevaert (from a one-dimensional analysis) was substantial, but the addition of the piles was predicted to reduce the settlement to less than half of the value without piles. The measured settlements were about $20 \%$ less than the calculated settlements, but nevertheless confirmed the predictions reasonably well.

An approximate analysis developed by the author [58] was applied to this case, excluding the effects of ground settlements, which were not detailed by Zeevaert in his paper. The following approach was adopted:

1. The one-dimensional compressibility data presented by Zeevaert was used to obtain values of Young's modulus of the soil at various depths, for the case of

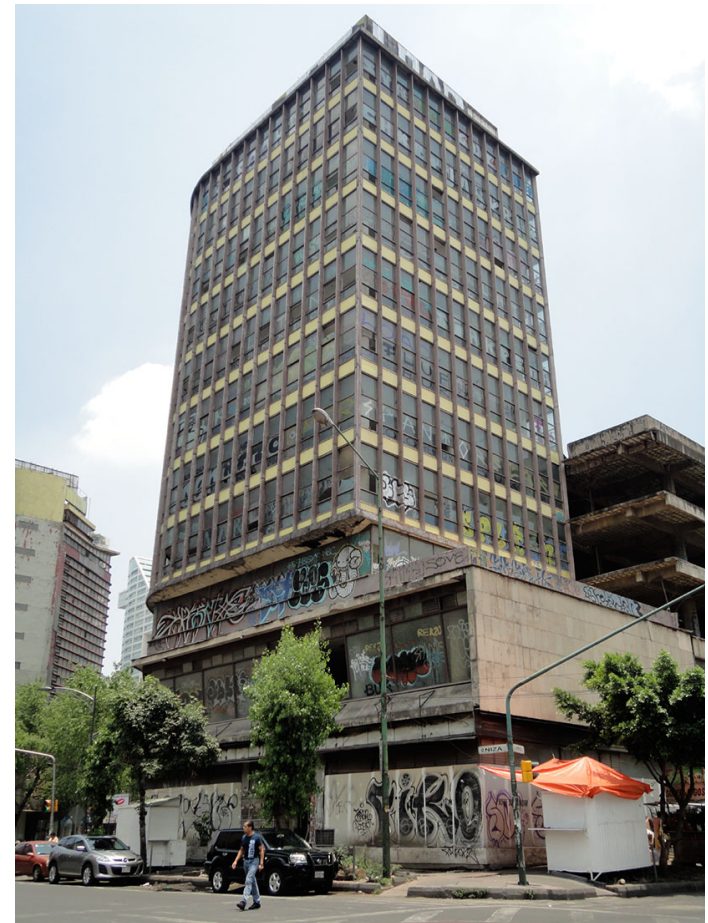

Fig. 8 The La Azteca building

the soft clays in a normally consolidated state. A drained Poisson's ratio of 0.4 was assumed. The modulus values thus obtained were typically very low, of the order of $0.5-1.0 \mathrm{MPa}$, and lower than what would have been anticipated on the basis of the measured shear strength of the clay.

2. The bearing capacity of the raft was estimated from the shear strength data provided by Zeevaert and was found to be about $200 \mathrm{kPa}$. This represented a factor of safety of about 1.7 on the average applied loading of $118 \mathrm{kPa}$.

3. The settlement of an uncompensated raft was computed using these modulus values together with conventional elastic theory. A very large settlement, in excess of $2.3 \mathrm{~m}$, was obtained for the final settlement. 
Fig. 9 Details of La Azteca building on compensated piled raft [78]

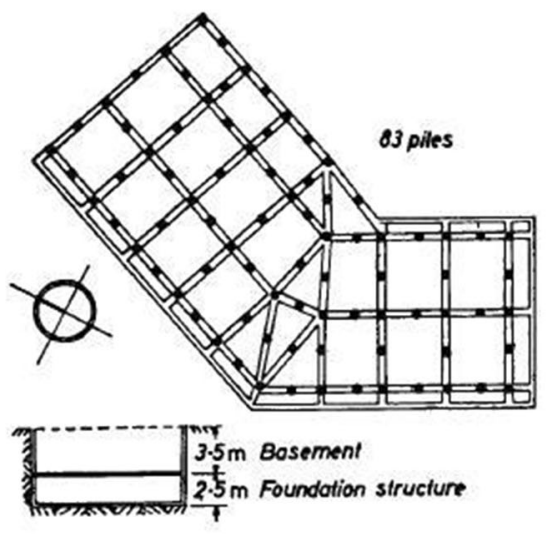

(a) FOUNDATION PLAN a PILE LAYOUT

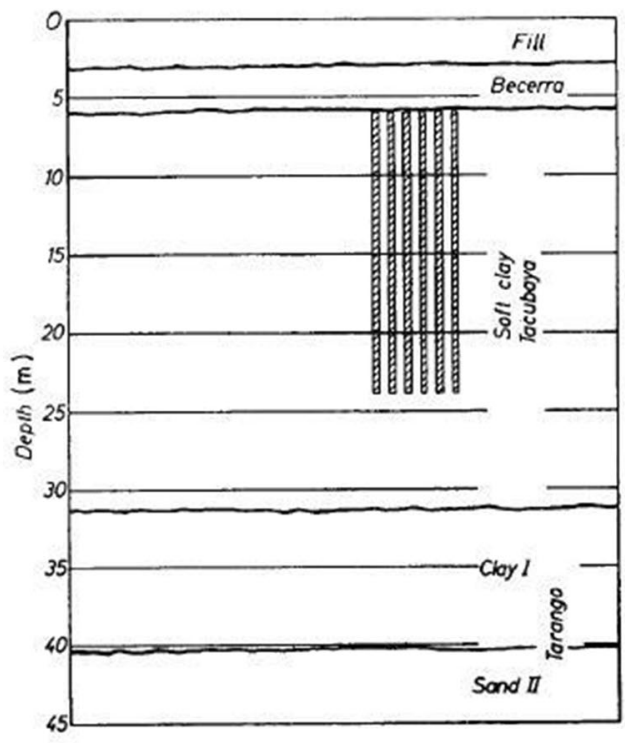

(b) SUBSOIL PROFILE

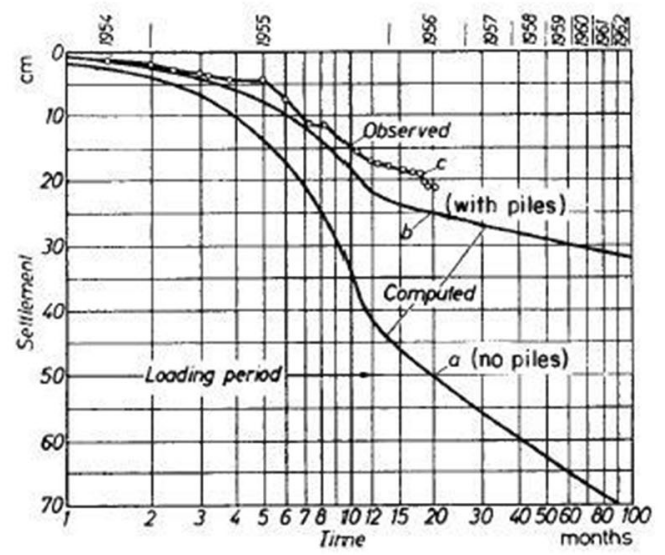

(c) SETTLEMENT CURVES

4. The settlement of a compensated raft was computed, assuming a 6-m depth of excavation and assuming that the soil modulus values for the over-consolidated state were ten times those for the normally consolidated state (based on the oedometer data presented by Zeevaert). The additional raft pressure to recommence virgin loading conditions, $p_{\mathrm{ec}}$, was taken to be zero. A settlement of the order of $988 \mathrm{~mm}$ was thus computed.

5. From the pile load tests reported by Zeevaert, values of the single pile capacity and stiffness were obtained, these being about $735 \mathrm{kN}$ and $25 \mathrm{MN} / \mathrm{m}$, respectively.

6. For the 83 piles used in the foundation, the group stiffness was computed using the approximation of Poulos [53] and applying a factor of 9.1 (the square root of the number of piles, i.e., $83^{0.5}$ ) to the single pile stiffness. A group stiffness of about $230 \mathrm{MN} / \mathrm{m}$ was calculated.
7. The average settlement of the foundation for an uncompensated piled raft was computed, using the equations developed by Randolph [68] for the piled raft stiffness. A settlement of about $1.08 \mathrm{~m}$ was obtained. The analysis indicated that, in this case, the raft would carry only about $4 \%$ of the load under elastic conditions and that the capacity of the piles would be mobilised fully under the design load of about $78 \mathrm{MN}$.

8. The effects of carrying out a 6-m deep excavation (as was actually used) was simulated by reducing the thickness of the soil profile accordingly, and again assuming that, for the raft, the soil Young's modulus for the over-consolidated state was ten times that for the normally consolidated state (based on the laboratory oedometer data published by Zeevaert). The stiffness of the raft was thus increased significantly, 
Table 11 Summary of computed average settlements

\begin{tabular}{lll}
\hline Case & $\begin{array}{l}\text { Computed average } \\
\text { final settlement }(\mathrm{mm})\end{array}$ & $\begin{array}{l}\text { Ratio of settlement to } \\
\text { settlement of } \\
\text { compensated raft }\end{array}$ \\
\hline $\begin{array}{c}\text { Raft alone, no } \\
\text { compensation }\end{array}$ & 2342 & 2.37 \\
$\begin{array}{c}\text { Raft alone, with } \\
\text { compensation }\end{array}$ & 988 & 1.0 \\
$\begin{array}{c}\text { Piled raft, no } \\
\text { compensation }\end{array}$ & 1084 & 1.10 \\
$\begin{array}{c}\text { Piled raft, with } \\
\text { compensation }\end{array}$ & 283 & 0.29 \\
\hline
\end{tabular}

leading also to a significant increase in the stiffness of the piled raft foundation, to about $300 \mathrm{MN} / \mathrm{m}$. The raft, at the design load, was found to carry about $40 \%$ of the total load, and the computed settlement under that load was reduced to about $280 \mathrm{~mm}$.

The analysis results are summarised in Table 11. It can be seen that the settlement of the compensated piled raft is about $26 \%$ of the settlement of the piled raft without compensation, $29 \%$ of the settlement of the compensated raft alone and only about $12 \%$ of the value for the uncompensated raft.

Zeevaert's calculations gave larger settlements than those computed above, being about $1000 \mathrm{~mm}$ for the compensated raft alone, and about $370 \mathrm{~mm}$ for the compensated piled raft. This represented a reduction in settlement of about $63 \%$ in using the compensated piled raft rather than the compensated raft alone. This compares reasonably well to the $71 \%$ reduction in settlement computed from the present approach. It is also interesting to note that the measured settlements about 2 years after the commencement of construction were about $20 \%$ less than those predicted by Zeevaert. At that stage, the measured settlement was about $205 \mathrm{~mm}$ and the computed settlement from Zeevaert was $250 \mathrm{~mm}$, i.e., about $68 \%$ of the final predicted settlement. Assuming a similar rate of settlement, the prediction made by the current approach for the settlement after 2 years would be about $192 \mathrm{~mm}$, in fair agreement with, but somewhat less than, the measured $205 \mathrm{~mm}$.

\section{Case 2-The Burj Khalifa, Dubai}

\section{Introduction}

The Burj Khalifa project in Dubai comprised the construction of a 160-storey high rise tower, with a podium development around the base of the tower, including a 4-6 storey garage. The client for the project was

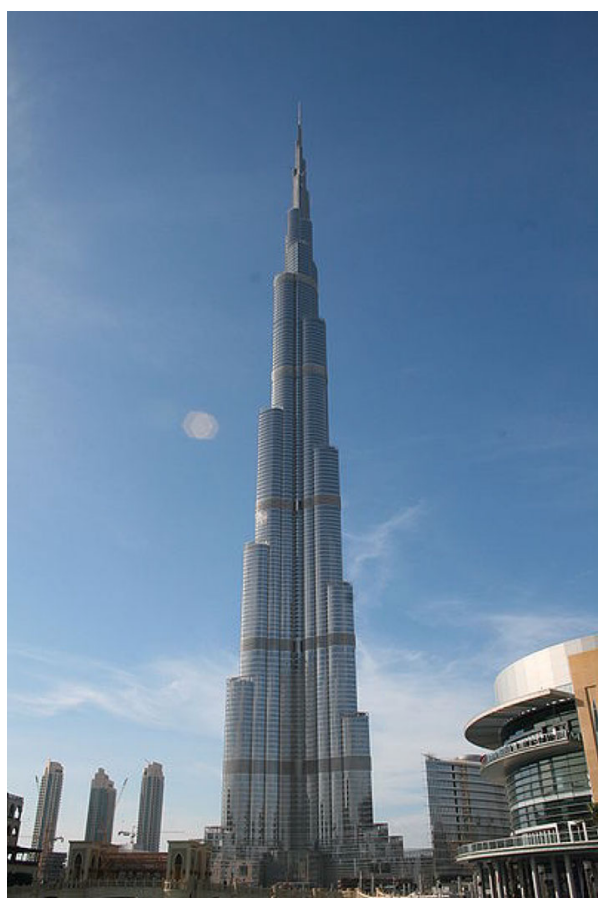

Fig. 10 The Burj Khalifa

Emaar, a leading developer based in Dubai. The Burj Khalifa Tower (originally denoted as the Burj Dubai prior to completion and opening) is the world's tallest building at $828 \mathrm{~m}$. It is founded on a $3.7-\mathrm{m}$ thick raft supported on bored piles, $1.5 \mathrm{~m}$ in diameter, extending approximately $50 \mathrm{~m}$ below the base of the raft. Figure 10 shows the completed tower. The site is generally level and site levels are related to Dubai Municipality Datum (DMD).

The key challenges in this case were to undertake an economical foundation design for the world's tallest building, where the founding conditions were relatively weak rock and where significant wind loadings were to be resisted. A detailed description of this case is given by Poulos and Bunce [61].

The Architects and Structural Engineers for the project were Skidmore Owings and Merrill LLP (SOM) in Chicago. Hyder Consulting (UK) Ltd (HCL) were appointed geotechnical consultant for the works by Emaar and carried out the design of the foundation system, while an independent peer review was undertaken by Coffey Geosciences (Coffey). The process of foundation design and verification process is described below, together with the results of the pile load testing programs. The predicted settlements are then compared with those measured during construction.

The building was ' $\mathrm{Y}$ ' shaped in plan, to reduce the wind forces on the tower and to keep the structure relatively simple and aid constructability. Baker et al. [3] describe the 
structural system as a "buttressed core". Each wing had its own high-performance concrete corridor walls and perimeter columns, and buttressed the others via a six-sided central core or hexagonal hub. As a consequence, the tower was very stiff laterally and torsionally. The structural aspects are described by Baker et al. [3], while Smith [74] provides an architectural perspective of the building. The structural design involved a three-dimensional model consisting of the reinforced concrete walls, link beams, slabs, raft and piles, together with the steel structural steel system. Gravity, wind and seismic loadings were considered. According to Baker et al. [3], under lateral wind loading, the building deflections were assessed to be well below commonly used criteria. Dynamic analyses indicated a period of $11.3 \mathrm{~s}$ for the first lateral mode of vibration, a period of $10.2 \mathrm{~s}$ for the second mode, with the fifth mode (torsional motion) having a period of $4.3 \mathrm{~s}$.

The construction of the Burj Khalifa utilised recent advancements in construction techniques and material technology, using 80 and $60 \mathrm{MPa}$ concrete with flyash, the higher strength being used for the lower portion of the structure. The walls were formed using an automatic selfclimbing formwork system, and the circular nose columns were formed with steel forms, while the floor slabs were poured on to special formwork. The wall reinforcement was fabricated on the ground in $8 \mathrm{~m}$ sections to allow for rapid placement. The central core and slabs were cast first, in three sections: the wing walls and slabs then followed, and after them, the wing nose and slabs followed. Concrete was pumped by specially designed pumps, capable of pumping to heights of $600 \mathrm{~m}$ in a single stage. A special GPS system was developed to monitor the verticality of the structure during construction.

\section{Geotechnical investigation and testing program}

The geotechnical investigation was carried out in four phases as follows:

- Phase 1 (main investigation) 23 boreholes, in situ SPT's, 40 pressuremeter tests in three boreholes, installation of four standpipe piezometers, laboratory testing, specialist laboratory testing and contamination testing-1 st June to 23rd July 2003;

- Phase 2 (main investigation) Three geophysical boreholes with cross-hole and tomography geophysical surveys carried out between three new boreholes and one existing borehole-7th to 25th August, 2003;

- Phase 3 Six boreholes, in situ SPT's, 20 pressuremeter tests, installation of two standpipe piezometers and laboratory testing - 16th September to 10th October 2003;

- Phase 4 One borehole, in situ SPTs, cross-hole geophysical testing in three boreholes and down-hole geophysical testing in one borehole and laboratory testing.

- The drilling was carried out using cable percussion techniques with follow-on rotary drilling methods to depths between 30 and $140 \mathrm{~m}$ below ground level. The quality of core recovered in some of the earlier boreholes was somewhat poorer than that recovered in later boreholes, and, therefore, the defects noted in the earlier rock cores may not have been representative of the actual defects present in the rock mass. Phase 4 of the investigation was targeted to assess the difference in core quality and this indicated that the differences were probably related to the drilling fluid used and the overall quality of drilling.

Disturbed and undisturbed samples and split spoon samples were obtained from the boreholes. Undisturbed samples were obtained using double tube core barrels (with Coreliner) and wire line core barrels producing core varying in diameter between 57 and $108.6 \mathrm{~mm}$. Standard Penetration Tests (SPTs) were carried out at various depths in the boreholes and were generally carried out in the overburden soils, in weak rock or soil bands encountered in the rock strata.

Pressuremeter testing, using an OYO Elastmeter, was carried out in five boreholes between depths of about 4 and $60 \mathrm{~m}$ below ground level typically below the Tower footprint.

The geophysical survey comprised cross-hole seismic survey, cross-hole tomography and down-hole geophysical survey. The main purpose of the geophysical survey was to complement the borehole data and provide a check on the results obtained from borehole drilling, in situ testing and laboratory testing.

The cross-hole seismic survey was used to assess compression $(P)$ and shear $(S)$ wave velocities through the ground profile. Cross-hole tomography was used to develop a detailed distribution of $P$-wave velocity in the form of a vertical seismic profile of $P$-wave with depth, and to highlight any variations in the nature of the strata between boreholes. Down-hole seismic testing was used to determine shear $(S)$ wave velocities through the ground profile.

The geotechnical laboratory testing program consisted of two broad classes of test:

- Conventional tests, including moisture content, Atterberg limits, particle size distribution, specific gravity, unconfined compressive strength, point load index, direct shear tests, and carbonate content tests.

- Sophisticated tests, including stress path triaxial, resonant column, cyclic undrained triaxial, cyclic simple shear and constant normal stiffness (CNS) direct shear tests. These tests were undertaken by a variety of 
commercial, research and university laboratories in the UK, Denmark and Australia.

\section{Geotechnical conditions}

The ground conditions comprised a horizontally stratified subsurface profile which was complex and highly variable, due to the nature of deposition and the prevalent hot arid climatic conditions. Medium dense to very loose granular silty sands (Marine Deposits) were underlain by successions of very weak to weak sandstone interbedded with very weakly cemented sand, gypsiferous fine-grained sandstone/siltstone and weak to moderately weak conglomerate/calcisiltite.

Groundwater levels were generally high across the site and excavations were likely to encounter groundwater at approximately $+0.0 \mathrm{~m}$ DMD (approximately $2.5 \mathrm{~m}$ below ground level). The ground conditions encountered in the investigation were consistent with the available geological information.

The ground profile and derived geotechnical design parameters assessed from the investigation data are summarised in Table 11. Values of Young's modulus derived by various means are plotted in Fig. 11. Non-linear stress-strain responses were derived for each strata type using the results from the SPT's, the pressuremeter, the geophysics and the standard and specialist laboratory testing. An allowance for degradation of the mass stiffness of the materials was incorporated in the derivation of the non-linear stress-strain curves used in the numerical design analyses.

An assessment of the potential for degradation of the stiffness of the strata under cyclic loading was carried out through a review of the CNS and cyclic triaxial specialist test results and also using the computer program SHAKE91 [34] for potential degradation under earthquake loading. The results indicated that there was a potential for degradation of the mass stiffness of the materials, but limited potential for degradation at the pile-soil interface.

\section{Foundation design}

An assessment of the foundations for the structure was carried out and it was clear that piled foundations would be appropriate for both the Tower and Podium construction. An initial assessment of the pile capacity was carried out using the following design recommendations given by Horvath and Kenney [32], as presented by Burland and Mitchell [9]:

Ultimate unit shaft resistance $f_{\mathrm{s}}=0.25\left(q_{\mathrm{u}}\right)^{0.5}$,

where $f_{\mathrm{s}}$ is in $\mathrm{kPa}$, and $q_{\mathrm{u}}=$ uniaxial compressive strength in $\mathrm{MN} / \mathrm{m}^{2}$
The adopted ultimate compressive unit shaft friction values for the various site rock strata are tabulated in Table 12. The ultimate unit pile skin friction of a pile loaded in tension was taken, conservatively, as half the ultimate unit shaft resistance of a pile loaded in compression. The initial ABAQUS runs indicated that the strains in the strata were within the initial small strain region of the non-linear stress strain curves developed for the materials. The secant elastic modulus values at small strain levels were, therefore, adopted for the validation and sensitivity analyses carried out using PIGLET and REPUTE. A nonlinear analysis was carried out in VDISP using the nonlinear stress strain curves developed for the materials.

Linear and non-linear analyses were carried out to obtain predictions for the load distribution in the piles and for the settlement of the raft and podium. The assessed pile capacities were provided to the structural designers and they then supplied details on the layout, number and diameter of the piles. Tower piles were $1.5 \mathrm{~m}$ in diameter and $47.45 \mathrm{~m}$ long with the tower raft founded at $-7.55 \mathrm{mDMD}$. The podium piles were $0.9 \mathrm{~m}$ in diameter and $30 \mathrm{~m}$ long with the podium raft being founded at $-4.85 \mathrm{mDMD}$. The thickness of the raft was $3.7 \mathrm{~m}$. Loading was provided by SOM and comprised eight load cases including four load cases for wind and three for seismic conditions.

The settlements from the FE Analysis (FEA) model and from VDISP were converted from those for a flexible pile cap to those for a rigid pile cap for comparison with the REPUTE and PIGLET models using the following approximate equation:

$\delta_{\text {rigid }}=1 / 2\left(\delta_{\text {centre }}+\delta_{\text {edge }}\right)_{\text {flexible }}$,

The computed settlements are shown in Table 13, and the settlements from the FEA model correlated acceptably well with the results obtained from REPUTE, PIGLET and VDISP.

A sensitivity analysis was carried out using the FE analysis model and applying the maximum design soil strata non-linear stress-strain relationships. The results from the stiffer soil strata response gave a $28 \%$ reduction in Tower settlement for the combined dead load, live load and wind load case analysed, from 85 to $61 \mathrm{~mm}$.

The maximum and minimum pile loadings were obtained from the FE analysis for all loading combinations. The maximum loads were at the corners of the three "wings" and were of the order of $35 \mathrm{MN}$, while the minimum loads were within the centre of the group and were of the order of 12-13 MN. Figure 12 shows contours of the computed maximum axial load. The impact of cyclic loading on the pile was an important consideration and in order to address this, the load variation above or below the 
Fig. 11 Modulus values versus elevation
E Value (MPa)

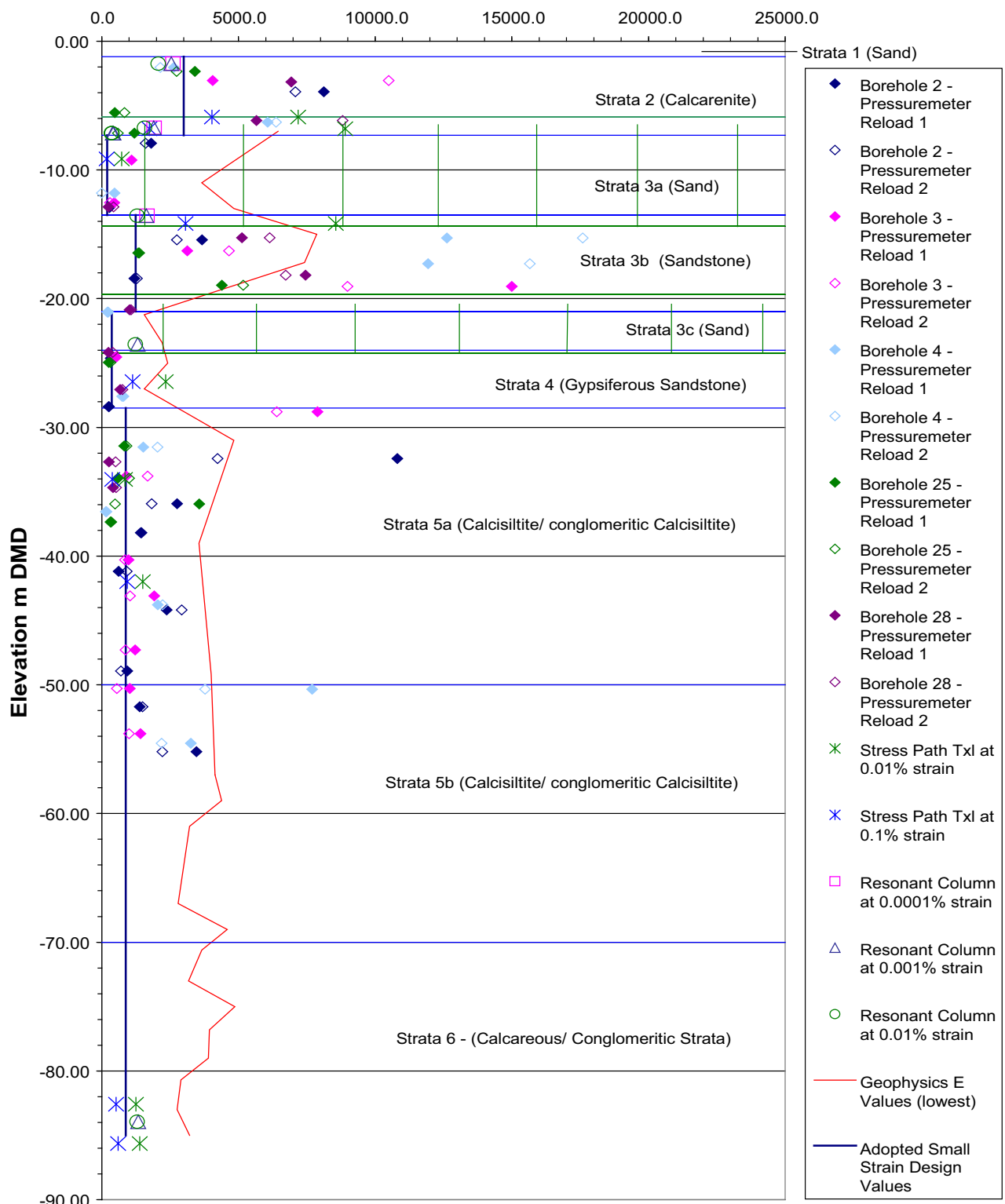

dead load plus live load cases was determined. The maximum load variation was found to be less than $10 \mathrm{MN}$.

SOM carried out an analysis of the pile loads and a comparison on the results indicated that although the maximum pile loads were similar, the distribution was different. The SOM calculations indicated that the largest pile loads were in the central region of the Tower piled raft and decreasing towards the edges. However, the FE analyses indicated the opposite where the largest pile loads were concentrated towards the edges of the pile group reducing towards the centre of the group. Similarly, the PIGLET and REPUTE standard pile group analyses carried out indicated that the largest pile loads were concentrated towards the edge of the pile cap. This may have resulted from the implicit assumption in these analyses that the raft is rigid.

The difference between the pile load distributions could be attributed to a number of reasons:

- The FE, REPUTE and PIGLET models take account of the pile-soil-pile interaction, whereas SOM modelled the soil as springs connected to the raft and piles using an S-Frame analysis.

- The HCL FE analysis modelled the soil/rock using nonlinear responses compared to the linear spring stiffnesses assumed in the SOM analysis.

- The specified/assumed superstructure stiffening effects on the foundation response were modelled more accurately in the SOM analysis. 


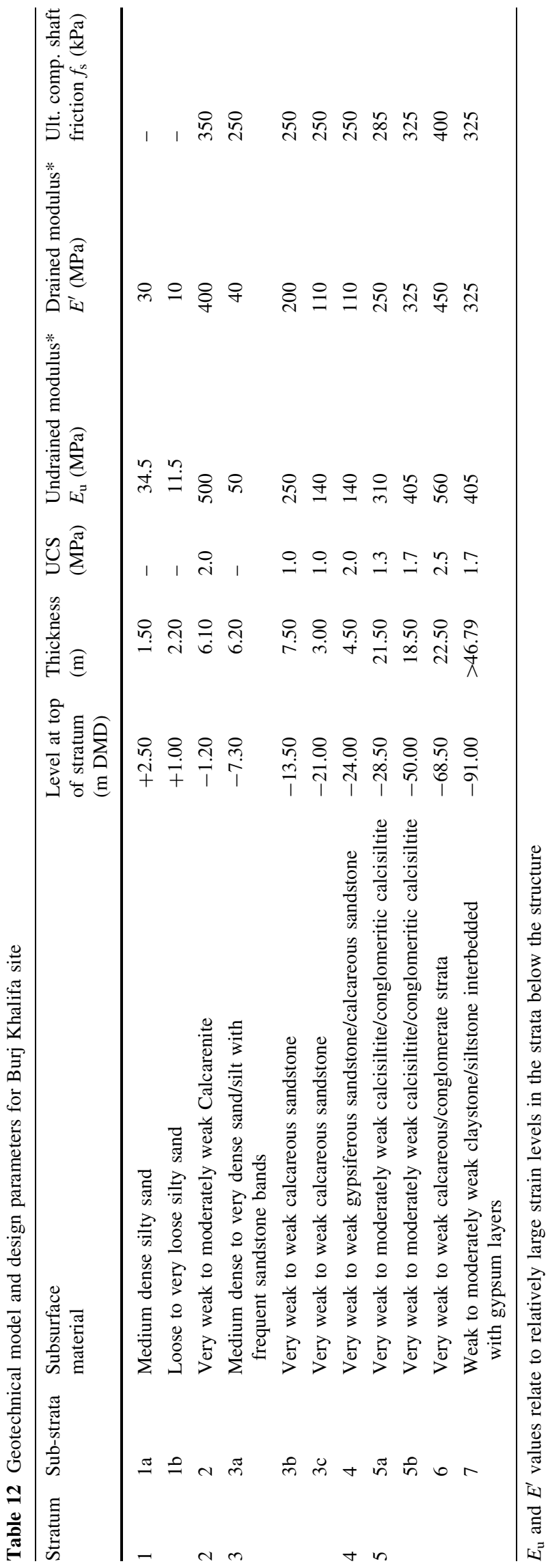

Table 13 Computed settlements

\begin{tabular}{llll}
\hline Analysis method & Loadcase & \multicolumn{2}{l}{ Settlement $(\mathrm{mm})$} \\
\cline { 3 - 4 } & & Rigid & Flexible \\
\hline FEA & Tower only (DL + LL) & 56 & 66 \\
REPUTE & Tower only (DL + LL) & 45 & - \\
PIGLET & Tower only (DL + LL) & 62 & - \\
VDISP & Tower only (DL + LL) & 46 & 72 \\
\hline
\end{tabular}

The actual pile load distribution was expected to be somewhere between the two models, depending on the impact of the different modelling approaches.

\section{Overall stability assessment}

The minimum centre-to-centre spacing of the piles for the tower was 2.5-times that of the pile diameter. A check was, therefore, carried out to ensure that the Tower foundation was stable both vertically and laterally, assuming that the foundation acted as a block comprising the piles and soil/ rock. A factor of safety of slightly less than 2 was assessed for vertical block movement, excluding base resistance of the block while a factor of safety of greater than 2 was determined for lateral block movement excluding passive resistance. A factor of safety of approximately 5 was obtained against overturning of the block.

\section{Liquefaction assessment}

An assessment of the potential for liquefaction during a seismic event at the Burj Dubai site was carried out using the Japanese Road Association Method and the method of Seed et al. [72]. Both approaches gave similar results and indicated that the Marine Deposits and sand to $3.5 \mathrm{~m}$ below ground level (from $+2.5 \mathrm{~m}$ DMD to $-1.0 \mathrm{~m}$ DMD) could potentially liquefy. However, the foundations of the Podium and Tower structures were below this level. Consideration was, however, required in the design and location of buried services and shallow foundations which were within the top $3.5 \mathrm{~m}$ of the ground. Occasional layers within the sandstone layer between $-7.3 \mathrm{~m}$ DMD and $-11.75 \mathrm{~m}$ DMD could potentially liquefy. However, taking into account the imposed confining stresses at the foundation level of the Tower this potential liquefaction was considered to have a negligible effect on the design of the Tower foundations. The assessed reduction factor to be applied to the soil strength parameters, in most cases, was found to be equal to 1.0 and hence liquefaction would have a minimal effect upon the design of the Podium foundations. However, consideration was given in design for potential downdrag loads on pile foundations constructed through the liquefiable strata. 
Fig. 12 Contours of maximum axial load

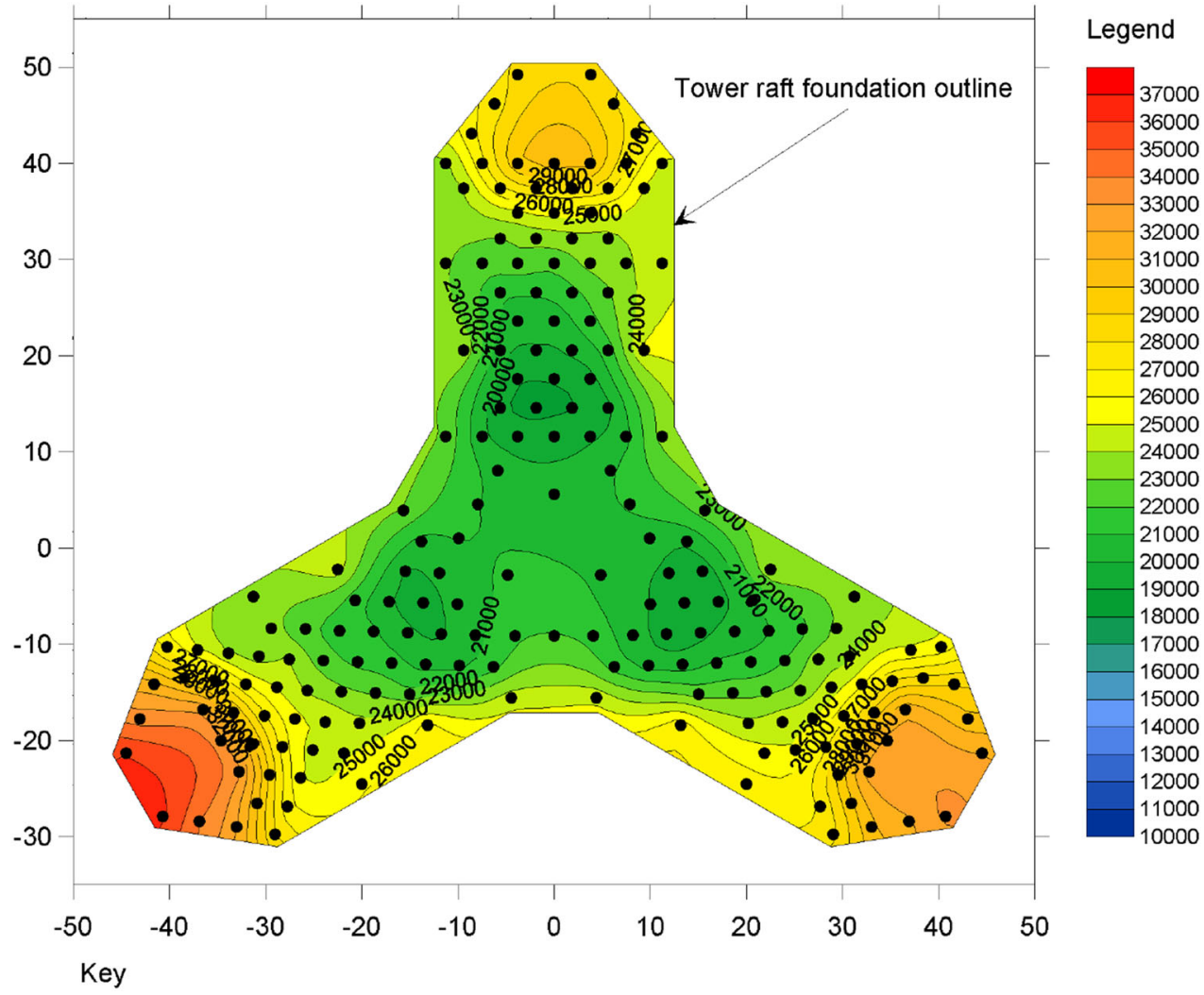

- Pile location

\section{Independent verification analyses}

The geotechnical model used in the verification analyses is summarised in Table 14. The parameters were assessed independently on the basis of the available information and experience gained from the nearby Emirates project [64]. In general, this model was rather more conservative than the original model employed by HCL for the design. In particular, the ultimate end bearing capacity was reduced together with the Young's modulus in several of the upper layers, and the presence was assumed of a stiffer layer, with a modulus of $1200 \mathrm{MPa}$ below RL $-70 \mathrm{~m} \mathrm{DMD}$, to allow for the fact that the strain levels in the ground decrease with increasing depth.

The following three-stage approach was employed for the independent verification process:

- The commercially available computer program FLAC was used to carry out an axisymmetric analysis of the foundation system for the tower. The foundation plan was represented by a circle of equal area, and the piles were represented by a solid block containing piles and soil. The axial stiffness of the block was taken to be the same as that of the piles and the soil between them. The total dead plus live loading was assumed to be uniformly distributed. The soil layers were assumed to be Mohr-Coulomb materials, with the modulus values as shown in Table 14, and values of cohesion taken as 0.5 times the estimated unconfined compressive strength. The main purpose of this analysis was to calibrate and check the second, and more detailed, analysis, using the computer program for pile group analysis, PIGS [59].

- An analysis using PIGS was carried out for the tower alone, to check the settlement with that obtained by FLAC. In this analysis, the piles were modelled individually, and it was assumed that each pile was subjected to its nominal working load of $30 \mathrm{MN}$. The stiffness of each pile was computed via the program DEFPIG [54], allowing for contact between the raft section above the pile and the underlying soil. The pile stiffness values were assumed to vary hyperbolically with increasing load level, using a hyperbolic factor $\left(R_{\mathrm{f}}\right)$ of 0.4 .

- Finally, an analysis of the complete tower-podium foundation system was carried out using the program PIGS, and considering all 926 piles in the system. Each of the piles was subjected to its nominal working load. 
Table 14 Summary of geotechnical model for independent verification analyses

\begin{tabular}{|c|c|c|c|c|c|c|}
\hline $\begin{array}{l}\text { Stratum } \\
\text { number }\end{array}$ & Description & $\begin{array}{l}\mathrm{RL} \text { range } \\
\mathrm{DMD}\end{array}$ & $\begin{array}{l}\text { Undrained } \\
\text { modulus } E_{\mathrm{u}}(\mathrm{MPa})\end{array}$ & $\begin{array}{l}\text { Drained } \\
\text { modulus } E^{\prime}(\mathrm{MPa})\end{array}$ & $\begin{array}{l}\text { Ultimate skin } \\
\text { friction }(\mathrm{kPa})\end{array}$ & $\begin{array}{l}\text { Ultimate end } \\
\text { bearing }(\mathrm{MPa})\end{array}$ \\
\hline $1 \mathrm{a}$ & Med. dense silty sand & +2.5 to +1.0 & 30 & 25 & - & - \\
\hline $1 b$ & Loose-v. loose silty sand & +1.0 to -1.2 & 12.5 & 10 & - & - \\
\hline 2 & $\begin{array}{l}\text { Weak-mod. weak } \\
\text { calcarenite }\end{array}$ & -1.2 to -7.3 & 400 & 325 & 400 & 4.0 \\
\hline 3 & V. weak calc. sandstone & -7.3 to -24 & 190 & 150 & 300 & 3.0 \\
\hline 4 & $\begin{array}{l}\text { V. weak-weak } \\
\text { sandstone/calc. sandstone }\end{array}$ & -24 to -28.5 & 220 & 175 & 360 & 3.6 \\
\hline $5 \mathrm{a}$ & $\begin{array}{l}\text { V. weak-weak-mod. weak } \\
\text { calcisiltite/conglomerate }\end{array}$ & -28.5 to -50 & 250 & 200 & 250 & 2.5 \\
\hline $5 b$ & $\begin{array}{l}\text { V. weak-weak-mod. weak } \\
\text { calcisiltite/conglomerate }\end{array}$ & -50 to -70 & 275 & 225 & 275 & 2.75 \\
\hline 6 & Calcareous siltstone & -70 and below & 500 & 400 & 375 & 3.75 \\
\hline
\end{tabular}

\section{FLAC and PIGS results for the tower alone}

Because of the difference in shape between the actual foundation and the equivalent circular foundation, only the maximum settlement was considered for comparison purposes. The following results were obtained for the central settlement:

- FLAC analysis, using an equivalent block to represent the piles: $72.9 \mathrm{~mm}$.

- PIGS analysis, modelling all 196 piles: $74.3 \mathrm{~mm}$.

Thus, despite the quite different approaches adopted, the computed settlements were in remarkably good agreement. It should be noted that, as found with the Emirates project, the computed settlement is influenced by the assumptions made regarding the ground properties below the pile tips. For example, if in the PIGS analysis the modulus of the ground below RL-70 m DMD was taken as $400 \mathrm{MPa}$ (rather than $1200 \mathrm{MPa}$ ), the computed settlement at the centre of the tower would increase to about $96 \mathrm{~mm}$.

\section{PIGS results for tower and podium}

Figure 13 shows the contours of computed settlement for the entire area. It can be seen that the maximum settlements are concentrated in the central area of the tower.

Figure 14 shows the settlement profile across a section through the centre of the tower. The notable feature of this figure is that the settlements reduce rapidly outside the tower area and become of the order of 10-12 $\mathrm{mm}$ for much of the podium area.

\section{Cyclic loading effects}

The possible effects of cyclic loading were investigated via the following means:
- Cyclic triaxial laboratory tests;

- Cyclic direct shear tests;

- Cyclic constant normal stiffness (CNS) laboratory tests;

- Via an independent theoretical analysis carried out by the independent verifier.

The cyclic triaxial tests indicated that there was some potential for degradation of stiffness and accumulation of excess pore pressure, while the direct shear tests indicated a reduction in residual shear strength, although these were carried out using large strain levels which were not representative of the likely field conditions.

The CNS tests indicated that there is not a significant potential for cyclic degradation of skin friction, provided that the cyclic shear stress remains within the anticipated range.

The independent analysis of cyclic loading effects was undertaken using the approach described by Poulos $[51,52]$ and implemented via the computer program Static and cyclic axial response of piles (SCARP). This analysis involved a number of simplifying assumptions, together with parameters that were not easily measured or estimated from available data. As a consequence, the analysis was indicative only. Since the analysis of the entire foundation system was not feasible with SCARP, only a typical pile (assumed to be a single isolated pile) with a diameter of $1.5 \mathrm{~m}$ and a length of $48 \mathrm{~m}$ was considered. The results were used to explore the relative effects of the cyclic loading, with respect to the case of static loading.

It was found that a loss of capacity would be experienced when the cyclic load exceeded about $\pm 10 \mathrm{MN}$. The maximum loss of capacity (due to degradation of the skin friction) was of the order of 15-20\%. The capacity loss was relatively insensitive to the mean load level, except when the mean load exceeded about $30 \mathrm{MN}$. It was predicted that, at a mean load equal to the working load and 
Fig. 13 Computed settlement contours for tower and podium

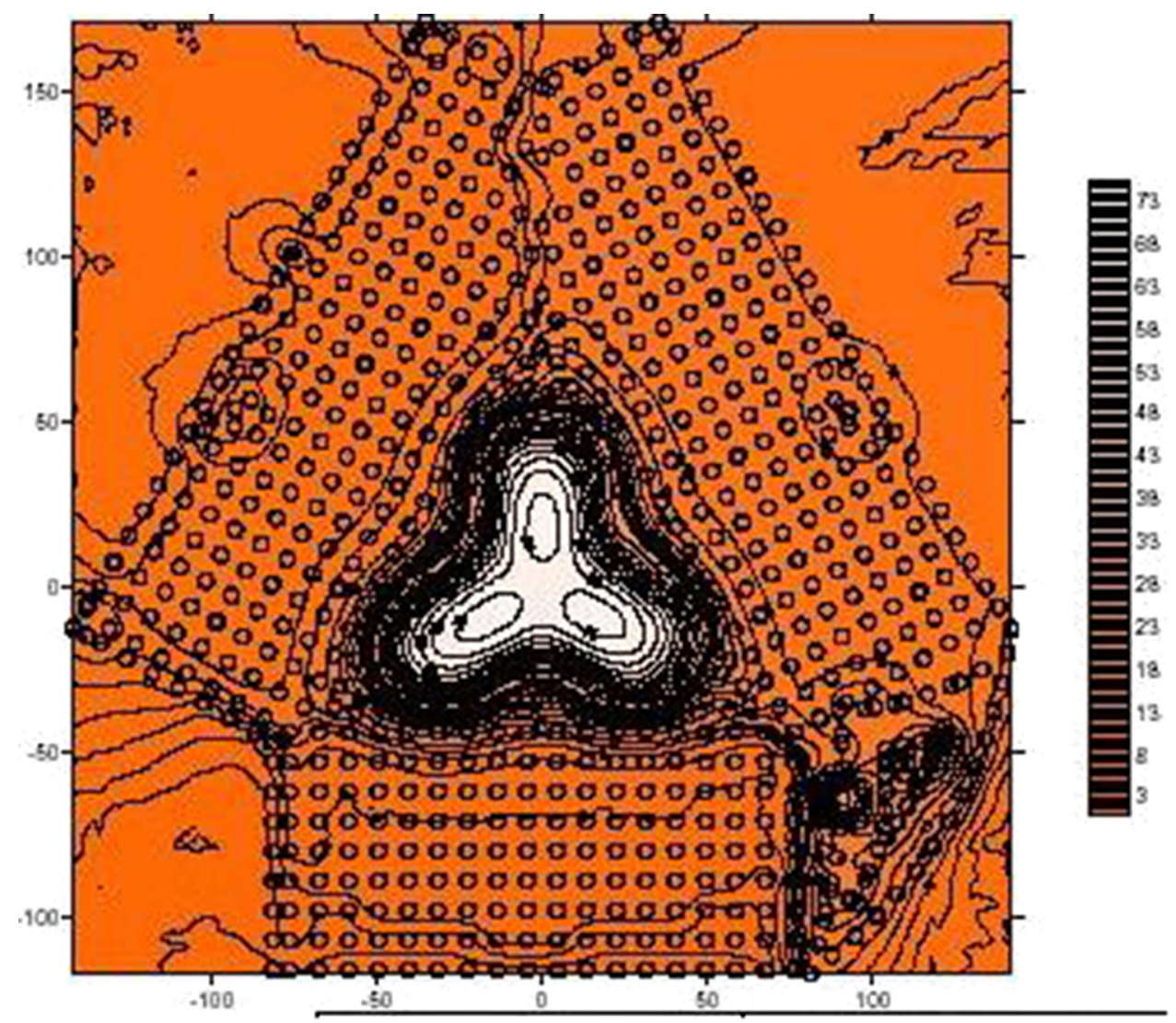

Fig. 14 Computed settlement across section through centre of tower

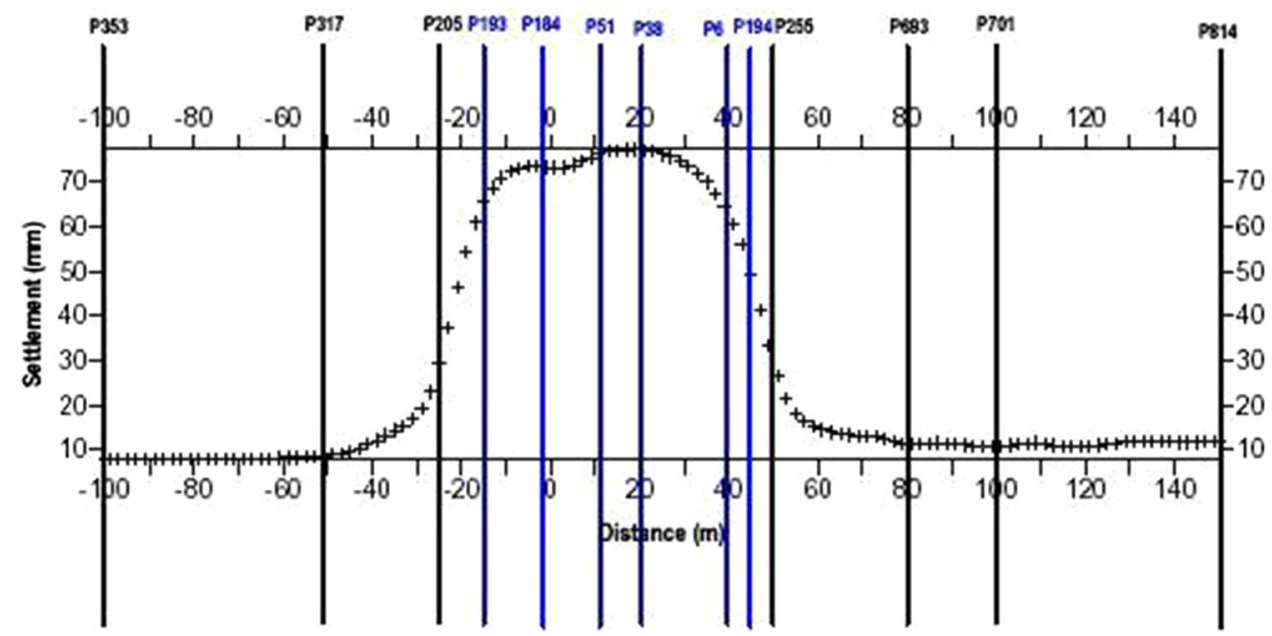

under a cyclic load of about $25 \%$ of the working load, the relative increase in settlement for ten cycles of load would be about $27 \%$.

The indicative pile forces calculated from the ABAQUS finite-element analysis of the structure suggested that cyclic loading of the Burj Tower foundation would not exceed $\pm 10 \mathrm{MN}$. Thus, it seemed reasonable to assume that the effects of cyclic loading would not significantly degrade the axial capacity of the piles and that the effects of cyclic loading on both capacity and settlement were unlikely to be significant.

\section{Pile load testing}

Two programs of static load testing were undertaken for the Burj Khalifa project: 
- Static load tests on seven trial piles prior to foundation construction.

- Static load tests on eight works piles, carried out during the foundation construction phase (i.e., on about $1 \%$ of the total number of piles constructed).

In addition, dynamic pile testing was carried out on 10 of the works piles for the tower and 31 piles for the podium, i.e., on about $5 \%$ of the total works piles. Sonic integrity testing was also carried out on a number of the works piles. Attention here is focused on the static load tests.

\section{Preliminary pile testing program}

The details of the piles tested within this program are summarised in Table 15. The main purpose of the tests was to assess the general load-settlement behaviour of piles of the anticipated length below the tower and to verify the design assumptions. Each of the test piles was different, allowing various factors to be investigated, as follows:

- The effects of increasing the pile shaft length are as follows;

- The effects of shaft grouting,

- the effects of reducing the shaft diameter,

- the effects of uplift (tension) loading,

- the effects of lateral loading and

- the effect of cyclic loading.

The piles were constructed using polymer drilling fluid, rather than the more conventional bentonite drilling fluid. The use of the polymer appears to have led to piles whose performance exceeded expectations. Strain gauges were installed along each of the piles, enabling detailed evaluation of the load transfer along the pile shaft and the assessment of the distribution of mobilised skin friction with depth along the shaft. The reaction system provided for the axial load tests consisted of four or six adjacent reaction piles (depending on the pile tested), and these reaction piles had the potential to influence the results of the pile load tests via interaction with the test pile through the soil. The possible consequences of this are discussed subsequently.

\section{Ultimate axial load capacity}

None of the six axial pile load tests appears to have reached its ultimate axial capacity, at least with respect to geotechnical resistance. The 1.5-m diameter piles (TP1, TP2 and TP3) were loaded to twice the working load, while the 0.9-m diameter test piles TP4 and TP6 were loaded to 3.5 times the working load, and TP5 was loaded to four times working load. With the exception of TP5, none of the other piles showed any strong indication of imminent geotechnical failure. Pile TP5 showed a rapid increase in settlement at the maximum load, but this was attributed to structural failure of the pile itself. From a design viewpoint, the significant finding was that, at the working load, the factor of safety against geotechnical failure appeared to be in excess of 3 , thus giving a comfortable margin of safety against failure, especially as the raft would also provide additional resistance to supplement that of the piles.

\section{Ultimate shaft friction}

From the strain gauge readings along the test piles, the mobilised skin friction distribution along each pile was evaluated. Figure 15 summarises the ranges of skin friction deduced from the measurements, together with the original design assumptions and the modified design recommendations made after the preliminary test results were evaluated. The following comments can be made:

1. The skin friction values down to about RL-30 m DMD appear to be ultimate values, i.e., the available skin friction has been fully mobilised.

2. The skin friction values below about RL-30 m DMD do not appear to have been fully mobilised, and thus were assessed to be below the ultimate values.

3. The original assumptions appear to be comfortably conservative within the upper part of the ground profile.
Table 15 Summary of pile load tests-preliminary pile testing

\begin{tabular}{lllll}
\hline Pile no. & Pile diameter $(\mathrm{m})$ & Pile length $(\mathrm{m})$ & Side grouted? & Test type \\
\hline TP1 & 1.5 & 45.15 & No & Compression \\
TP2 & 1.5 & 55.15 & No & Compression \\
TP3 & 1.5 & 35.15 & Yes & Compression \\
TP4 & 0.9 & 47.10 & No & Compression (cyclic) \\
TP5 & 0.9 & 47.05 & Yes & Compression \\
TP6 & 0.9 & 36.51 & No & Tension \\
TP7A & 0.9 & 37.51 & No & Lateral \\
\hline
\end{tabular}


Fig. 15 Measured and design values of shaft friction

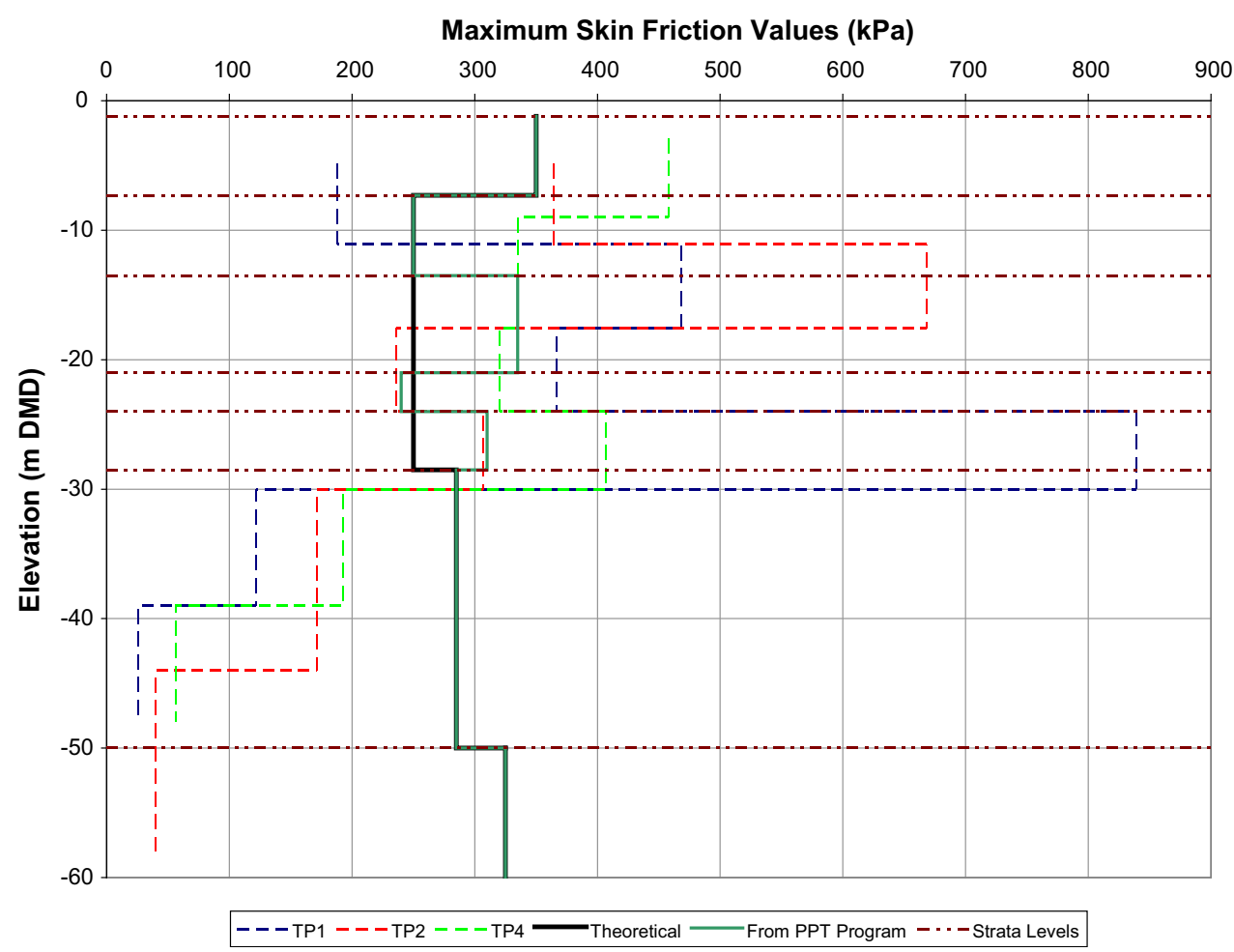

4. Shaft grouting appeared to enhance the skin friction developed along the pile.

Because the skin friction in the lower part of the ground profile did not appear to have been fully mobilised, it was recommended that the original values (termed the "theoretical ultimate unit skin friction") be used in the lower strata. It was also recommended that the "theoretical" values in the top layers (Strata 2 and 3a) be used because of the presence of the casing in the tests would probably have given skin friction values that may have been too low. For Strata $3 b, 3 c$ and 4 , the minimum measured skin friction values were used for the final design.

\section{Ultimate end bearing capacity}

None of the load tests was able to mobilise any significant end bearing resistance, because the skin friction appeared to be more than adequate to resist loads well in excess of the working load. Therefore, no conclusions could be reached about the accuracy of the estimated end bearing component of pile capacity. For the final design, the length of the piles was increased where the proposed pile toe levels were close to or within the gypsiferous sandstone layer (Stratum 4).
This was the case for the 0.9-m diameter podium piles. It was considered prudent to have the pile toes founded below this stratum, to allow for any potential long-term degradation of engineering properties of this layer (e.g., via solution of the gypsum) that could reduce the capacity of the piles [62].

\section{Load-settlement behaviour}

Table 16 summarises the measured pile settlements at the working load and at the maximum test load, and the corresponding values of pile head stiffness (load/settlement). The following observations are made:

- The measured stiffness values were relatively large and were considerably in excess of those anticipated;

- As expected, the stiffness was greater for the larger diameter piles;

- The stiffness of the shaft grouted piles (TP3 and TP5) was greater than that of the corresponding ungrouted piles.

\section{Effect of reaction piles}

On the basis of the experience gained in the nearby Emirates Project [64] site, it had been expected that the pile 
Table 16 Summary of pile load test results—axial loading

\begin{tabular}{|c|c|c|c|c|c|c|}
\hline $\begin{array}{l}\text { Pile } \\
\text { number }\end{array}$ & $\begin{array}{l}\text { Working } \\
\text { load (MN) }\end{array}$ & $\begin{array}{l}\text { Max. load } \\
\text { (MN) }\end{array}$ & $\begin{array}{l}\text { Settlement } \\
\text { at W. load } \\
(\mathrm{mm})\end{array}$ & $\begin{array}{l}\text { Settlement } \\
\text { at max. load } \\
(\mathrm{mm})\end{array}$ & $\begin{array}{l}\text { Stiffness } \\
\text { at W. load } \\
(\mathrm{MN} / \mathrm{m})\end{array}$ & $\begin{array}{l}\text { Stiffness } \\
\text { at max. load } \\
(\mathrm{MN} / \mathrm{m})\end{array}$ \\
\hline TP1 & 30.13 & 60.26 & 7.89 & 21.26 & 3819 & 2834 \\
\hline TP2 & 30.13 & 60.26 & 5.55 & 16.85 & 5429 & 3576 \\
\hline TP3 & 30.13 & 60.26 & 5.78 & 20.24 & 5213 & 2977 \\
\hline TP4 & 10.1 & 35.07 & 4.47 & 26.62 & 2260 & 1317 \\
\hline TP5 & 10.1 & 40.16 & 3.64 & 27.45 & 2775 & 1463 \\
\hline TP6 & -1.0 & -3.5 & -0.65 & -4.88 & 1536 & 717 \\
\hline
\end{tabular}

head stiffness values for the Burj Dubai piles would be somewhat less than those for the Emirates Towers, in view of the apparently inferior quality of rock at the Burj Dubai site.

This expectation was certainly not realised, and it is possible that the improved performance of the piles in the present project may be attributable, at least in part, to the use of polymer drilling fluid, rather than bentonite, in the construction process. However, it was also possible that at least part of the reason for the high stiffness values was related to the interaction effects of the reaction piles. When applying a compressive load to the test pile, the reaction piles experience a tension and a consequent uplift, which tends to reduce the settlement of the test pile. Thus, the apparent high stiffness of the pile may not reflect the true stiffness of the pile beneath the structure. The mechanisms of such interaction are discussed by Poulos [55].

\section{Pile axial stiffness predictions}

"Class A" predictions of the anticipated load-settlement behaviour were made prior to the construction of the preliminary test piles. The designer used the finite-element program ABAQUS, while the independent verifier used the computer program PIES [53]. No allowance was made for the effects of interaction from the reaction piles. There was close agreement between the predicted curves for the $1.5-\mathrm{m}$ diameter piles extending to RL-50 m, but for the 0.9-m diameter piles extending to RL-40 $\mathrm{m}$, the agreement was less close, with the designer predicting a somewhat softer behaviour than the independent verifier.

The measured load-settlement behaviour was considerably stiffer than either of the predictions. This is shown in Fig. 16, which compares the measured stiffness values with the predicted values, at the working load. As mentioned above, the high measured stiffness may be, at least partly, a consequence of the effects of the adjacent reaction piles. An analysis of the effects of these reaction piles on the settlement of pile TP1 revealed that the presence of the reaction piles could reduce the settlement at the working

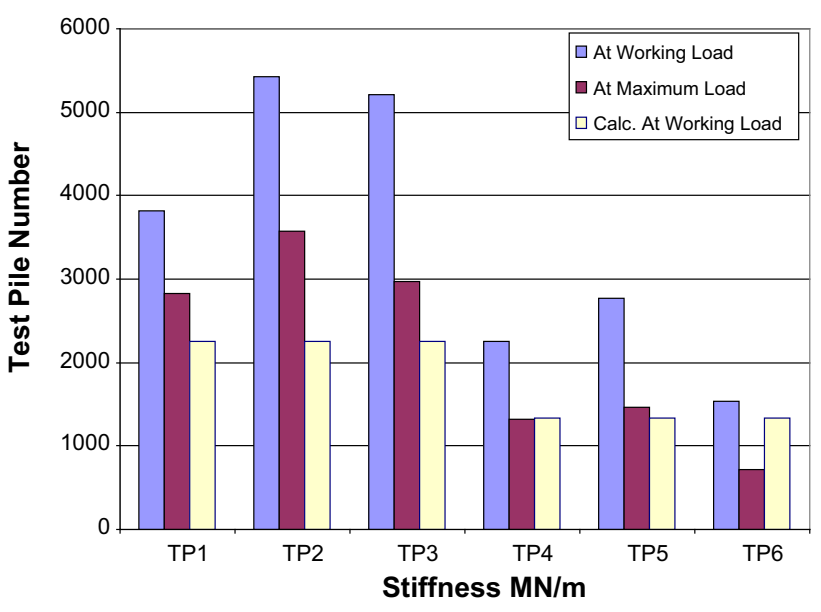

Fig. 16 Measured and predicted pile head stiffness values

load of $30 \mathrm{MN}$ by $30 \%$. In other words, the real stiffness of the piles might be only about $70 \%$ of the values measured from the load test. This would then reduce the stiffness to a value which is more in line with the stiffness values experienced in the Emirates project, where the reaction was provided by a series of inclined anchors that would have had a very small degree of interaction with the test piles.

\section{Uplift versus compression loading}

On the basis of the tension test on pile TP6, the ultimate skin friction in tension was taken as 0.5 times that for compression. It is customary to allow for a reduction in skin friction for piles in granular soils or rocks subjected to uplift. De Nicola and Randolph [17] have developed a theoretical relationship between the tensile and compressive skin friction values and have shown that this relationship depends on the Poisson's ratio of the pile, the relative stiffness of the pile to the soil, the interface friction characteristics and the pile length to diameter ratio. This theoretical relationship was applied to the Burj Khalifa case, and the calculated ratio of tension to compression 
Table 17 Summary of displacement accumulation for cyclic loading

\begin{tabular}{lllll}
\hline Pile number & Mean load $/ P_{\mathrm{w}}$ & Cyclic load $/ P_{\mathrm{w}}$ & No. of cycles $(N)$ & $S_{N} / S_{1}$ \\
\hline TP1 & 1.0 & \pm 0.5 & 6 & 1.12 \\
TP2 & 1.0 & \pm 0.5 & 6 & 1.25 \\
TP3 & 1.0 & \pm 0.5 & 6 & 1.25 \\
TP4 & 1.25 & \pm 0.25 & 9 & 1.25 \\
TP5 & 1.25 & \pm 0.25 & 6 & 1.3 \\
TP6 & 1.0 & \pm 0.5 & 6 & 1.1 \\
\hline
\end{tabular}

$P w$ working load, $S N$ settlement after $N$ cycles, $S 1$ settlement after one cycle skin friction was about 0.6 , which was reasonably consistent with the initial assumption of 0.5 made in the design.

\section{Cyclic loading effects}

In all of the axial load tests, a relatively small number of cycles of loading was applied to the pile after the working load was reached. Table 17 summarises the test results inferred from the load-settlement data. The settlement after cycling was related to the settlement for the first cycle, both settlements being at the maximum load of the cycling process. It can be seen that there was an accumulation of settlements under the action of the cyclic loading, but that this accumulation was relatively modest, given the relatively high levels of mean and cyclic stress that were applied to the pile (in all cases, the maximum load reached is 1.5 times the working load).

These results were consistent with the assessments made during design that cyclic loading effects would be unlikely to be significant for this building.

\section{Lateral loading}

One lateral load test was carried out, on pile TP7A, with the pile being loaded to twice the working load $(50 t)$. At the working lateral load of $25 t$, the lateral deflection was about $0.47 \mathrm{~mm}$, giving a lateral stiffness of about $530 \mathrm{MN} /$ $\mathrm{m}$, a value which was consistent with the designer's predictions using the program ALP [47]. An analysis of lateral deflection was also carried out by the independent verifier using the program DEFPIG. In this latter analysis, the Young's modulus values for lateral loading were assumed to be $30 \%$ less than the values for axial loading, while the ultimate lateral pile-soil pressure was assumed to be similar to the end bearing capacity of the pile, with allowances being made for near-surface effects. These calculations indicated a lateral movement of about $0.7 \mathrm{~mm}$ at $25 \mathrm{t}$ load, which was larger than the measured deflection, but of a similar order.

Thus, pile TP7A appeared to perform better than anticipated under the action of lateral loading, mirroring the better-than-expected performance of the test piles under axial load. However, there may again have been some effect of the reaction system used for the test, as the reaction block developed a surface shear which would tend to oppose the lateral deflection of the test pile.

\section{Works pile testing program}

A total of eight works pile tests were carried, including two $1.5 \mathrm{~m}$ diameter piles and six $0.9 \mathrm{~m}$ diameter piles. All pile tests were carried out in compression, and each pile was tested approximately 4 weeks after construction. The piles were tested to a maximum load of 1.5 times the working load.

The following observations were made from the test results:

- The pile head stiffness of the works piles was generally larger than for the trial piles.

- None of the work piles reached failure, and indeed, the load-settlement behaviour up to 1.5 times the working load was essentially linear, as evident from the relatively small difference in stiffness between the stiffness values at the working load and 1.5 times the working load. In contrast, the relative difference between the two stiffnesses was considerably greater for the preliminary trial piles.

At least three possible explanations could be offered for the greater stiffness and improved load-settlement performance of the trial piles:

1. The level of the bottom of the casing was higher for the works piles than for the trial piles (about 3.5-3.6 m higher), thus leading to a higher skin friction along the upper portion of the shaft;

2. A longer period between the end of construction and testing of the works piles (about 4 vs about 3 weeks for the trial piles);

3. Natural variability of the strata.

Cyclic loading was undertaken on two of the works piles, and it was observed that there was a relatively small amount of settlement accumulation due to the cyclic loading, and certainly less than that observed on TP1 or the 
other trial piles (see Table 16). The smaller amount of settlement accumulation could be attributed to the lower levels of mean and cyclic loading applied to the works piles (which were considered to be more representative of the design condition) and also to the greater capacity that the works piles seem to possess. Thus, the results of these tests reinforced the previous indications that the cyclic degradation of capacity and stiffness at the pile-soil interface appeared to be negligible.

\section{Summary of pile testing outcomes}

Both the preliminary test piling program and the tests on the works piles provided very positive and encouraging information on the capacity and stiffness of the piles. The measured pile head stiffness values were well in excess of those predicted. The interaction effects between the test piles and the reaction piles may have contributed to the higher apparent pile head stiffnesses, but the piles nevertheless exceeded expectations. The capacity of the piles also appeared to be in excess of the predicted values, although none of the tests fully mobilised the available geotechnical resistance. The works piles performed even better than the preliminary trial piles and demonstrated almost linear load-settlement behaviour up to the maximum test load of 1.5 times working load.

Shaft grouting appeared to have enhanced the load-settlement response of the piles, but it was assessed that shaft grouting would not need to be carried out for this project, given the very good performance of the ungrouted piles.

The inferences from the pile load test data were that the design estimates of capacity and settlement may be conservative, although it was recognised that the overall settlement behaviour (and perhaps the overall load capacity) would be dependent not only on the individual pile characteristics, but also on the characteristics of the ground within the zone of influence of the structure.

\section{Settlement performance during construction}

The settlement of the Tower raft was monitored after completion of concreting. The stress conditions within the raft were determined with the placement of strain rosettes at the top and base of the raft. In addition, three pressure cells were placed at the base of the raft and five piles have been strain gauged to determine the load distribution between and down the pile. This paper presents only the measured settlements.

A summary of the settlements to February 2008 in Wing $\mathrm{C}$ is shown on Fig. 17 which also shows the final predicted settlement profile from the design. At that time, the majority of the dead loading would have been applied to the foundation, and the maximum settlement measured was about $43 \mathrm{~mm}$. It will be seen that the measured settlements are less than those predicted during the design process. However, there remains some dead and live load to be
Fig. 17 Measured and predicted settlements for Wing C, Burj Khalifa

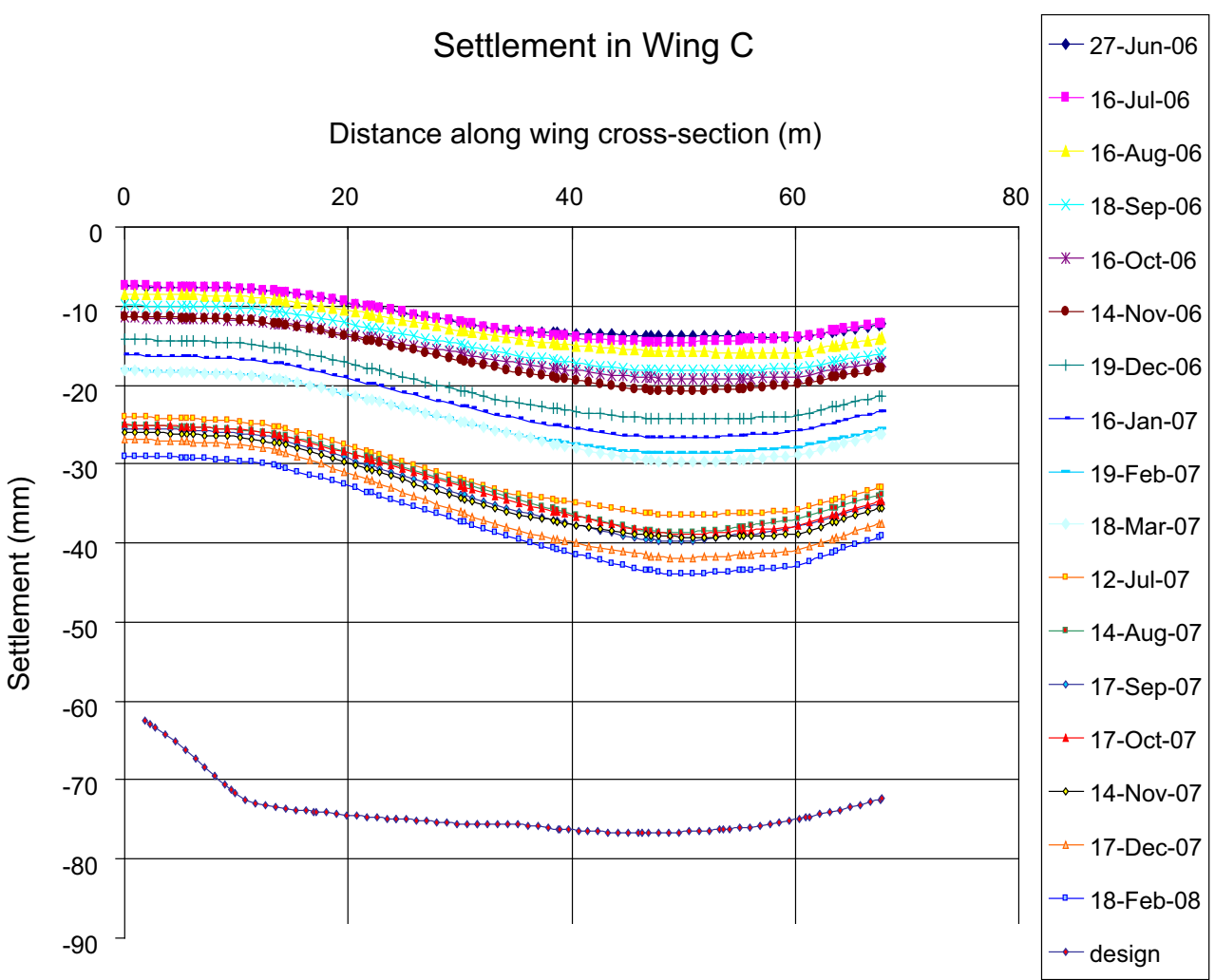


applied to the foundation system, and it should also be noted that the monitored figures do not include the impact of the raft, cladding and live loading which would be in excess of $20 \%$ of the overall mass. Extrapolating for the full dead plus live load, it was anticipated that the final settlement would be of the order of 55-60 mm, which was comfortably less than the predicted final settlement of about 70-75 $\mathrm{mm}$.

Russo et al. [71] have carried out a careful re-assessment of the settlement analyses, taking into account such factors as the structure stiffness, the interpretation of the preliminary pile tests and the effects of the reaction piles in the load tests. They found that the total predicted maximum settlement could then be reduced to about $52 \mathrm{~mm}$.

Figure 18 shows contours of measured settlement. The general distribution is similar to that predicted by the various analyses.

To put the foundation settlements into perspective, the computed shortening of the structure after 30 years was estimated to be about $300 \mathrm{~mm}$ [3], which is substantially greater than the foundation settlements.

\section{Summary}

For the Burj Khalifa, the maximum settlement predicted by ABAQUS for the tower and podium foundation compared reasonably well with the maximum settlement estimated by the revised PIGS analysis carried out during the independent verification process.

It was assessed that there was a potential for a reduction in axial load capacity and stiffness of the foundation strata under cyclic loading, but based on the pile load test data, laboratory tests and on theoretical analyses, it would appear that the cyclic degradation effects at the pile-soil interface were relatively small.

Both the preliminary test piling program and the tests on the works piles provided very positive and encouraging information on the capacity and stiffness of the piles.

The measured pile head stiffness values were well in excess of those predicted, and those expected on the basis of the experience with the nearby Emirates Towers. However, the interaction effects between the test piles and the reaction piles may have contributed to the higher apparent pile head stiffnesses. The capacity of the piles also appeared to be in excess of that predicted, and none of the tests appeared to have fully mobilised the available geotechnical resistance.

The works piles performed even better than the preliminary trial piles and demonstrated almost linear loadsettlement behaviour up to the maximum test load of 1.5 times working load.
Fig. 18 Contours of measured settlement as at February 2008

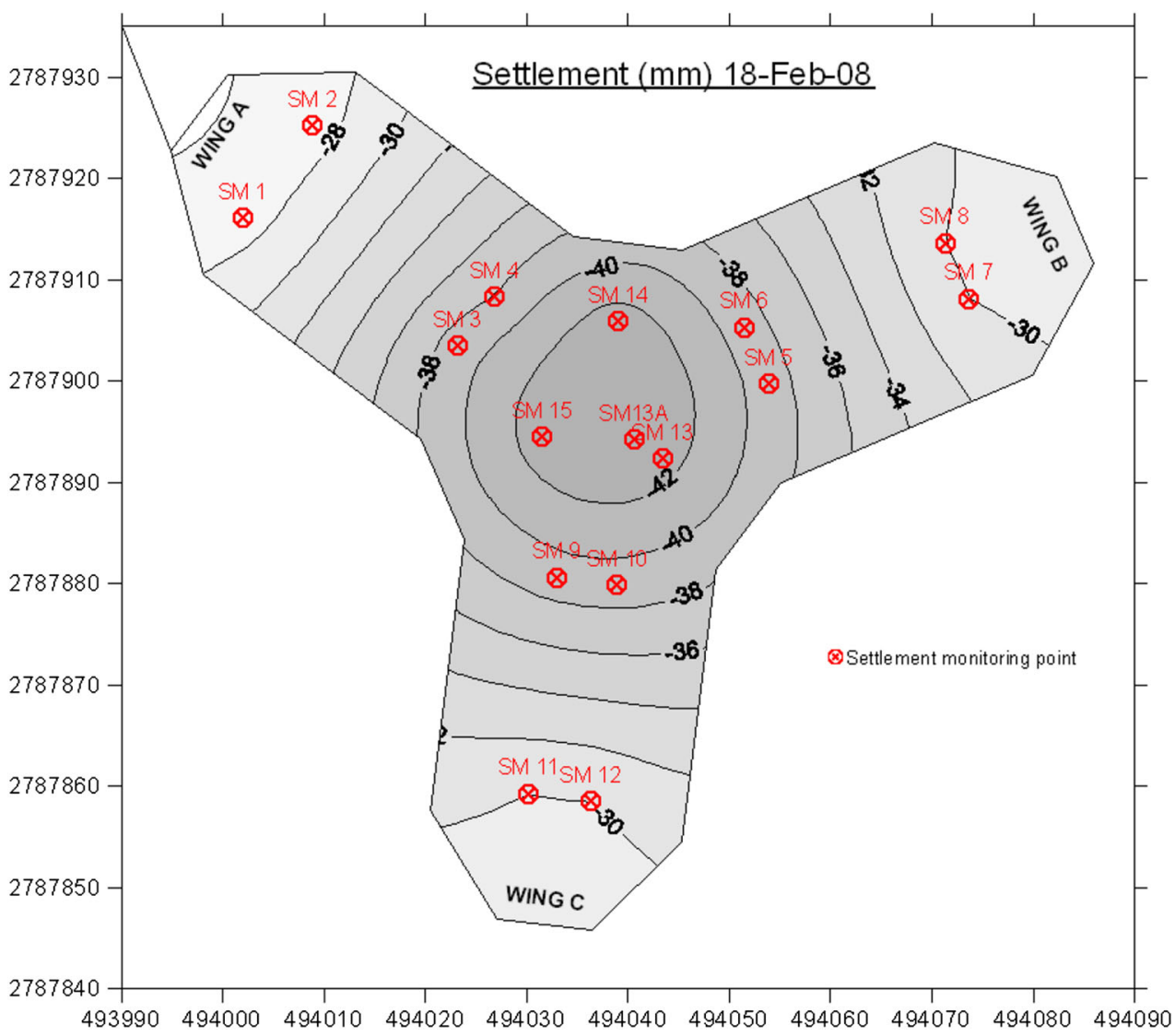


The settlements measured during construction were consistent with, but comfortably smaller than, those predicted. Overall, the performance of the piled raft foundation system exceeded expectations.

As with previous high-rise projects, the Burj Khalifa involved close interaction between the structural and geotechnical designers in designing piled raft foundations for the complex and significant high-rise structures. Such interaction has some major benefits in avoiding over-simplification of geotechnical matters by the structural engineer and over-simplification of structural matters by the geotechnical engineer. Such interaction, therefore, promotes the development of effective and economical foundation and structural designs.

\section{Case 3-Incheon 151 tower, South Korea}

\section{Introduction}

A 151 storey super highrise building project is currently under design, located in reclaimed land constructed on soft marine clay in Songdo, Korea. The foundation system considered comprises 172 No. $2.5 \mathrm{~m}$ diameter bored piles, socketed into the soft rock layer and connected to a $5.5-\mathrm{m}$ thick raft. This building is illustrated in Fig. 19 and is described in detail by Badelow et al. [2] and Abdelrazaq et al. [1]; thus, only a brief summary is presented here.

The challenges in this case relate to a very tall building, sensitive to differential settlements, to be constructed on a site with very complex geological conditions.

\section{Ground conditions and geotechnical model}

The Incheon area has extensive sand/mud flats and nearshore intertidal areas. The site lies entirely within an area of reclamation, comprises approximately $8 \mathrm{~m}$ of loose sand and sandy silt, constructed over approximately $20 \mathrm{~m}$ of soft to firm marine silty clay, referred to as the Upper Marine Deposits (UMD). These deposits are underlain by approximately $2 \mathrm{~m}$ of medium dense to dense silty sand, referred to as the lower marine deposits (LMD), which overlie residual soil and a profile of weathered rock.

The lithological rock units present under the site are referred to as "soft rock" and comprise granite, granodiorite, gneiss (interpreted as possible roof pendant metamorphic rocks) and aplite. The rock materials within about $50 \mathrm{~m}$ from the surface have been affected by weathering which has reduced their strength to a very weak rock or a soil-like material. This depth increases where the bedrock is intersected by closely spaced joints, and sheared and crushed zones that are often related to the existence of the roof pendant sedimentary/metamorphic rocks. The

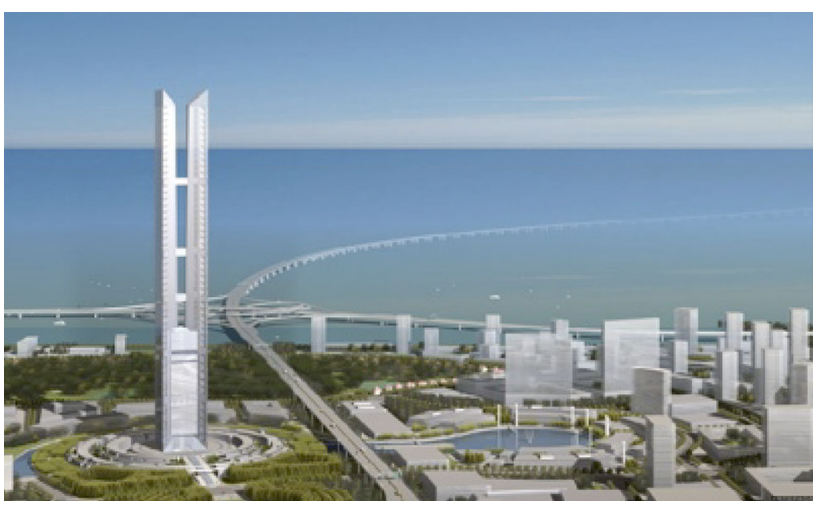

Fig. 19 Incheon 151 Tower (artist's impression)

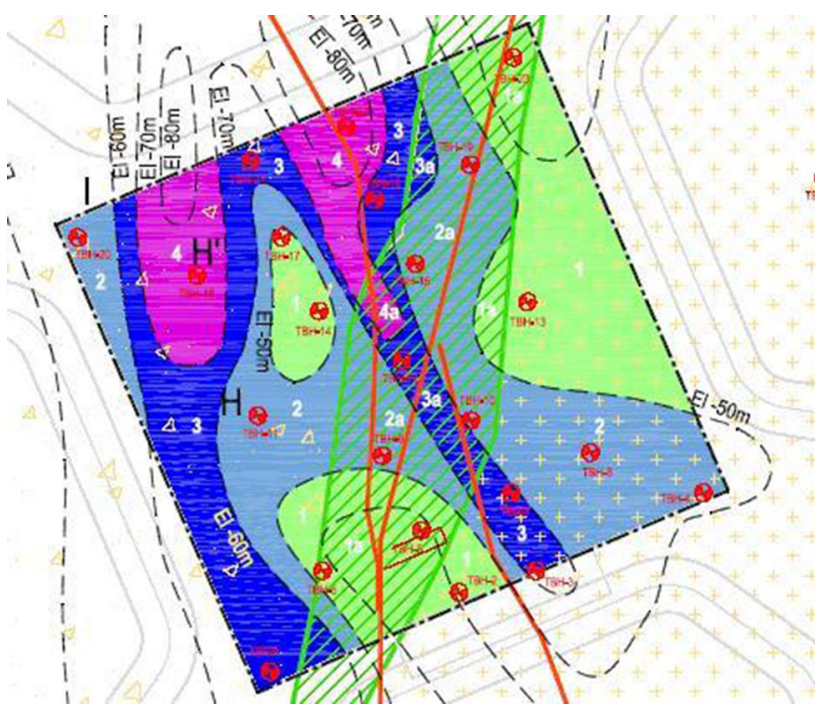

Fig. 20 Inferred contours of top of soft rock-Incheon Tower

geological structures at the site are complex and comprise geological boundaries, sheared and crushed seams-possibly related to faulting movements, and jointing.

From the available borehole data for the site, inferred contours were developed for the surface of the "soft rock" founding stratum within the tower foundation footprint. These are reproduced in Fig. 20. It can be seen that there is a potential variation in level of the top of the soft rock (the pile founding stratum) of up to $40 \mathrm{~m}$ across the foundation.

The footprint of the tower was divided into eight zones which were considered to be representative of the variation of ground conditions and geotechnical models were developed for each zone. Appropriate geotechnical parameters were selected for the various strata based on the available field and laboratory test data, together with experience of similar soils on adjacent sites. One of the critical design issues for the tower foundation was the performance of the soft UMD under lateral and vertical loading, and hence careful consideration was given to the selection of parameters for this stratum. Typical 
Table 18 Summary of geotechnical parameters

\begin{tabular}{lllll}
\hline Strata & $E_{\mathrm{v}}(\mathrm{MPa})$ & $E_{\mathrm{h}}(\mathrm{MPa})$ & $f_{\mathrm{s}}(\mathrm{kPa})$ & $f_{\mathrm{b}}(\mathrm{MPa})$ \\
\hline UMD & $7-15$ & $5-11$ & $29-48$ & - \\
LMD & 30 & 21 & 50 & - \\
Weathered soil & 60 & 42 & 75 & - \\
Weathered rock & 200 & 140 & 500 & - \\
Soft rock (above EL-50 m) & 300 & 210 & 750 & 12 \\
Soft rock (below EL-50 m) & 1700 & 1190 & 750 & 12 \\
\hline
\end{tabular}

$E_{\mathrm{v}}$ vertical modulus, $f_{\mathrm{s}}$ ultimate shaft friction, $E_{\mathrm{h}}$ horizontal modulus, $f_{\mathrm{b}}$ ultimate end bearing

parameters adopted for the initial foundation design are presented in Table 18.

\section{Foundation layout}

The foundation comprises a mat and piles supporting columns and core walls. The numbers and layout of piles and the pile size were obtained from a series of trial analyses through collaboration between the geotechnical engineer and the structural designer. The pile depth was determined by the geotechnical engineer, considering the performance and capacity of piles. The pile layout was selected from the various options considered and is presented in Fig. 21.

\section{Loadings}

Typical loads acting on the tower were as follows:

Vertical dead plus live load: $\operatorname{Pz}(\mathrm{DL}+\mathrm{LL})=$ $6622 \mathrm{MN}$.

Horizontal wind loads: $\mathrm{Px}(\mathrm{WL})=149 \mathrm{MN} \mathrm{Py}(\mathrm{WL})=$ $115 \mathrm{MN}$.

Horizontal earthquake loads: $\operatorname{Px}(E)=105 \mathrm{MN} \operatorname{Py}(\mathrm{E})$ $105 \mathrm{MN}$

Wind load moments: $\mathrm{Mx}(\mathrm{WL})=12578 \mathrm{MN}-\mathrm{m}$ $\mathrm{My}(\mathrm{WL})=21173 \mathrm{MN}-\mathrm{m}$.

Wind load torsional load: $\mathrm{Mz}(\mathrm{WL})=1957 \mathrm{MN}-\mathrm{m}$.

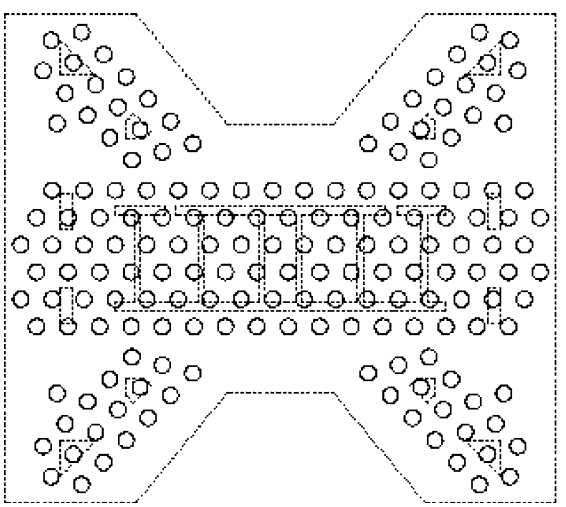

Fig. 21 Pile layout plan
The vertical loads (DL + LL) and overturning moments (Mx, My) were represented as vertical load components at column and core locations. The load combinations, as provided by the structural designer, were adopted throughout the geotechnical analysis, and 24 wind load combinations were considered.

\section{Assessment of pile capacities}

The geotechnical capacities of piles were estimated from the shaft friction and end bearing capacities of pile, and the required pile length was generally assessed based on these geotechnical capacities to provide the required load capacity. For a large pile group founding in weak rock, the overall settlement behaviour of the pile group could control the required pile lengths rather than the overall geotechnical capacity. In this case, the soft rock layer was considered to be a more appropriate founding stratum than the overlying weathered rock, in particular the soft rock below EL-50 m. This is because this stratum provides a more uniform stiffness and, therefore, is likely to result in a more consistent settlement behaviour of the foundation. The basic guide lines to establish the pile founding depth were as follows:

- $\quad$ Minimum socket length in soft rock $=2$ diameters;

- Minimum toe level = EL-50 m.

The pile depths required to control settlement of the tower foundation were greater than those required to provide the geotechnical capacity required. The pile design parameters for the weathered/soft rock layer are shown in Table 19 and were estimated on the basis of the pile test results in the adjacent site and the ground investigation data such as pressuremeter tests and rock core strength tests.

\section{Assessment of vertical pile behaviour}

The vertical pile head stiffness values for each of the 172 foundation piles under serviceability loading conditions (DL + LL) were assessed using the computer programs CLAP and GARP. CLAP was used to assess the geotechnical capacities, interaction factors and stiffness values for 
Table 19 Ultimate capacities for pile analysis

\begin{tabular}{lll}
\hline Material & $\begin{array}{l}\text { Ultimate } \\
\text { friction } f_{\mathrm{s}}(\mathrm{kPa})\end{array}$ & $\begin{array}{l}\text { Ultimate end } \\
\text { bearing } f_{\mathrm{b}}(\mathrm{MPa})\end{array}$ \\
\hline Weathered rock & 500 & 5 \\
Soft rock & 750 & 12 \\
\hline
\end{tabular}

each pile type under serviceability loading for input into the group assessment. CLAP computed the distributions of axial and lateral deflections, rotations and axial and lateral loads and moments, at the top of a group of piles, subjected to a combination of vertical loads, lateral loads, moments and torsion. GARP was used to assess the group foundation behaviour of the Tower.

Individual pile vertical stiffness values were computed, and it was found that the outer piles were stiffer. The analysis was non-linear, and, therefore, the higher stiffness values for the outer piles degraded more rapidly under loading than the central piles. The concentration of loads on outer piles within a group is a real phenomenon that has been measured in the field. Therefore, it was considered that foundation behaviour can be simulated more realistically using the individual pile stiffness values, rather than an average value for all piles within the group. Lower and upper bound estimates of pile stiffness values were provided to the structural engineers to include in their analysis to capture the upper and lower bound behaviour of the raft foundation and the potential impact on the tower superstructure.

\section{Predicted settlements}

The overall settlement of the foundation system was estimated during all three stages of design, using the available data at that stage, and relevant calculation techniques. Table 20 summarises the predicted maximum settlements and indicates that the very simple equivalent pier estimate during the first stage was of a similar order to that predicted from more refined estimates carried out during the later stages of design.

\section{Assessment of lateral pile behaviour}

One of the critical design issues for the tower foundation was the performance of the pile group under lateral loading. Therefore, several numerical analysis programs were used to validate the predictions of lateral behaviour obtained. The numerical modelling packages used in the analyses were as follows:

- 3D finite-element computer program PLAXIS 3D Foundation;

- Computer program DEFPIG developed by Sydney University in conjunction with Coffey;

- Coffey's in-house computer program CLAP.

- 3D finite Element Structural Analysis Programs (Midas Set, Etabs, Safe) that included the effect of soil structure interaction.

PLAXIS 3D provided an assessment of the overall lateral stiffness of the foundation. The programs DEFPIG and CLAP were used to assess the lateral stiffness provided by the pile group assuming that the raft is not in contact with the underlying soil and a separate calculation was carried out to assess the lateral stiffness of the raft and basement. Table 21 presents the computed lateral stiffness for the piled mat foundation obtained from the analyses.
Table 20 Summary of predicted settlements

Table 21 Summary of lateral stiffness of pile group and raft

\begin{tabular}{llll}
\hline Design stage & Method & $\begin{array}{l}\text { Predicted settlement } \\
(\mathrm{mm})\end{array}$ & Remarks \\
\hline 1 & Equivalent pier & 75 & Average settlement \\
$\begin{array}{l}\text { (Preliminary) } \\
2 \text { (Detailed) }\end{array}$ & Program GARP & 67 & $\begin{array}{l}\text { Maximum, taking account of all eight ground } \\
\text { profiles }\end{array}$ \\
3 (Final) & $\begin{array}{c}\text { Program } \\
\text { PLAXIS3D }\end{array}$ & 56 & $\begin{array}{l}\text { Maximum, adopting a single representative } \\
\text { ground profile }\end{array}$ \\
\hline
\end{tabular}

\begin{tabular}{lllll}
\hline $\begin{array}{l}\text { Horizontal load } \\
(\mathrm{MN})\end{array}$ & $\begin{array}{l}\text { Pile group disp. } \\
(\mathrm{mm})\end{array}$ & $\begin{array}{l}\text { Lateral pile stiffness } \\
(\mathrm{MN} / \mathrm{m})\end{array}$ & $\begin{array}{l}\text { Lateral raft stiffness } \\
(\mathrm{MN} / \mathrm{m})\end{array}$ & $\begin{array}{l}\text { Total lateral stiffness } \\
(\mathrm{MN} / \mathrm{m})\end{array}$ \\
\hline $\begin{array}{l}149 \\
(x \text { direction })\end{array}$ & 17 & 8760 & 198 & 8958 \\
$\begin{array}{l}115 \\
(y \text { direction })\end{array}$ & 14 & 8210 & 225 & 8435 \\
\hline
\end{tabular}


Table 22 Rotational spring constants including horizontal loads applied at the pile heads

\begin{tabular}{lll}
\hline Pile & $\begin{array}{l}\text { Pile head angular } \\
\text { rotation }(\mathrm{rad})\end{array}$ & $\begin{array}{l}\text { Pile head rotational } \\
\text { spring stiffness (MN m/rad) }\end{array}$ \\
\hline 3 & & \\
Maximum & 0.094 & 2680 \\
Minimum & 0.036 & 1380 \\
27 & & 1750 \\
Maximum & 0.144 & 903 \\
Minimum & 0.056 & \\
70 & & 2000 \\
Maximum & 0.126 & 1030 \\
Minimum & 0.049 & 1350 \\
78 & & 700 \\
Maximum & 0.187 & \\
Minimum & 0.073 & \\
\hline
\end{tabular}

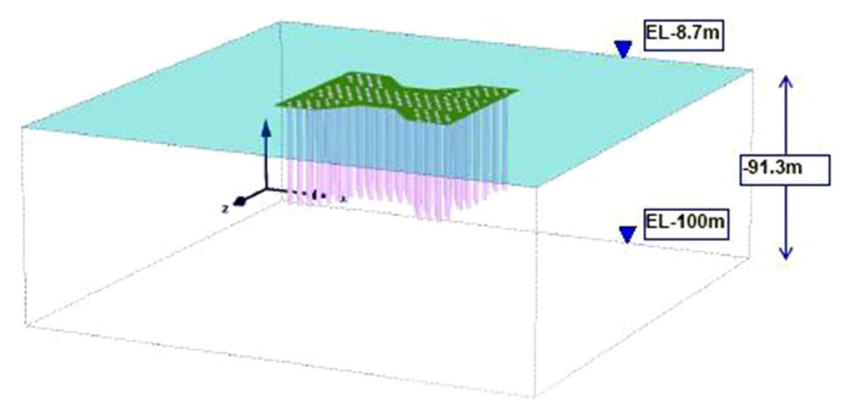

Fig. 22 Schematic of PLAXIS 3D model

\section{Assessment of pile group rotational stiffness}

An assessment of the rotational spring stiffness values at selected pile locations within the foundation was undertaken using Coffey's in-house computer program CLAP. To assess the rotational spring constant at each pile location, the average dead load, horizontal load ( $x$ and $y$ direction) and moment (about the $x, y$ and $z$ axes) were applied to each pile head. The passive resistance of the soil surrounding the raft, and the friction between the soil and the raft, were not included in the analysis as it was assessed that the base friction of the raft footing and the passive resistance of the soil on the raft would be relatively small when compared to lateral resistance of the piles. Table 22 presents a summary of the assessed rotational spring stiffness values obtained from the analysis for four piles considered to represent the range of values for different piles within the pile foundation.

The overall torsional stiffness of the piled mat was assessed using the computer program PLAXIS 3D Foundation. A schematic of the PLAXIS model analysed is given in Fig. 22. The overall torsional stiffness of the piled
Table 23 Summary of cyclic loading assessment

\begin{tabular}{lc}
\hline Quantity & Value \\
\hline Maximum half amplitude cyclic axial wind load $S_{c}^{*}(\mathrm{MN})$ & 29.2 \\
Maximum ratio $\eta=S_{c}^{*} / R_{\mathrm{gs}}^{*}$ & 0.43 \\
Cyclic loading criterion satisfied? & Yes \\
\hline
\end{tabular}

mat estimated using PLAXIS was 10,750,000 MNm/radian, which is approximately equivalent to $16 \mathrm{~mm}$ displacement at the edge of the raft for the applied torsional moment of $1956 \mathrm{MN}-\mathrm{m}$ applied at the centre of the raft.

\section{Cyclic loading due to wind action}

Wind loading for the tower structure was quite severe; therefore, to assess the effect of low-frequency cyclic wind loading, an assessment based on the method suggested in Eq. 3 of "Cyclic loading considerations". The factor $\eta$ was selected to be 0.5 , based on experience with similar projects. To assess the half amplitude of cyclic axial wind induced load, the difference in pile load between the following load cases was computed:

- CASE A: 0.75(DL + LL).

- CASE B: 0.75(DL + LL + $\left.\mathrm{WL}_{x}+\mathrm{WL}_{y}\right)$,

where $\mathrm{DL}=$ dead load; $\mathrm{LL}=$ live load, $\mathrm{WL}_{x}=$ vertical load resulting from $x$-component of wind and $\mathrm{WL}_{y}=$ vertical load resulting from $y$-component of wind.

The difference in axial load between the two load cases was the half-amplitude of the cyclic load $\left(S_{c}^{*}\right)$. Table 23 summarises the results of the cyclic loading assessment and Fig. 23 shows the assessed factor for each pile within the foundation system. The assessment indicates that degradation of shaft capacity due to cyclic loading is unlikely to occur.

\section{Pile load tests}

A total of five pile load tests were undertaken: four on vertically loaded piles via the Osterberg cell (O-cell) procedure and one on a laterally loaded pile jacked against one of the vertically loaded test piles. For the vertical pile test, two levels of O-cells were installed in each pile: one at the pile tip and another at between the weathered rock layer and the soft rock layer. The cell movement and pile head movement were measured by LVWDTs in each of four locations, and the pile strains were recorded by the strain gauges attached to the vertical steel bars. The monitoring system is shown schematically in Fig. 24.

The double cell test system was planned to obtain more accurate and detailed data for the main bearing layer, and so the typical test was performed in two stages as shown in 
Fig. 23 Results of cyclic loading analysis
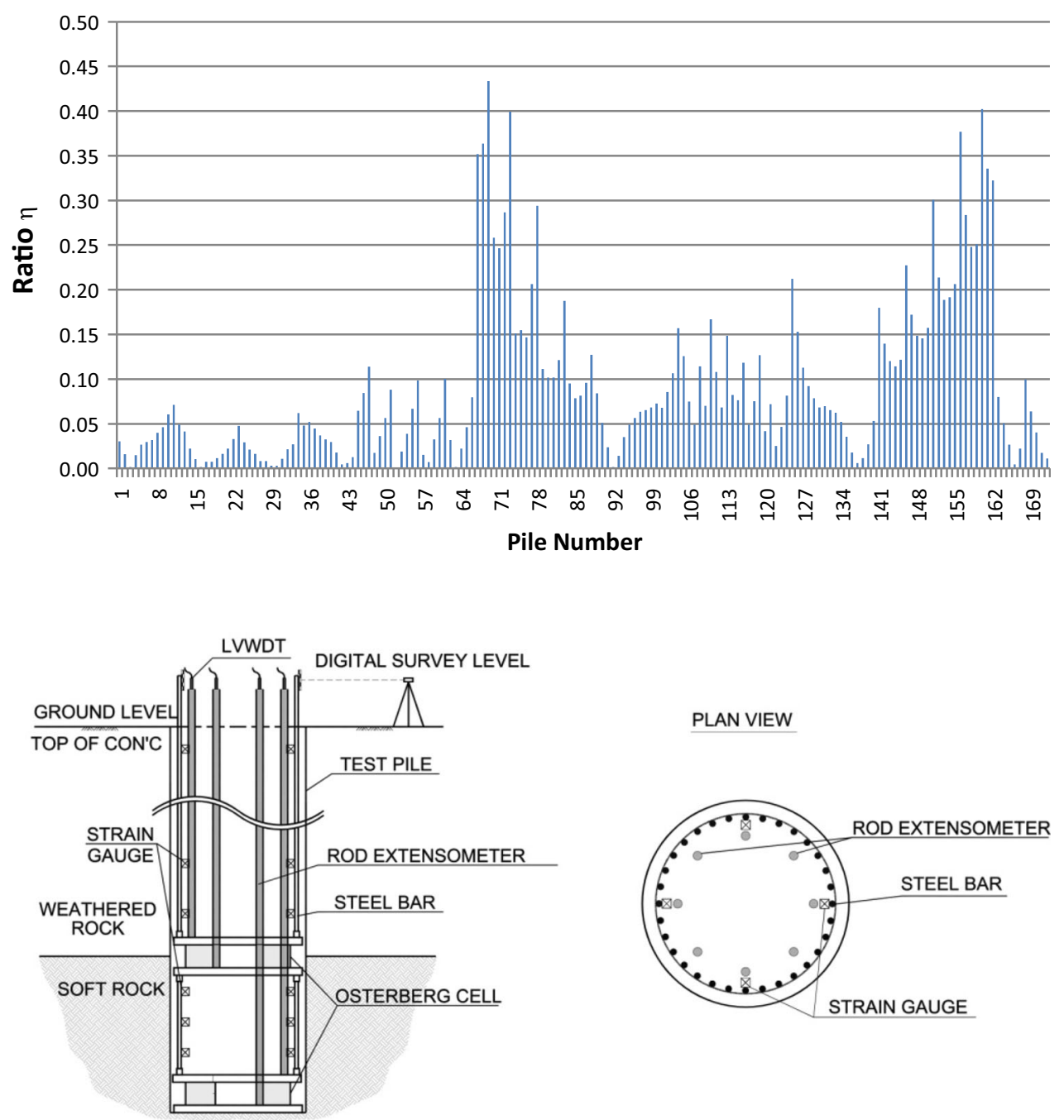

Fig. 24 Schematic of monitoring for vertical pile load test weathered rock and the movement of soft rock socket and pile shaft in the weathered rock layer, while stage 2 focused on the friction and end bearing capacities of the soft rock, with the upper O-cell open to separate the soft rock socket from the remaining upper pile section.

The vertical test piles were loaded up to a maximum one-way load of $150 \mathrm{MN}$ in about 30 incremental stages, in accordance with ASTM recommended procedures. The dynamic loading-unloading test was carried out at the design loading ranges by applying 20 load cycles to obtain the dynamic characteristics of the pile rock socket.

A borehole investigation was carried out at each test pile location to confirm the ground conditions and confirm the pile length and soft rock socket depth of 5-6 m before piling work commenced and also to properly match the test results to the actual ground strata. The pile tests were undertaken in mid 2010 and a summary of the vertical pile test results is shown in Table 24, which is based on the pile test analysis performed by the Load Test Corporation.
Stage 1
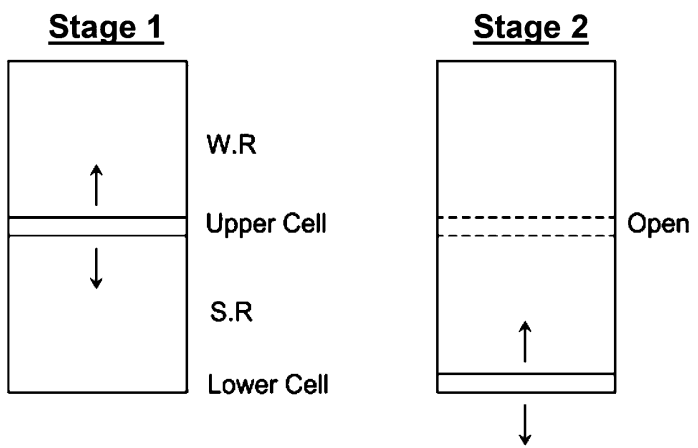

Fig. 25 Typical procedure of O-cell test

Test Pile 3 (TP3) results are not shown herein due to construction defects identified in the pile [60]; thus, the test results were ignored in obtaining the average results. While the overall performance of the test piles exceeded expectations, Test Pile 3 highlighted that the possibility that variability in rock elevation within a short distance could affect the overall pile quality of the pile and may require 
Table 24 Summary of vertical pile test results (allowable pile bearing capacities)

\begin{tabular}{llllll}
\hline Strata & Design value & \multicolumn{5}{l}{ Pile test } \\
\cline { 3 - 6 } & & TP1 & TP2 & TP4 & Aver \\
\hline Soft rock & & & & & \\
End bearing (MPa) & 4.0 & 6.3 & 9.0 & 9.2 & 8.1 \\
Friction $(\mathrm{kPa})$ & 350 & 743 & 897 & 663 & 767 \\
Weathered rock & & & & & \\
Friction $(\mathrm{kPa})$ & 250 & 357 & 527 & 178 & 354 \\
\hline
\end{tabular}

FOS $=3$ is applied for end bearing from ultimate or test load

FOS $=2$ for shaft friction from yield loading point

careful assessment, during construction, of the pile excavation and the quality of the rock at all levels. The pile testing program also demonstrated that the foundation system could still be optimised, given the higher than anticipated shaft and base resistances that were obtained in the other four pile tests.

A lateral pile load test was also performed after excavation of about $8 \mathrm{~m}$ of the upper soil to simulate a similar ground condition and performance as designed for the tower foundation. Both the test pile (TP 5) and the reaction pile (TP 4) were monitored by inclinometers to obtain the lateral displacement along the pile depth, and strain gauges were installed to obtain the stress in the pile section, and eventually the bending moment distribution along the pile shaft. An LVWDT was used for each pile head displacement measurement. A schematic diagram of the monitoring system is shown in Fig. 26.

The lateral test pile was subjected to a maximum lateral load of $2.7 \mathrm{MN}$. The dynamic load-unloading test was carried out at 900,1350 and $1800 \mathrm{kN}$ by applying 20 cycles to obtain the lateral dynamic performance of the pile, especially within the marine clay layer. The load-pile head displacement relationship from the lateral pile test is shown in the Fig. 27. The result indicates that the lateral stiffness of the pile was greater than expected during the

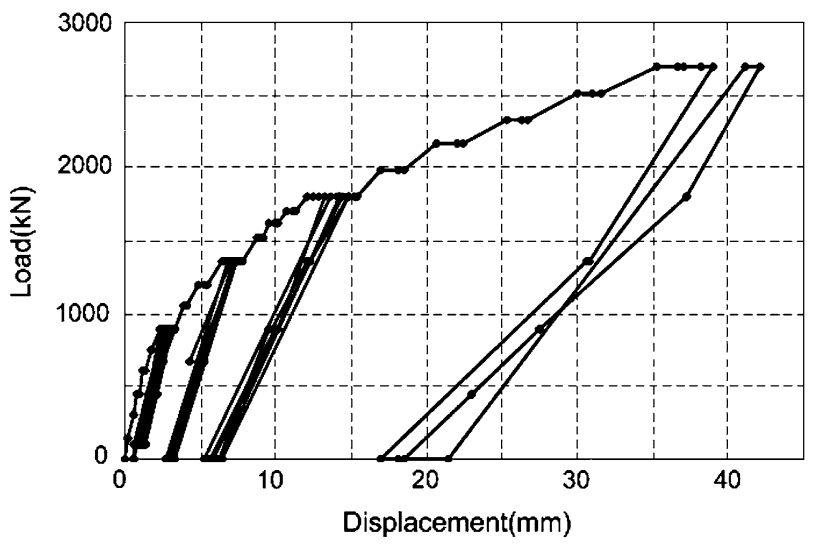

Fig. 27 Load versus displacement curve TP5

initial loading stage, presumably due to the repeated loading condition and also due to the overconsolidated ground conditions arising from excavation. The stiffer behaviour under cyclic loading is summarised in Table 25 . This stiffer pile behaviour will be also considered in the final structural design of the tower foundation system, as well as the predicted pile group movement.

\section{Summary}

This case involved the design and testing process of a pile raft foundation system for a super high rise building to be located within the reclaimed area in Songdo, Korea. The design process involved four principal phases, namely concept design, the main design phase, the post design/ study phase and the vertical and lateral load testing programs.

The use of a suite of commercially available and inhouse computer programs allowed the detailed analysis of the large group of piles to be undertaken, incorporating pile-soil-pile interaction effects, varying pile lengths and varying ground conditions in the foundation design. An independent finite-element analysis using readily available
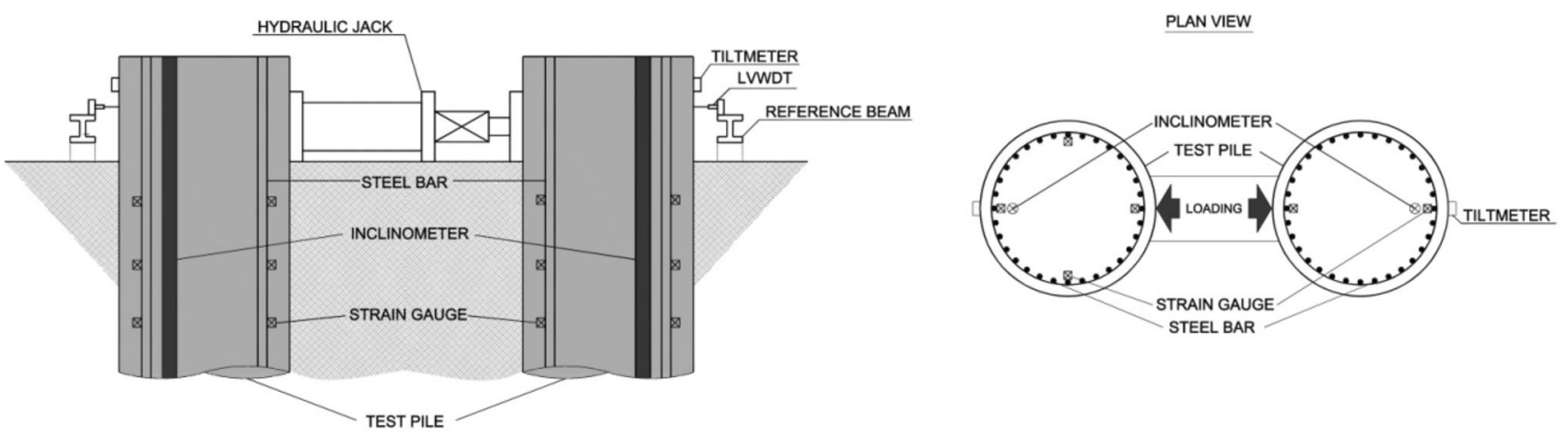

Fig. 26 Schematic of monitoring for lateral pile load test 
Table 25 Lateral stiffness of the test pile

\begin{tabular}{|c|c|c|c|c|}
\hline \multirow[t]{3}{*}{ Design stiffness (MN/m) } & \multicolumn{4}{|c|}{ Measured secant stiffness of test pile $(\mathrm{MN} / \mathrm{m})$} \\
\hline & \multicolumn{2}{|l|}{ Static } & \multicolumn{2}{|l|}{ Dynamic } \\
\hline & $0-900 \mathrm{kN}$ & $900-1350 \mathrm{kN}$ & $0-900 \mathrm{kN}$ & $900-1350 \mathrm{kN}$ \\
\hline $86-120$ & 294 & 97 & 488 & 326 \\
\hline
\end{tabular}

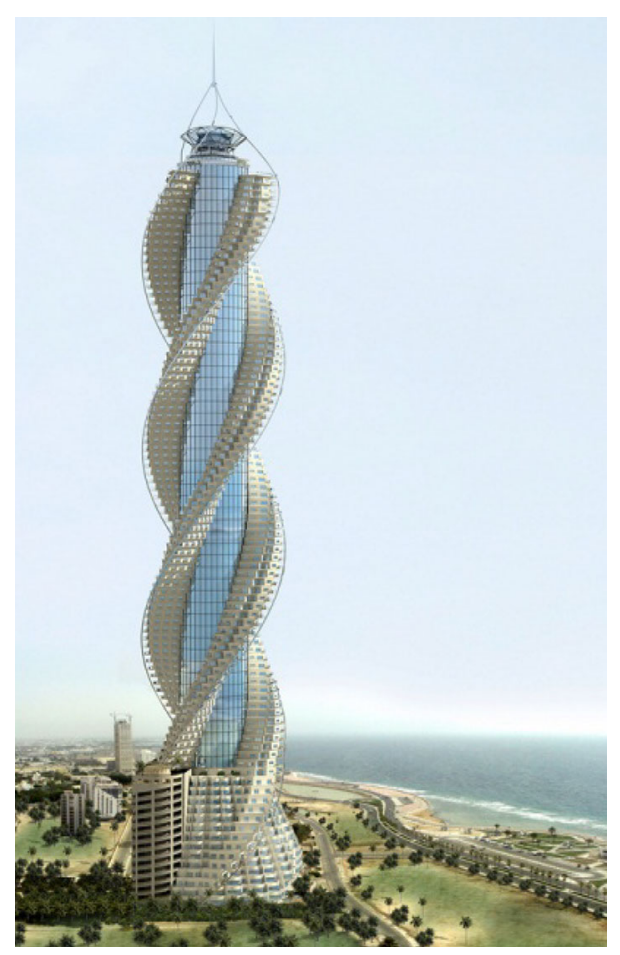

Fig. 28 Architectural rendering of tower in Jeddah, Saudi Arabia

commercial programs was used to include the effect of soil-structure interaction and to include the impact of the foundation system on the overall behaviour of the tower.

The post-design process was extended to obtain the actual response of the ground and the piles due to various loadings. From the results of pile load tests carried out in the post-design period, the prediction of pile behaviour can be refined and the pile capacities can be updated which may result in confirmation or modification of the design, which may lead to a more cost-effective design.

An extensive high-quality vertical and lateral pile testing program was developed and performed for the project and it has been shown that the pile behaviour and capacities are higher than expected so that it may be beneficial to revise some of the more conservative assumptions made in the design.

Presently the tower site is fully reclaimed and fenced, and enabling works are being planned.

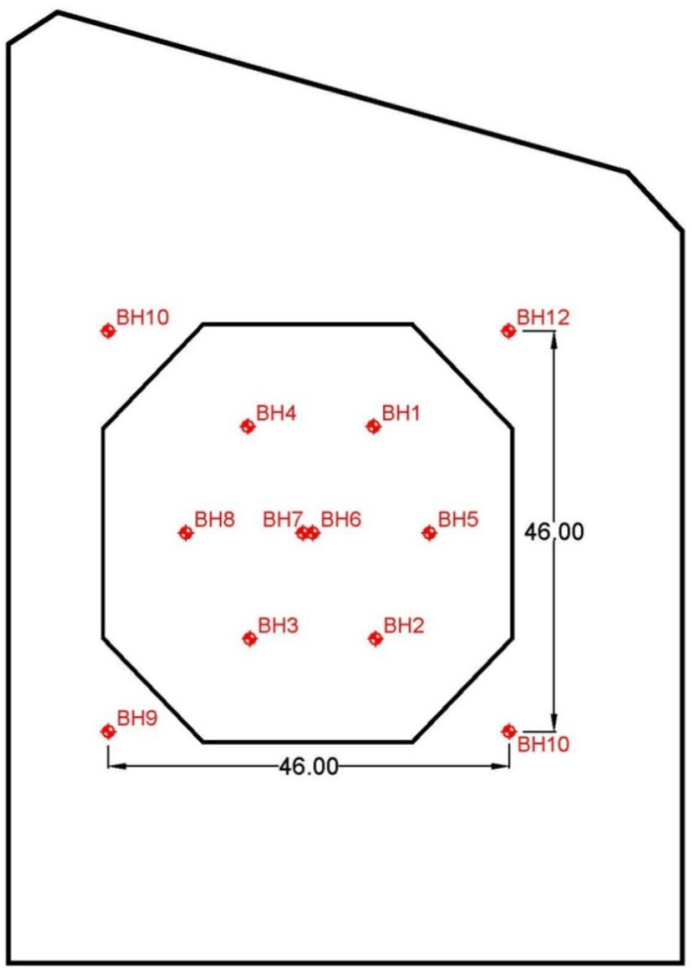

Fig. 29 Site plan and borehole locations

\section{Case 4-tower on karstic limestone, Saudi Arabia}

\section{Introduction}

Karstic limestone is relatively widespread around the world, including many parts of the Middle East. The identification of cavities in karstic limestone often creates, at best, a sense of anxiety among foundation designers, who may then proceed to take extreme measures to overcome the perceived dangers and high risks associated with the proximity of cavities to a foundation system.

For a high-rise project in Jeddah, Saudi Arabia, involving a tower over $390 \mathrm{~m}$ high, potentially karstic conditions were identified in some parts of the site. Figure 28 shows an architectural rendering of the tower. A piled raft foundation system was developed for this tower, as it was considered that such a system would allow the raft to redistribute load to other piles in the group if cavities 
Fig. 30 Details of BH05

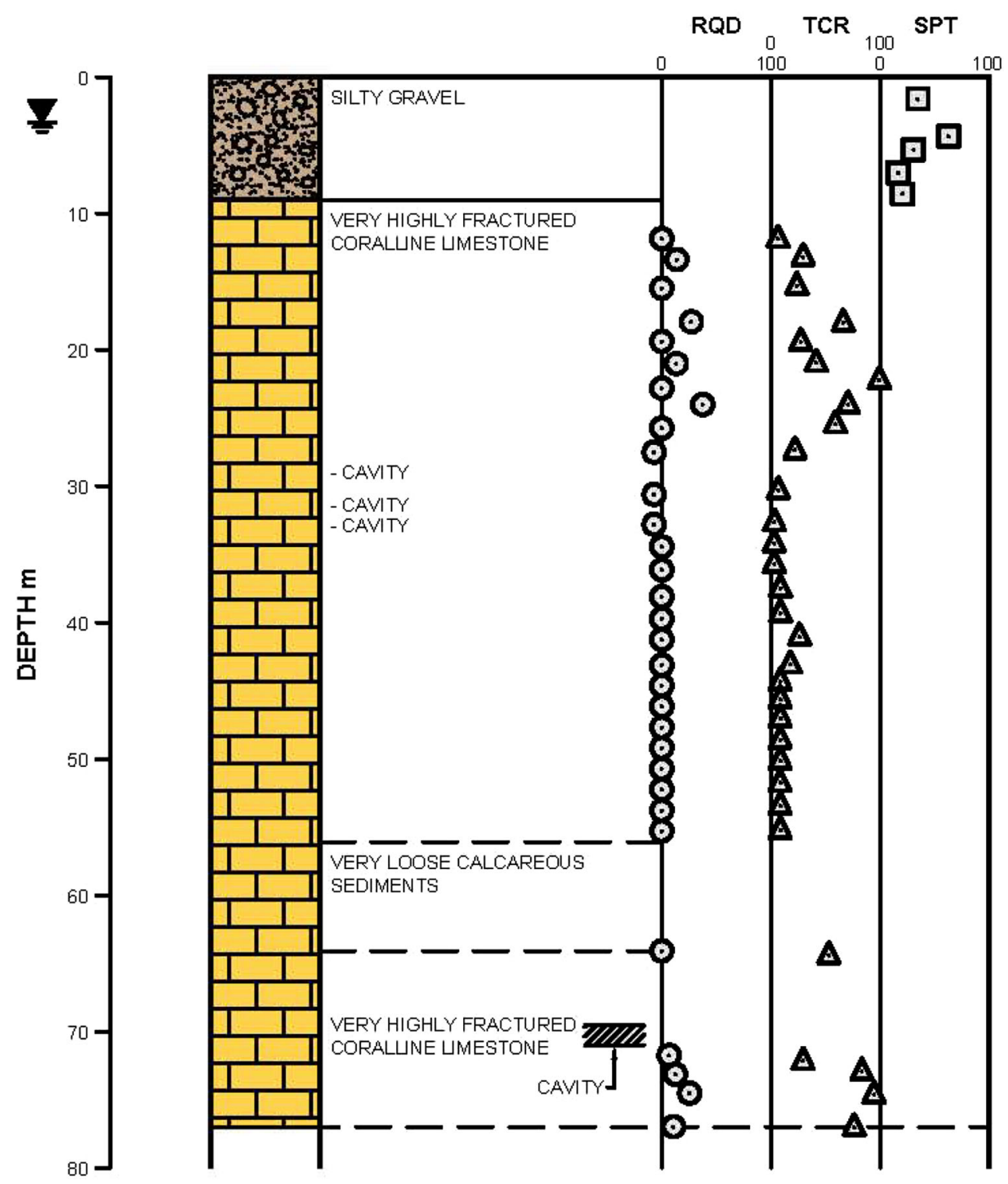

caused a reduction of capacity or stiffness in some piles within the group.

A brief description of the foundation design aspects of the project is presented below, and then a post-design investigation is described for the assessment of the consequences on foundation performance of cavities being present within the underlying limestone.

The key challenges in this project were to assess whether the adverse effects on foundation performance of cavities within the limestone would be within acceptable limits, or whether special treatment would be required to provide an adequate foundation system. A more complete description of this case is given by Poulos et al. [66].

\section{Geological and geotechnical conditions}

The city of Jeddah is located within the Makkah quadrangle in the southern part of the Hijaz geographic province in Saudi Arabia. Eastward of the flat, low-lying coastal plain are the Sarawat mountains that culminate in a major erosional escarpment that has resulted from uplift associated with Red Sea rifting. The underlying reefoidal limestone is considered to be a Quaternary deposit and is raised in some locations to about 3-5 m, above mean sea level, and is underlain by silty sand and gravel.

The reefoidal limestone is the dominant deposit in the Jeddah area. All the available boreholes indicate the presence of coastal coralline limestone (coral reef deposits) 
Table 26 Soil properties used for tower analysis

\begin{tabular}{lllll}
\hline Depth at bottom of geo-unit $(\mathrm{m})$ & Description of Geo-unit & $E_{\mathrm{v}}(\mathrm{MPa})$ & $f_{\mathrm{s}}(\mathrm{MPa})$ & $f_{\mathrm{b}}(\mathrm{MPa})$ \\
\hline 20 & Coralline limestone (1) & 450 & 0.2 & 2 \\
50 & Coralline limestone (2) & 600 & 0.2 & 9.8 \\
70 & Coralline limestone (3) & 1200 & 0.35 & 9.8 \\
100 & Coralline limestone (4) & 3000 & 0.4 & 9.8 \\
\hline
\end{tabular}

$E_{\mathrm{v}}$ modulus of soil for vertical pile response, $f_{\mathrm{s}}$ limiting pile shaft skin friction, $f_{\mathrm{b}}$ limiting pile base load

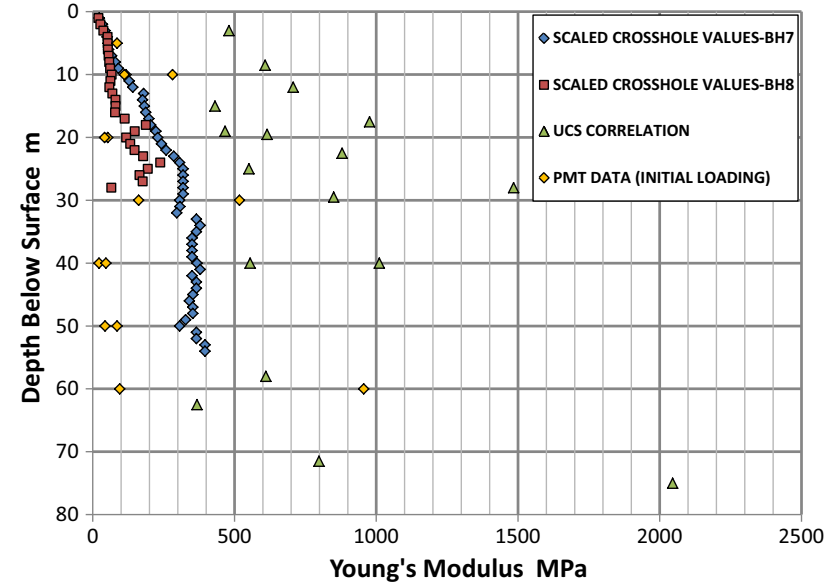

Fig. 31 Young's modulus values derived from various sources

which contain fresh shells and are typically cavernous in nature. Above these limestone deposits is a surficial soil layer which consists mainly of aeolian sands and gravels that were deposited in Holocene times.

A plan of the site showing borehole locations is presented in Fig. 29. Originally, 12 boreholes were drilled to depths of between 40 and $75 \mathrm{~m}$, and subsequently, two deeper boreholes were drilled to $100 \mathrm{~m}$. The borehole data show that the soil profile consists mainly of coralline limestone deposits that are highly fractured and can contain cavities. Standard Penetration tests carried out in the boreholes show that the coralline limestone is dense to very dense. Figure 30 shows the stratigraphy derived from a typical borehole, BH05. Features of this particular borehole are the low RQD values of the recovered core samples, the low values of total core recovery (TCR), especially below a depth of about $25 \mathrm{~m}$, the occasional presence of small cavities and the presence of what appear to be very loose sediments between about 55 and $62 \mathrm{~m}$ below ground surface. It is possible that the process of drilling may have affected the cores and made them appear to be weaker than they are in reality. The groundwater table ranged between 2.1 and $3.8 \mathrm{~m}$ below ground surface.

Cross-hole seismic testing was carried out at boreholes BH07 and BH08, and distributions with depth of P-wave velocity, shear wave velocity were obtained. These

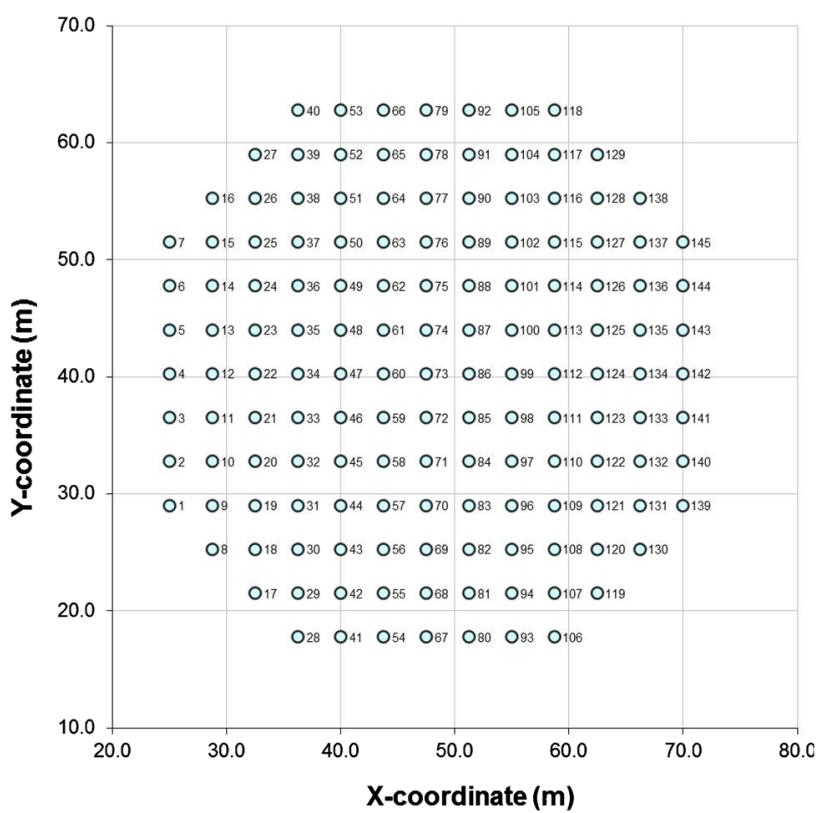

Fig. 32 Pile layout for tower

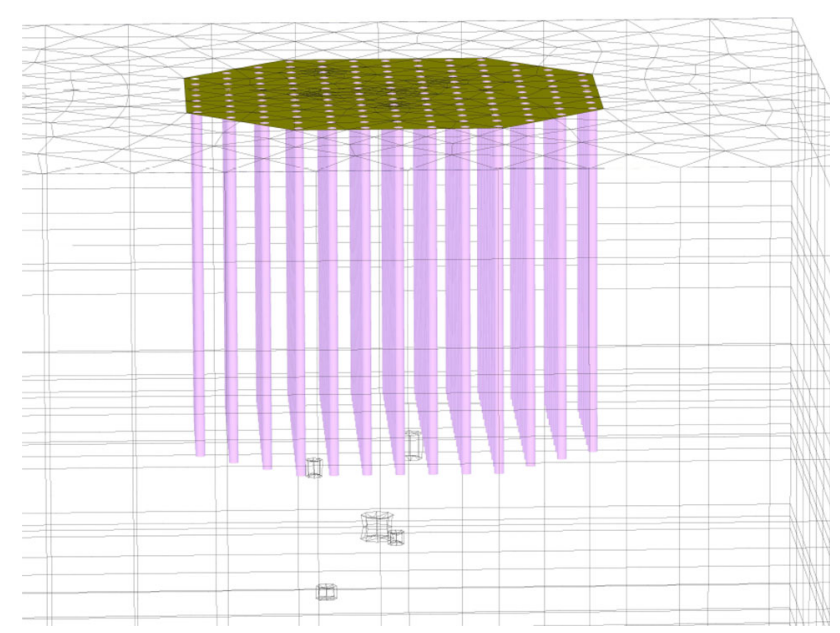

Fig. 33 PLAXIS 3D finite-element mesh for the piled raft

distributions indicated increasing velocities with depth up to about $20 \mathrm{~m}$, with relatively little systematic increase at greater depths. There was no evidence of a hard layer 
Table 27 Deflection of central point of raft for cavity at various depths along centreline

\begin{tabular}{ll}
\hline $\begin{array}{l}\text { Depth of cavity } \\
(\mathrm{m})\end{array}$ & $\begin{array}{l}\text { Max. raft displacement } \\
(\mathrm{mm})\end{array}$ \\
\hline 0 & 55.7 \\
20 & 55.5 \\
40 & 56.7 \\
50 & 58.0 \\
60 & 58.4 \\
70 & 55.9 \\
80 & 55.8 \\
90 & 55.7 \\
100 & 55.7 \\
\hline
\end{tabular}

within the depths investigated, and this conclusion was consistent with the borehole data.

\section{Geotechnical model}

The quantitative data from which engineering properties could be estimated was relatively limited and included the following:

1. Unconfined compression test (UCS);

2. Shear wave velocity data;

3. Pressuremeter testing;

\section{SPT data in the weaker strata.}

Use was made of these data to assess the following engineering properties which were required for the settlement analysis, primarily the Young's modulus of the ground deposits (long-term drained values), the ultimate distribution of pile shaft friction with depth and the ultimate pile end bearing capacity. The values adopted for the analyses are summarised in Table 26, and the procedures adopted to assess each of these parameters are described briefly below.

\section{Long-term Young's modulus}

The assessment of this parameter was critical as it greatly influenced the predicted settlement. Three different methods of assessment were used:

1. Modulus values from the pressuremeter (PMT) tests;

2. Values correlated to UCS via the correlation $E_{s}^{\prime}=$ $100 \mathrm{UCS}$, where $E_{s}^{\prime}$ is long-term Young's modulus;

3. Values derived from the small-strain Young's modulus values obtained from shear wave velocity measurements, but scaled by a factor of 0.2 to allow for the effects of practical strain levels, as discussed in "Derivation of secant values of soil modulus for foundation analysis" section.

Table 28 Effects of randomly selected cavities

\begin{tabular}{|c|c|c|c|c|c|c|}
\hline \multirow[t]{2}{*}{ Case } & \multicolumn{2}{|c|}{ Cavity location (centre) } & \multicolumn{2}{|l|}{ Depth below raft } & \multirow{2}{*}{$\begin{array}{l}\text { Diameter of cavity } \\
\text { (m) }\end{array}$} & \multirow{2}{*}{$\begin{array}{l}\text { Raft displacement } \\
(\mathrm{mm})\end{array}$} \\
\hline & $X(\mathrm{~m})$ & $Y(\mathrm{~m})$ & Top of cavity, $Z_{1}(\mathrm{~m})$ & Bottom of cavity, $Z_{2}(\mathrm{~m})$ & & \\
\hline \multirow[t]{5}{*}{1} & 1.875 & 0 & 40 & 43 & 3 & 72 \\
\hline & -1.875 & -1.875 & 50 & 53 & 4 & \\
\hline & 0 & 7.5 & 50 & 51.5 & 2 & \\
\hline & -9.25 & 0 & 43 & 45 & 2 & \\
\hline & -7.5 & -15 & 61.5 & 63 & 1.25 & \\
\hline \multirow[t]{5}{*}{2} & 11 & 13 & 34 & 35 & 2 & 74 \\
\hline & 10 & 20 & 44 & 45 & 2 & \\
\hline & -2 & 4 & 49 & 51 & 4 & \\
\hline & -10 & -9 & 53 & 55 & 4 & \\
\hline & 3 & 16 & 28 & 31 & 3 & \\
\hline \multirow[t]{5}{*}{3} & -13 & 10 & 48 & 51 & 4 & 68 \\
\hline & -7 & 2 & 23 & 25 & 3 & \\
\hline & 13 & -10 & 41 & 44 & 3 & \\
\hline & 16 & 11 & 69 & 71 & 1 & \\
\hline & 16 & -2 & 44 & 47 & 2 & \\
\hline \multirow[t]{5}{*}{4} & 2 & -7 & 59 & 62 & 2 & 65 \\
\hline & 15 & 7 & 39 & 41 & 4 & \\
\hline & -19 & -7 & 50 & 52 & 4 & \\
\hline & -6 & -12 & 66 & 68 & 2 & \\
\hline & 0 & 4 & 38 & 39 & 1 & \\
\hline
\end{tabular}




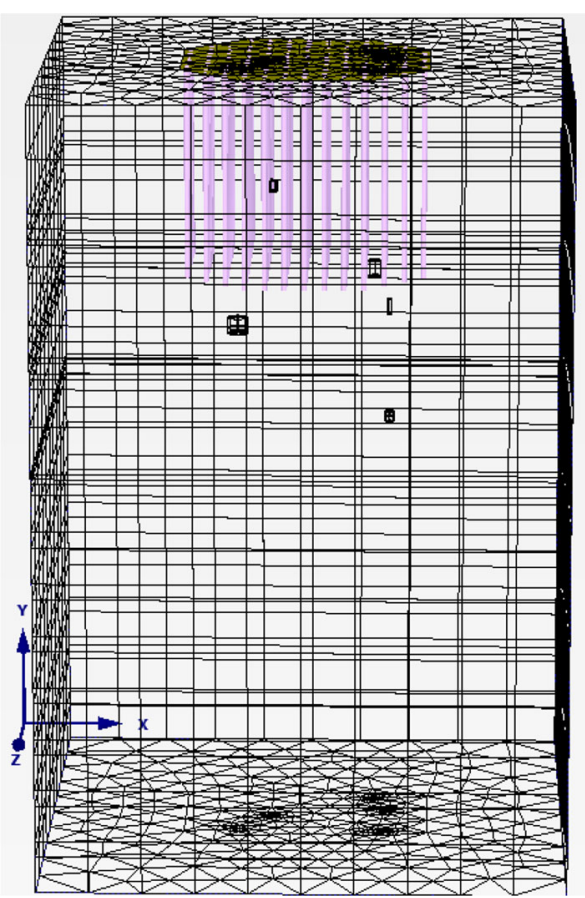

Fig. 34 Location of randomly placed cavities in the finite-element mesh

Figure 31 compares the values obtained from each of these three approaches. On the basis of these data, the following assumptions were originally made:
1. From the surface to a depth of $20 \mathrm{~m}$, an average longterm Young's modulus (for vertical loading), $E_{s}^{\prime}$, is $150 \mathrm{MPa}$,

2. From 20 to $50 \mathrm{~m}, E_{s}^{\prime}=200 \mathrm{MPa}$,

3. From 50 to $70 \mathrm{~m}, E_{s}^{\prime}=400 \mathrm{MPa}$,

4. Below $70 \mathrm{~m}, E_{s}^{\prime}=1000 \mathrm{MPa}$, which reflects the greater stiffness expected because of the smaller levels of strain within the ground at greater depths.

Subsequent to these initial assessments, a load test was undertaken using the Osterberg Cell technique. The pile head stiffness derived from this test was considerably larger than that implied by the initially selected values of Young's modulus. Accordingly, the initially selected values were multiplied by a factor of 3 for the final settlement prediction.

\section{Ultimate pile shaft friction and end bearing}

Use was made of correlations between the ultimate shaft friction, $f_{\mathrm{s}}$, and end bearing, $f_{\mathrm{b}}$, with unconfined compressive strength (UCS). For the reefoidal coral deposits, the following conservative relationship was used for the assessment:

$f_{\mathrm{s}}=0.1(\mathrm{UCS})^{0.5} \mathrm{MPa}$,

where UCS $=$ unconfined compressive strength $(\mathrm{MPa})$.
Fig. 35 Computed settlement contours (Case 3). Maximum settlement is $68 \mathrm{~mm}$

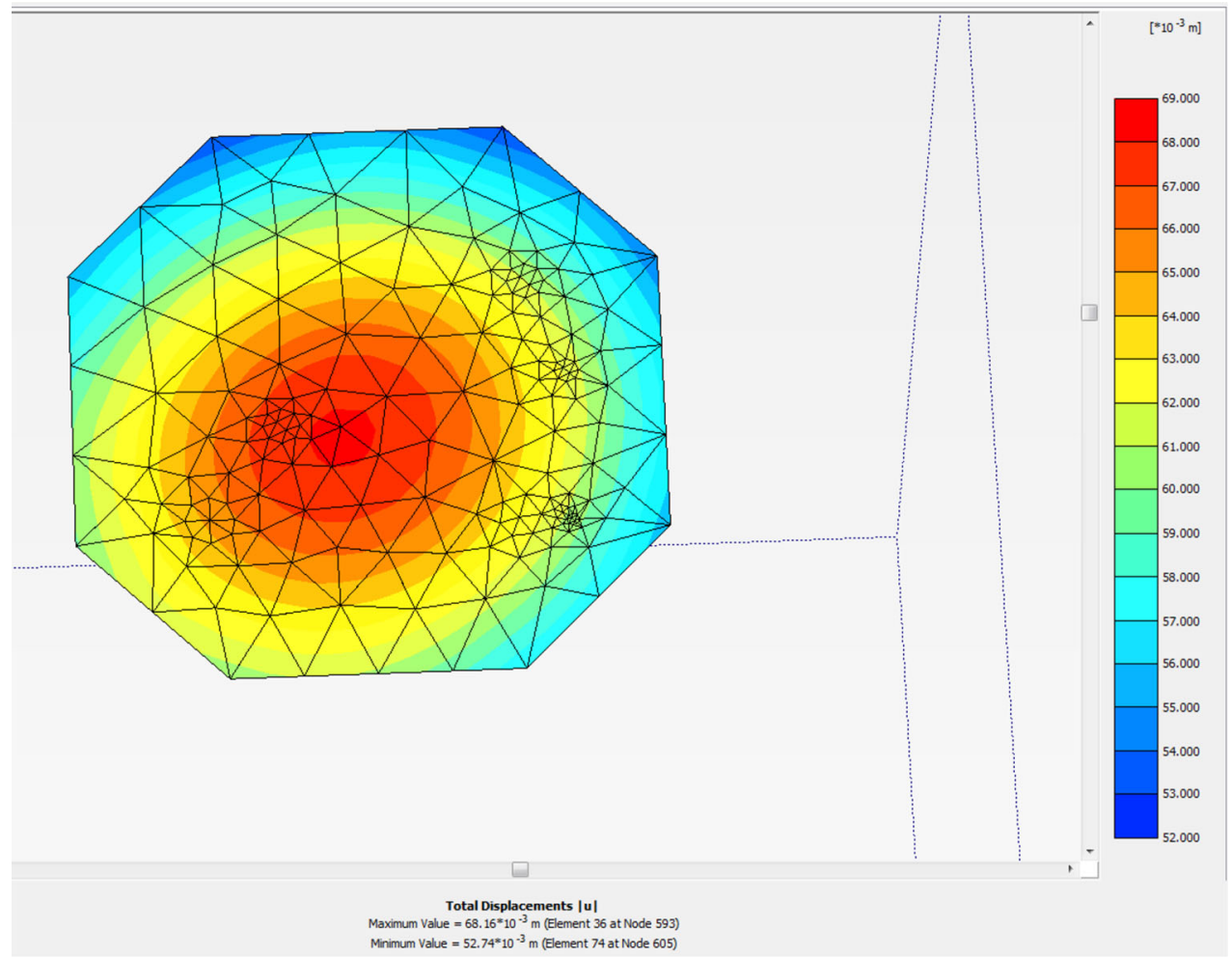


The average ultimate shaft friction for the upper $50 \mathrm{~m}$ was thus taken to be $0.2 \mathrm{MPa}(200 \mathrm{kPa})$. The subsequent pile load test revealed that this was a conservative estimate of shaft friction, as values of about $500 \mathrm{kPa}$ were mobilised along some portions of the test pile, with an average value of about $310 \mathrm{kPa}$.

The following correlation for end bearing capacity, suggested by Zhang and Einstein [80], was employed:

$f_{\mathrm{b}}=4.8(\mathrm{UCS})^{0.5} \mathrm{MPa}$

On this basis, for an average UCS of $4 \mathrm{MPa}, f_{\mathrm{b}}$ was 9.6 MPa. This value assumes that there were no cavities in the area of influence of the base of a pile.

\section{Tower foundation details}

Figure 32 shows the foundation layout for the tower. The basement of the building is to be located at shallow depth above the water table. The raft beneath the tower was taken to be $5.5 \mathrm{~m}$ thick and is to be supported on 145 bored piles $1.5 \mathrm{~m}$ in diameter. A pile length of $40 \mathrm{~m}$ was assessed to be required to support the stated working load of $22 \mathrm{MN}$ per pile, based on a factor of safety of about 2.4. For the analyses described herein, only the central $5.5 \mathrm{~m}$ thick raft and $40 \mathrm{~m}$ long piles were analysed. The total vertical load for serviceability conditions was specified as $2859 \mathrm{MN}$.

\section{Foundation analyses for design}

At the design stage, analyses were undertaken using the computer program geotechnical analysis of raft with piles (GARP) developed by Small and Poulos [73]. The complete foundation system was divided into 2095 elements with 6484 nodes, and no account was taken in this present analysis of the stiffness of the superstructure. From the GARP analysis, the maximum settlement was predicted to be approximately $50 \mathrm{~mm}$.

\section{Study of effects of cavities on foundation performance}

The initial analyses assumed that no significant cavities exist below the pile toes. If cavities were to be found during construction, then it would be necessary to re-assess the performance of the foundation system and make provision for grouting of the cavities if this was deemed to be necessary. Thus, subsequent to the foundation design, a further series of analyses was undertaken to investigate the possible effects of cavities on the settlements and also on the raft bending moments and pile loads. For these analyses, the commercially available program PLAXIS 3D was used.
Figure 33 shows the pile group and the raft as modelled by the three-dimensional finite-element software Plaxis 3D. The raft was octagonal in shape and $5.5 \mathrm{~m}$ thick while the piles were $40 \mathrm{~m}$ long and $1.5 \mathrm{~m}$ in diameter and were laid out on a rectangular grid at $3.75 \mathrm{~m}$ centre to centre spacings. In plan, the raft was $47.5 \mathrm{~m}$ wide and $47.5 \mathrm{~m}$ high (from flat to flat of the octagon).

First, the effect of a single cavity at different locations along the centre line of the raft at different depths was examined. The cavity was introduced into the finite-element mesh at the depths shown in Table 27 and was taken as being $3 \mathrm{~m}$ wide by $2 \mathrm{~m}$ deep.

It may be seen from the table that the vertical displacement of the raft does not change much when the cavity is within the pile group (i.e., at a depth of less than $40 \mathrm{~m}$ ). However, when the cavity is below the toe of the
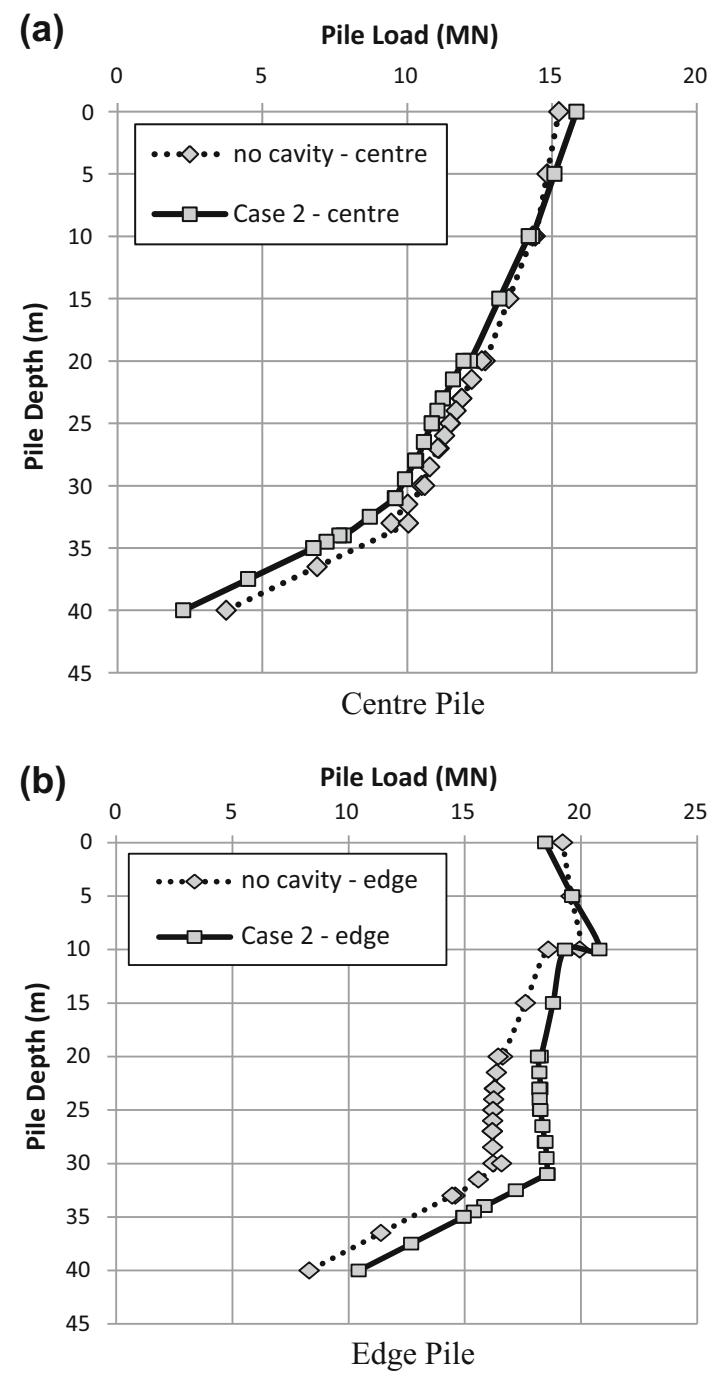

Fig. 36 Axial load with depth in centre and edge piles (with and without cavities). a Centre pile, $\mathbf{b}$ edge pile 
piles at about $50-60 \mathrm{~m}$ depth, the deflection reaches its maximum value.

\section{Random cavities beneath the piled raft}

Generally the locations of cavities beneath the foundation are not known, and only cavities found in specific boreholes can be identified. It is, therefore, of interest to gauge the effect of boreholes at random locations and of random sizes. To do this, a random number generator was used to select a random number between 0 and 1 and then this was used to obtain the location and size of the cavity. A different scaling was used for selecting a given location or size, for example the $X$-coordinate of the centre of the cavity was scaled so that it had to lie within the confines of the raft, and the depth was scaled so that it lay within $70 \mathrm{~m}$ depth.

The number of randomly placed cavities was limited to 5 for each of the cases listed in Table 28. A new threedimensional mesh had to be generated for each case because the location and sizes of the cavities changed. One example of the location of the cavities is shown in Fig. 34.

Results of the analyses are presented in Table 28, where it may be seen that the vertical deflection of the central point of the raft changes from $65 \mathrm{~mm}$ for Case 3 to $74 \mathrm{~mm}$ for Case 2, a range of $9 \mathrm{~mm}$. The piled raft system,
Fig. 37 a Moments in raft for no foundation cavities, b moments in raft for Case 2 (Table 28) set of cavities

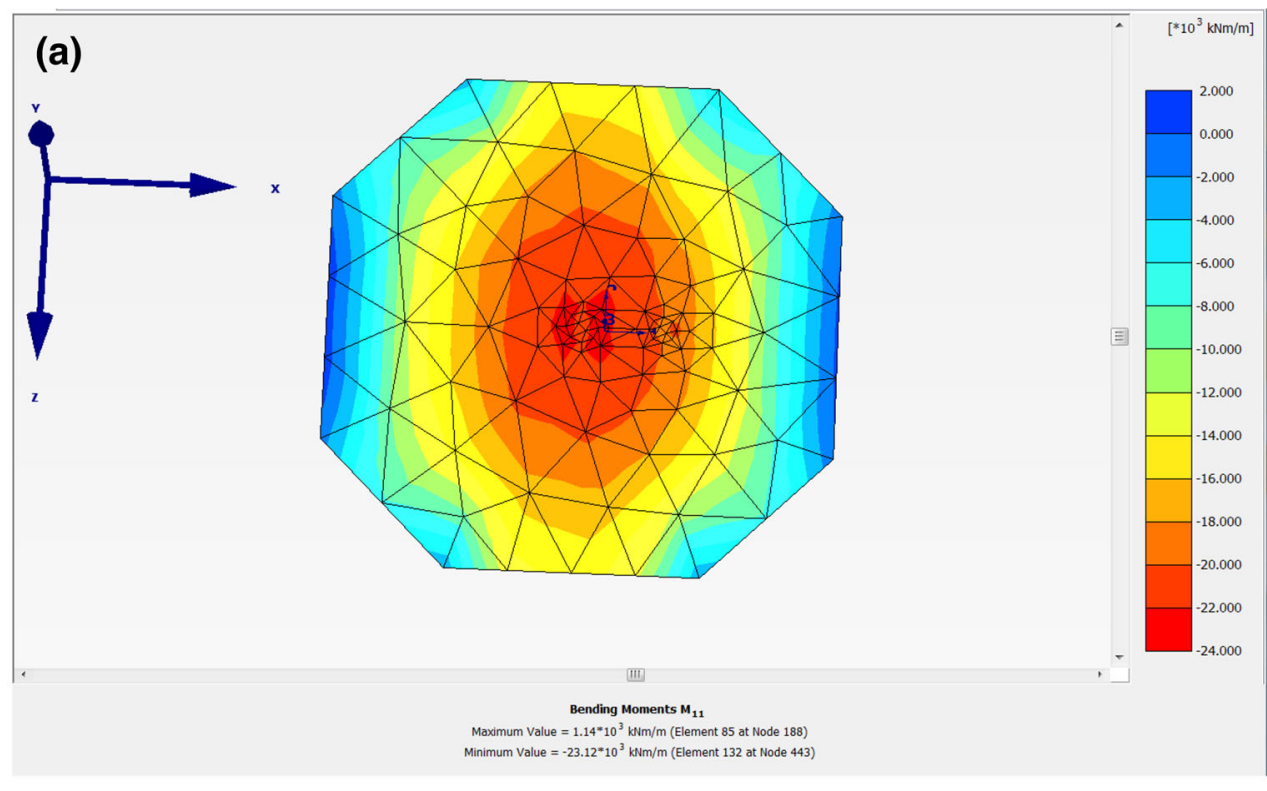

(b)

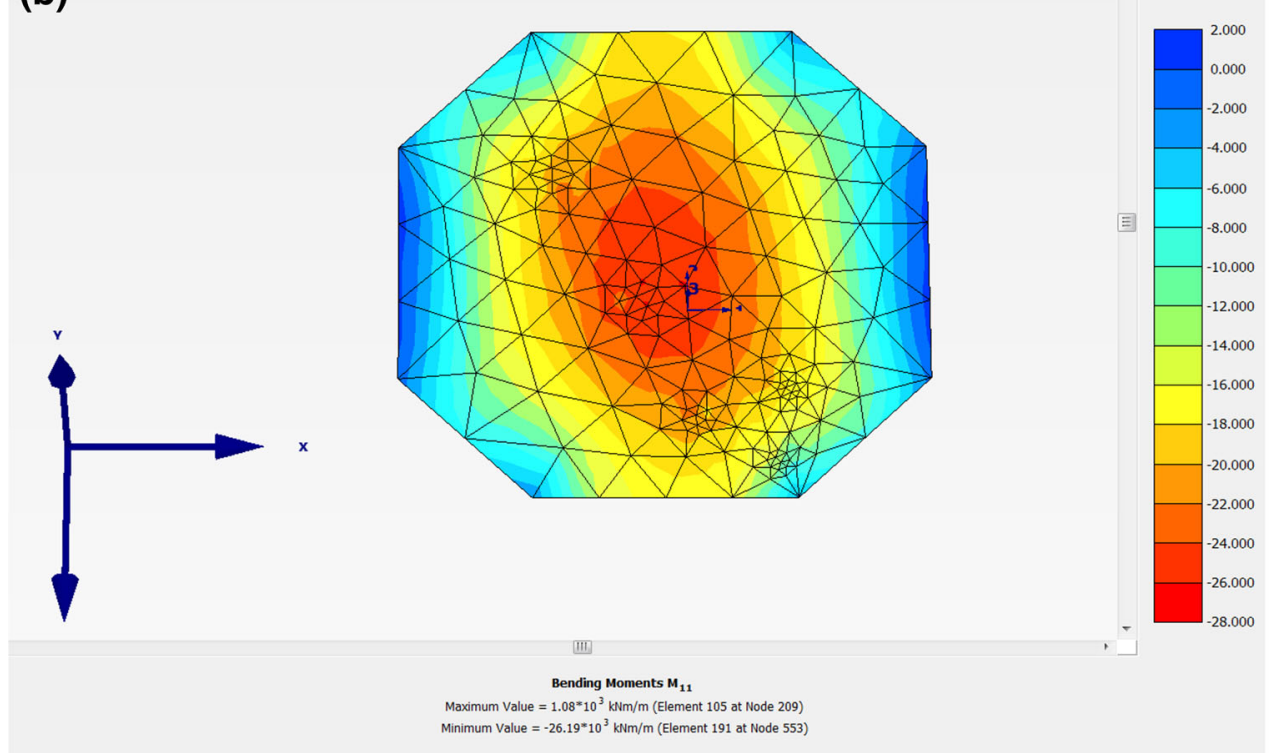


Table 29 Maximum moment in raft

\begin{tabular}{lll}
\hline Problem & $\begin{array}{l}\text { Maximum moment } \\
(\mathrm{k} \mathrm{N}-\mathrm{m} / \mathrm{m} \text { run })\end{array}$ & $\begin{array}{l}\text { Minimum moment } \\
(\mathrm{kN}-\mathrm{m} / \mathrm{m} \text { run })\end{array}$ \\
\hline No cavities & 1140 & $-23,120$ \\
Case 2 cavities & 1080 & $-26,190$ \\
\hline
\end{tabular}

therefore, appears to be effective in smoothing out the effect of the cavities on the overall settlement of the foundation.

For Case 3 the vertical settlement contours of the raft are shown in Fig. 35. It may be seen from the plot that the raft is tilting due to the effect of the cavities and that the maximum settlement is about $68 \mathrm{~mm}$. This is because the larger cavities are to the bottom left of the raft (see finer mesh regions in Fig. 34).

\section{Pile loads for random cavities}

The effect that the random set of cavities has on the loads in the piles may be seen from the plots of Fig. 36a (pile 73 at centre of raft) and 36b (pile 142 at edge of raft). The plots are presented for the case of no cavities in the foundation, and Case 2 (of Table 27) where there are five randomly placed cavities in the foundation. It may be seen from the figures that there is not a great deal of change in the axial load, with the load general decreasing in the centre pile and increasing in the edge pile for the locations of cavities in this example.

\section{Moments in raft for random cavities}

Moments in the raft may be calculated and plots are shown for the case of no cavities (Fig. 37a) and for a set of random cavities (Case 2 of Table 27) in Fig. 37b. The maximum and minimum moments are shown in Table 29.

The minimum moment (that has the largest absolute value) is increased to $26,190 \mathrm{kN}-\mathrm{m} / \mathrm{m}$ from $23,120 \mathrm{kN}-\mathrm{m} /$ $\mathrm{m}$. when cavities are present. This represents an increase of about $13 \%$ in the largest moment in the raft. Thus, for design purposes, it is possible to make allowance for the effects of cavities by increasing the moment capacity of the raft by $10-15 \%$ or so.

\section{Summary}

From this post-design investigation of the piled raft foundation system for a tall tower in Jeddah, Saudi Arabia, it has been demonstrated that the consequences of cavities, while not insignificant, may not be as serious as might be feared, because of the inherent redundancy of the piled raft foundation system. While the analyses undertaken were insufficient to enable a quantitative assessment of risk to be assessed, they did enable a good appreciation to be gained of the sensitivity of the computed foundation response to the presence of random cavities. Clearly, using redundant foundation systems may not only reduce the risks associated with building towers on karstic limestone but may also provide a much more economical foundation than using deep foundation piles in an attempt to carry foundation loads through the karstic zones.

\section{Conclusions}

This paper has set out the following three-stage process for the design of high-rise building foundations:

1. A preliminary design stage, which provides an initial basis for the development of foundation concepts and costing.

2. A detailed design stage, in which the selected foundation concept is analysed and progressive refinements are made to the layout and details of the foundation system. This stage is desirably undertaken collaboratively with the structural designer, as the structure and the foundation act as an interactive system.

3. A final design phase, in which both the analysis and the parameters employed in the analysis are finalised.

It is emphasised that the geotechnical parameters used for each stage may change as knowledge of the ground conditions and the results of in situ and laboratory testing become available. The parameters for the final design stage should desirably incorporate the results of foundation load tests.

The application of the design principles has been illustrated via four projects, each of which has presented a different challenge to the foundation designers:

1. The La Azteca building in Mexico City, Mexicohere, the challenge was to construct a tall building on a very deep deposit of soft clay and limit the settlements.

2. The Burj Khalifa in Dubai-the world's tallest building, founded on a layered deposit of relatively weak rock.

3. The Incheon 151 Tower in Incheon, South Korea-a settlement sensitive building on reclaimed land, with variable geotechnical conditions across the site.

4. A high-rise tower in Jeddah, Saudi Arabia-karstic conditions were present and it was necessary to assess the sensitivity of performance to the possible presence of cavities in the supporting ground.

The value of pile load testing, in conjunction with advanced methods of analysis and design, has been emphasised in the last three cases. 
Acknowledgments The author gratefully acknowledges the contributions of Frances Badelow, Tristan McWilliam, Helen Chow and Patrick Wong in relation to the analyses for most of the towers described in the paper, and to Jay Ameratunga for reviewing the final manuscript. Gabriel Auvinet kindly provided information and photographs for the La Azteca building. Grahame Bunce led the foundation design for the Burj Khalifa. S.H. Kim, Ahmad Abdelrazaq and their teams in Korea had a major involvement in the Incheon Tower foundation design. Eng Wael Satea provided information and instructions for the Jeddah tower. Professor John Small has been pivotal in developing the GARP program and implementing it in a user-friendly form.

Open Access This article is distributed under the terms of the Creative Commons Attribution 4.0 International License (http://crea tivecommons.org/licenses/by/4.0/), which permits unrestricted use, distribution, and reproduction in any medium, provided you give appropriate credit to the original author(s) and the source, provide a link to the Creative Commons license, and indicate if changes were made.

\section{References}

1. Abdelrazaq A, Poulos HG, Badelow F, Ho-Kim S (2011) Foundation design and pile testing program for the 151 Story Incheon Tower in a Reclamation Area, Incheon, Korea. Paper TS21-02, international conference on Tall Buildings and urban habitat (CTBUH), Seoul, Korea

2. Badelow F, Kim S, Poulos HG, Abdelrazaq A (2009) Foundation design for a tall tower in a reclamation area. In: Au FTK (ed) Proc. 7th international conference at Tall Buildings, Hong Kong, Research Publishing, pp 815-823

3. Baker WF, Korista DS, Novak LC (2007) Burj Dubai: engineering the World's Tallest Building. Struct Des Tall Spec Build $16: 361-375$

4. Baker WF, Pawlikowski JJ (2014) "Burj Khalifa". In: Tamboli AR (ed) Chapter 7 in Tall and Supertall Buildings, McGraw Hill, New York

5. Bermingham P, Janes M (1989) An innovative approach to load testing of high capacity piles. Proc Int Conf Piling Deep Founds 1:409-413

6. Bermingham P, Ealy CD, White JK (1994) A comparison of statnamic and static field tests at seven FHWA sites. Proc Int Conf Des Constr Deep Founds FHWA, Orlando 2:616-630

7. Briaud J-L (1992) The pressuremeter. Balkema, Rotterdam

8. Brown PT, Yu KR (1986) Load sequence and structure-foundation-interaction. J Struct Eng 112:481-488

9. Burland JB, Mitchell JM (1989) Piling and deep foundations. Proceedings of international conference on piling and deep foundations, London

10. Bustamante M, Gianeselli L (1982) Pile bearing capacity prediction by means of static penetrometer CPT. Proc ESOPT II 2:492-500

11. Chen Y-J, Fang Y-C (2009) Critical evaluation of compression interpretation criteria for drilled shafts. J Geotech Geoenviron Eng ASCE 135:1056-1069

12. Chin FK (1970) Estimation of the ultimate load of pile from tests not carried to failure. In: Proceedings of 2 nd SE Asian conference soil mechanical found engineering, Singapore, pp 81-92

13. CTBUH (2011) Council for tall buildings and the urban habitat, Press release, 8 Dec 2011

14. Davisson MT (1972) High capacity piles. In: Proceedings of lecture series on innovations in foundation construction. ASCE Illinois Section, Chicago
15. Decourt L (1982) Prediction of the bearing capacity of piles based exclusively on $\mathrm{N}$ values of the SPT. Proc ESOPT II, Amsterdam 1:29-34

16. Decourt L (1995) Prediction of Load-settlement relationships for foundations on the basis of the SPT-T. Ciclo de Conferencias Intern. "Leonardo Zeevaert", UNAM, Mexico, pp 85-104

17. De Nicola A, Randolph MF (1993) Tensile and compressive shaft capacity of piles in sand. J Geotech Eng, ASCE 119(12): 1952-1973

18. De Ruiter J, Beringen FL (1979) Pile foundations for large North Sea structures. Mar Geotech 3(3):267-314

19. Fleming K, Weltman A, Randolph M, Elson K (2009) Piling engineering, 3rd edn. Taylor and Francis, London

20. Frank R, Magnan J-P (1995) Cone penetration testing in France: national report. Proceedings of CPT '95, Linkoping, Swedish Geotechnical Society, vol 3, pp 147-156

21. Fraser RA, Wardle LJ (1976) A rational analysis of rectangular rafts on layered foundations. Geotechnique 26(4):613-630

22. Fujioka T, Yamada K (1994) The development of a new pile load testing system. Proc Int Conf Des Constr Deep Founds FHWA, Orlando 2:670-684

23. Fuller FM, Hoy HE (1971) Pile load tests including quick load test method, conventional methods and interpretations. High Res Rec No 333:74-86

24. Goble GG (1994) Pile driving — an international state-of-the-art. Proc Int Conf Des Constr Deep Founds, FHWA, Orlando 1:1-26

25. Gusmao Filho JA, Guimaraes LJ (1997) Limit stiffness in soil structure interaction in buildings. In: Proceedings of 14th international conference on soil mechanics found engineering, Hamburg, vol 2, pp 807-808

26. Haberfield CM (2013) Tall Tower Foundations-from concept to construction. In: Phoon KK (ed) Advances in foundation engineering. Research Publishing Services, Nandanam, pp 33-65

27. Hasancebi N, Ulusay R (2007) Empirical correlations between shear wave velocity and penetration resistance for ground shaking assessments. Bull Eng Geol Environ 66:203-213

28. Hemsley JA (2000) Design applications of raft foundations. Thomas Telford, London

29. Hirany A, Kulhawy FH (1989) Interpretation of load tests on drilled shafts I: axial compression. In: Kulhawy FH (ed) Foundation engineering: current principles and practices, GSP 22, ASCE, New York, pp 1132-1149

30. Hoek E, Diederichs MS (2006) Empirical estimation of rock mass modulus. Int J Rock Mech Min Sci 43(2006):203-215

31. Horikoshi K, Randolph MF (1998) Optimum design of piled rafts. Geotechnique 48(3):301-317

32. Horvath R, Kenney TC (1979) Shaft resistance of rock-socketed drilled piers. Presented at ASCE annual convention, Atlanta, GA, preprint No. 3698

33. Hwang JH, Li JCC, Liang N (2003) On methods for interpreting bearing capacity from a pile load test. Geotech Eng, SEAGS 34(1):27-39

34. Idriss IM, Sun JI (1992) "User's manual for SHAKE91", Structures Division, Building and Fire Research Laboratory, National Institute of Standards and Technology, Gaithersburg, Maryland and Center for Geotechnical Modeling. Department of Civil and Environmental Engineering, University of California, Davis, California

35. Katzenbach R, Arslan U, Moorman C, Reul O (1998) Piled raft foundations: interaction between piles and raft. Darmst Geotech, Darmst Univ Technol 4:279-296

36. Kramer S (1996) Geotechnical earthquake engineering. Prentice Hall, New Jersey

37. Lam TSK, Johnston IW (1982) A constant normal stiffness direct shear machine. In: Proceedings of 7th SE Asian conference on soil engineering, Hong Kong, pp 805-820 
38. Lee IK, Brown PT (1972) Structure-foundation interaction analysis. J Struct Div Am Soc Civil Eng 98(11):2413-2431

39. Mair RJ, Wood DM (1987) Pressuremeter testing: methods and interpretation. CIRIA, London

40. Mayne PW, Coop MR, Springman SM, Huang A-B, Zornberg JG (2009) Geomaterial behavior and testing. In: Proceedings of 17th international conference on soil mechanics. geotechnical engineering, Alexandria, Egypt, vol 4, pp 2777-2872

41. Mayne PW, Poulos HG (1999) Approximate displacement influence factors for elastic shallow foundations. J Geotech Geoenviron Eng ASCE 125(6):453-460

42. Mayne PW, Rix GJ (1993) Gmax-qc relationships for clays. Geotech Test J 16(1):54-60

43. MELT (1993) Regles techniques de conception et de calcul des fondations des ouvrages de genie civil. CCTG, Fascicule No. 62, Titre V, Min. de L'Equipement du Lodgement et des Transport, Paris

44. Mendis P, Ngo T, Haritos N, Hira A, Samali B, Cheung J (2007) Wind loading on Tall Buildings. EJSE special issue: loading on structures. EJSE International

45. Merifield RS, Lyamin AV, Sloan SW (2006) Limit analysis solutions for the bearing capacity of rock masses using the generalised Hoek-Brown criterion. Int $J$ Rock Mech Min Sci 43:920-937

46. Middendorp P, Bermingham P, Kuiper B (1992) Statnamic load testing of foundation piles. In: Proceedings of 4th international conference on applied of stress wave theory to piles, The Hague, Balkema, Rotterdam, pp 581-588

47. OASYS Geo (2001) VDISP 17 GEO suite for windows

48. Ooi LH, Carter JP (1987) A constant normal stiffness direct shear device for static and cyclic loading. Geotech Test J ASTM 10:3-12

49. Osterberg $J$ (1989) New device for load testing driven and drilled shafts separates friction and end bearing. In: Proceedings of international conference on piling and deep founds, London, pp 421-427

50. Poulos HG (1975) Settlement analysis of structural foundation systems. In: Proceedings of 4th St.-East Asian conference on soil engineering, Kuala Lumpur

51. Poulos HG (1988) The mechanics of calcareous sediments. John Jaeger Memorial Lecture, Aust Geomechanics, Spec. Edition, pp 8-41

52. Poulos HG (1988) Cyclic stability diagram for axially loaded piles. J Geotech Eng, ASCE 114(8):877-895

53. Poulos HG (1989) Pile behaviour-theory and application. Geotechnique 39(3):365-415

54. Poulos HG (1990) DEFPIG users manual. Centre for Geotechnical Research, University of Sydney, Sydney

55. Poulos HG (2000) Pile testing-from the designer's viewpoint. In: Kusakabe, Kuwabara, Matsumoto, Balkema (eds) Statnamic loading test. Rotterdam, pp 3-21

56. Poulos HG (2001) Piled raft foundations-design and applications. Geotechnique 51(2):95-113

57. Poulos HG (1994) Settlement prediction for driven piles and pile groups. Vert Horiz Deform Found Emban ASCE, New York 2:1629-1649

58. Poulos HG (2005) Piled raft and compensated piled raft foundations for soft soil sites. In: Vipulanandan C, Townsend FC (ed) Advances in designing and testing deep foundations, ASCE Geotechnical Spec. Pub. No. 129, pp 214-234

59. Poulos HG (2008) Simulation of the performance and remediation of imperfect pile groups. In: van Impe WF, van Impe PO (eds) Deep foundations on bored and auger piles, BAPV, Taylor and Francis, London, pp 143-154

60. Poulos HG, Badelow F, Tosen R, Abdelrazaq A, Kim SH (2013) Identification of test pile defects in a super-tall building foundation. In: Proceedings of 18th international conference on soil mechs. found. engineering, Paris, vol 4, pp 2823-2826
61. Poulos HG, Bunce G (2008) Foundation design for the Burj Dubai-the world's tallest building. In: Proceedings of 6th international conference on case histories in geotechnical engineering, Arlington, VA, Paper 1.47, CD volume

62. Poulos HG, Chua EW (1985) Bearing capacity of foundations on calcareous sand. In: Proceedings of 11th international conference on soil mechanics foundation engineering, San Francisco, vol 3, pp 1619-1622

63. Poulos HG, Carter JP, Small JC (2001) Foundations and retaining structures-research and practice. In: Proceedings of 15th international conference on soil mechanics geotechnical engineering, Istanbul, vol 4, pp 2527-2606

64. Poulos HG, Davids AJ (2005) Foundation design for the emirates twin towers, Dubai. Can Geotech J 42:716-730

65. Poulos HG, Davis EH (1980) Pile foundation analysis and design. Wiley, New York

66. Poulos HG, Small JC, Chow HSW (2013b) Foundation design for high-rise towers in karstic ground. In: Withiam JL, Phoon K-K, Hussein MH (eds) ASCE GSP229, Foundation Engineering in the Face of Uncertainty, pp 720-731

67. Randolph MF, Wroth CP (1978) Analysis of deformation of vertically loaded piles. J Geotech Eng ASCE 104(GT12): 1465-1488

68. Randolph MF (1994) Design methods for pile groups and piled rafts. In: Proceedings of XIII international conference on soil mechanics and foundation engineering, New Delhi, vol 5, pp 61-82

69. Rausche F, Goble GG, Likins G (1985) Dynamic determination of pile capacity. J Geotech Eng ASCE 111(3):367-383

70. Reese LC, O'Neill MW (1988) Drilled shafts: construction procedures and design methods. Pub. No. FHWA-H1-88-042, US Dept. Transportation

71. Russo G, Abagnara V, Poulos HG, Small JC (2013) Re-assessment of foundation settlements for the Burk Khalifa, Dubai. Acta Geotec 8(1):3-15

72. Seed HB, Tokimatsu K, Harder LF, Chung RM (1984) The Influence of SPT procedure in soil liquefaction resistance evaluation. EERC-84/15, University of California, Berkeley

73. Small JC, Poulos HG (2007) A method of analysis of piled rafts. In: Proceedings of 10th Australia-New Zealand conference on geomechanics, Aust Geomechs Society, vol 1, pp 550-555

74. Smith A (2008) Burj Dubai: designing the world's tallest. CTBUH 8th World Congress, Dubai

75. Sommer H, Wittmann P, Ripper P (1985) Piled raft foundation of a tall building in Frankfurt Clay. In: Proceedings of 11 ICSMFE, San Francisco, vol 4, pp 2253-2257

76. Sommer H (1993) Development of locked stresses and negative shaft resistance at the piled raft foundation Messeturm Frankfurt/ Main. In: van Impe WF (ed) Deep foundations on bored and auger piles BAP II, pp 347-349

77. Terzaghi K (1943) Theoretical soil mechanics. Wiley, New York

78. Zeevaert L (1957) Compensated friction pile foundation to reduce settlement of buildings on the highly compressible volcanic clay of Mexico City. In: Proceedings of 4th international conference on SMFE, London, vol 2, pp 81-86

79. Zeevaert L (1973) Foundation engineering for difficult subsoil conditions. Van Nostrand Reinhold, New York

80. Zhang L, Einstein H (1998) End bearing capacity of drilled shafts in rock. J Geotech Eng ASCE 124(7):574-584

81. Zhang L, Ng AMY (2006) Limiting tolerable settlement and angular distortion for building foundations. Geotechnical Special Publication No. 170, Probabilistic applications in geotechnical engineering, ASCE (on CD Rom)

82. Zhang, Small JC (1994) Finite layer analysis of soil-raft-structure interaction. In: Balkema AA (ed) Proceedings of 13th international conference on soil mechanical foundation engineering, New Delhi. India, vol 2, pp 587-590. Rotterdam 